Utah State University

DigitalCommons@USU

$12-2011$

\title{
Ultrasonic Flow Measurement for Pipe Installations with Non- Ideal Conditions
}

Devin M. Stoker

Utah State University

Follow this and additional works at: https://digitalcommons.usu.edu/etd

Part of the Civil and Environmental Engineering Commons

\section{Recommended Citation}

Stoker, Devin M., "Ultrasonic Flow Measurement for Pipe Installations with Non-Ideal Conditions" (2011). All Graduate Theses and Dissertations. 1060.

https://digitalcommons.usu.edu/etd/1060

This Thesis is brought to you for free and open access by the Graduate Studies at DigitalCommons@USU. It has been accepted for inclusion in All Graduate Theses and Dissertations by an authorized administrator of DigitalCommons@USU. For more information, please contact digitalcommons@usu.edu.

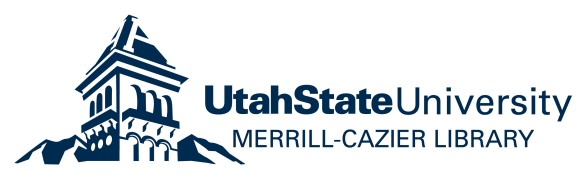




\section{ULTRASONIC FLOW MEASUREMENT FOR PIPE INSTALLATIONS \\ WITH NON-IDEAL CONDITIONS}

by

Devin M. Stoker

A thesis submitted in partial fulfillment

of the requirements for the degree

of

MASTER OF SCIENCE

in

Civil and Environmental Engineering

Approved:

Steven L. Barfuss

Michael C. Johnson

Major Professor

Committee Member

Robert E. Spall

Mark R. McLellan

Committee Member

Vice President for Research and

Dean of the School of Graduate Studies

UTAH STATE UNIVERSITY

Logan, Utah 
Copyright (C) Devin M. Stoker 2011

All Rights Reserved 


\author{
ABSTRACT \\ Ultrasonic Flow Measurement for Pipe Installations \\ with Non-Ideal Conditions \\ by \\ Devin M. Stoker, Master of Science \\ Utah State University, 2011
}

Major Professor: Steven L. Barfuss

Department: Civil \& Environmental Engineering

In the arid west, water is among the most valuable of resources. Typically, in order to successfully and accurately measure a flow rate using most types of flow meters, it is recommended that a straight section of pipe be installed immediately upstream from the flow meter to avoid distorted flow patterns and extreme turbulence at the metering location. In many field piping situations, however, such flow conditions are impossible to achieve.

The performance of ultrasonic flow meters in non-ideal piping scenarios was studied using laboratory experiments and numerical Computational Fluid Dynamics models. A Fuji PortaflowX clamp-on transit-time ultrasonic flow meter was calibrated in the laboratory and performed well within the manufacturer's stated level of accuracy of $\pm 1 \%$ for straight pipe. The ultrasonic flow meter was also used downstream of a single 12-inch long-radius elbow and the error in flow measurement resulting from the flow disturbance was measured. These tests were performed at four locations downstream of the elbow, at three orientations on the circumference of the pipe, and for three flow rates with Reynolds numbers ranging from 250,000 to 750,000 . Using the same physical conditions, numerical models were built that 
utilized the realizable $k-\varepsilon$ eddy viscosity model for turbulent flows. The resulting downstream velocity profiles from the numerical models were used to integrate the velocity of the flow across the ultrasonic signal path. The resulting velocity profiles were compared to similar profiles for fully developed flow to determine the error in flow measurement. The ultrasonic flow meter measurement errors downstream of the elbow were always negative, and were found to be as great as $-16 \%$. In general, the ultrasonic flow meter performed less accurately closer to the elbow due to the turbulent fluctuations and flow separation created by the elbow.

A correction curve was applied to the results of this study, which provided a method to correct the ultrasonic flow measurement. By applying the correction equation to the laboratory ultrasonic flow meter measurements downstream of the elbow, the measurement error was reduced by nearly $90 \%$. Computational Fluid Dynamics appears to be a viable tool for studying flow disturbances and making appropriate corrections for ultrasonic flow measurement in pipes. 


\title{
PUBLIC ABSTRACT
}

\author{
Ultrasonic Flow Measurement for Pipe Installations \\ with Non-Ideal Conditions
}

by

\author{
Devin M. Stoker, Master of Science \\ Utah State University, 2011
}

Major Professor: Steven L. Barfuss

Department: Civil \& Environmental Engineering

In the arid west, water is among the most valuable of resources. One of the most critical aspects of water resource management is that of flow measurement. Accurate flow measurement data is needed to effectively manage any water distribution system, whether for culinary or irrigation use. In order to successfully and accurately measure water flow in pipes, it is recommended that a straight section of pipe be installed immediately upstream from the flow meter to avoid distorted flow patterns at the metering location. In many existing piping scenarios, however, such flow conditions are impossible to achieve.

The performance of ultrasonic flow meters in non-ideal piping scenarios was studied using laboratory experiments and numerical computer models. The ultrasonic flow meter was installed downstream of a single 90-degeree elbow and the error in flow measurement downstream of the elbow was recorded. The ultrasonic flow meter measurement errors downstream of the elbow were always negative, with errors as great as $-16 \%$. This indicates that the ultrasonic flow meter under predicts the actual flow rate in a pipe when used in non- 
straight piping. In general, the ultrasonic flow meter performed less accurately closer to the elbow due to the distorted flow patterns created by the elbow.

Using the same physical conditions, numerical computer models were built that utilized Computational Fluid Dynamics for turbulent flows. Using the results from the numerical models, a correction curve was applied to the laboratory ultrasonic flow measurements. By applying the correction equation, the measurement error was reduced by nearly $90 \%$. Computational Fluid Dynamics appears to be a viable tool for studying flow disturbances and making corrections to flow measurements. It is anticipated that this approach may prove valuable for other non-ideal piping scenarios. This will result in more accurate flow measurement and better management of valuable water resources. 


\section{ACKNOWLEDGMENTS}

First of all, I would like to thank my major professor, Steve Barfuss, for his support and direction on this project and for providing me the opportunity to perform research at the Utah Water Research Laboratory over the last several years. My time working at the water lab has taught me a great deal, and I am grateful for the hands-on experience it has given me. I would also like to thank my other committee members, Dr. Michael Johnson and Dr. Robert Spall. Dr. Spall deserves special thanks for his guidance with regards to the CFD component of my research.

I would also like to thank Zac Sharp for his assistance in the hydraulics laboratory and Ryan Christensen for showing me the ropes while I was first familiarizing myself with the GAMBIT and FLUENT software packages. Additionally, I would like to thank any professors, colleagues, and classmates who have expressed interest in my research and have provided direction or given advice. Special thanks to Utah State University's Center for High Performance Computing for providing the computational resources necessary to run my CFD models.

Most of all I want to thank my wife, Emily, for her unending support and encouragement, and my beautiful daughter, Lorelai, for making me smile. I would not have made it this far without my family standing behind me each step of the way. Their support has meant the world to me. 
CONTENTS

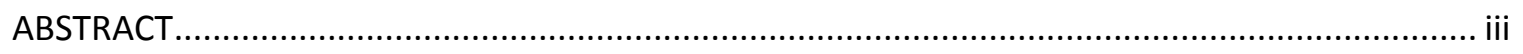

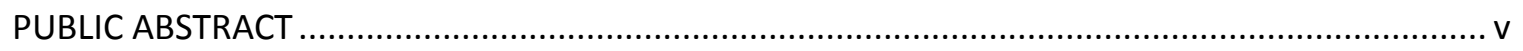

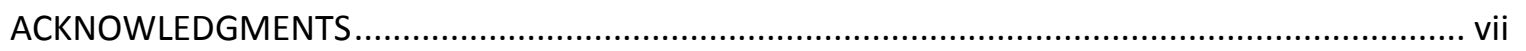

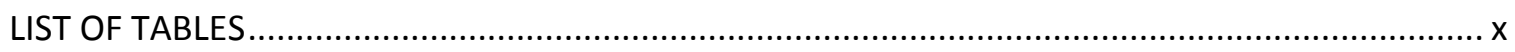

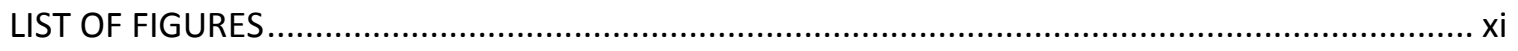

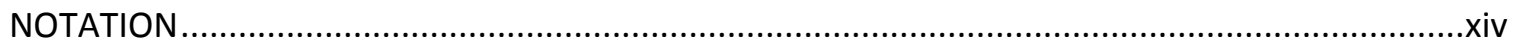

CHAPTER

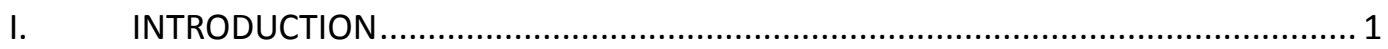

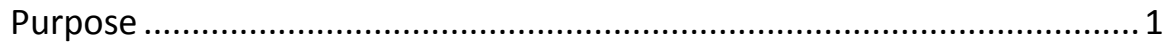

Ultrasonic Flow Meter Installation Requirements ........................... 2

Use of Computational Fluid Dynamics to Model Fluid Flow ............... 4

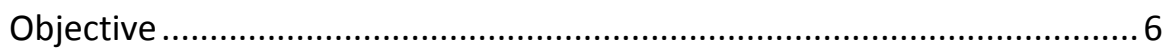

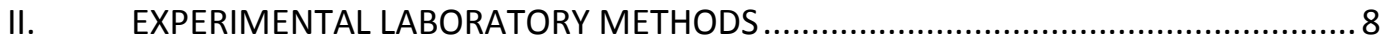

Fully Developed Velocity Profiles in Straight Pipe ................................. 8

Three-Dimensional Insert Velocity Probe Calibration....................... 8

Fully Developed Velocity Profiles in Straight Pipe .......................... 14

Ultrasonic Flow Measurements in Straight Pipe ....................................16

Ultrasonic Flow Measurements Downstream of 90-Degree Elbow .......... 17

Description of Laboratory Installation ......................................... 17

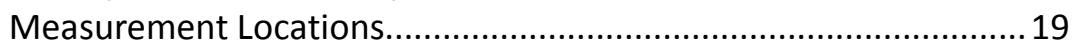

Ultrasonic Flow Measurements Downstream of 90-Degree

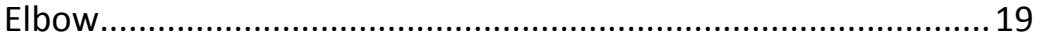

Full Profile of Ultrasonic Flow Measurements ............................... 21

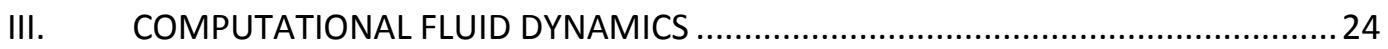


Description of Numerical Models ..........................................................24

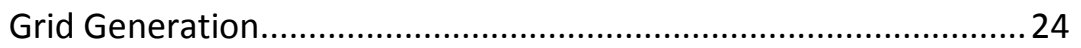

Numerical Method ................................................................. 25

Boundary Conditions ............................................................ 26

Velocity Profiles Downstream of 90-Degree Elbow.................................2 27

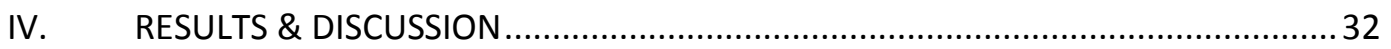

Fully Developed Velocity Profile (Lab vs. CFD)...................................... 32

Ultrasonic Performance Downstream of 90-Degree Elbow ...................... 34

Correction to Ultrasonic Flow Meter Measurements................................ 41

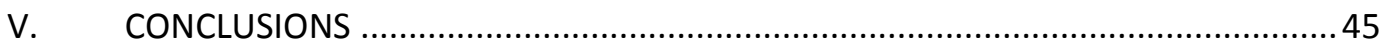

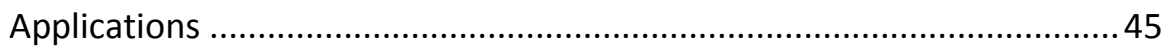

Need for Future Research ............................................................... 47

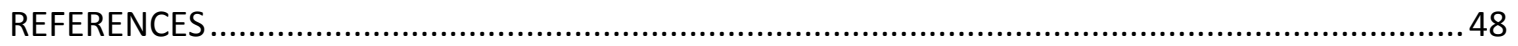

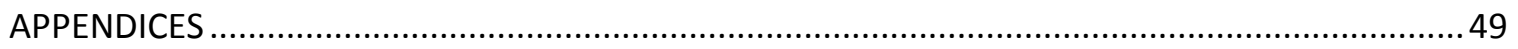

Appendix A. CFD Velocity Contour Plots of Fully Developed Profiles...............................50

Appendix B. CFD Velocity Contour Plots of Flow Profiles Downstream of 90-Degree

Elbow 
LIST OF TABLES

Table Page

$1 \quad$ Laboratory Ultrasonic Flow Meter Measurements...................................................... 16

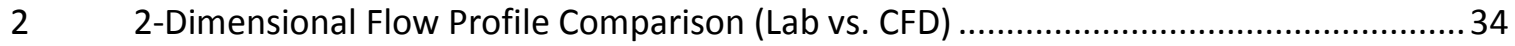

3 3-Dimensional Flow Profile Comparison (Lab vs. CFD) …............................................ 34

$4 \quad$ Ultrasonic Flow Measurement Error Before \& After Correction .....................................43

5 Standard Deviations of USFM Measurement Error from Correction Curve ..................... 44

6 Standard Deviations of USFM Measurement Error from Correction Curve .................... 44 


\section{LIST OF FIGURES}

Figure

Page

1 Bullen Farms Pump \#43 (Courtesy: Utah Division of Water Rights).....

2 Irrigation Pump on the Cub River (Courtesy: Utah Division of Water Rights) ..................... 5

3 Customer Drawing for United Sensor 3-D Insert Velocity Probe...................................... 9

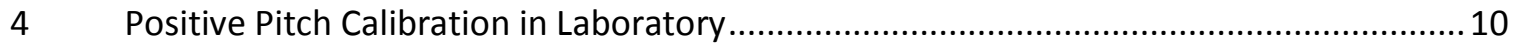

$5 \quad$ Pitch Angle Pressure Coefficients vs. Pitch Angle ......................................................... 11

$6 \quad$ Velocity Pressure Coefficients vs. Pitch Angle ............................................................ 13

$7 \quad$ Cross-Sectional View of Point Measurement Traverses .................................................. 14

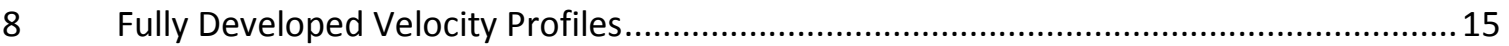

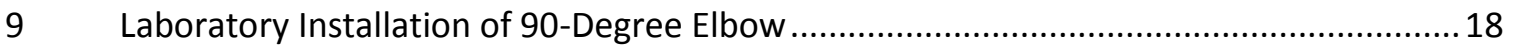

10 Laboratory Installation of 90-Degree Elbow........................................................... 18

11 Flow Conditioner Used Upstream of Elbow .............................................................. 19

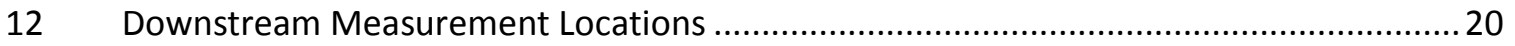

13 Ultrasonic Installation Orientations (Courtesy: Fuji Electric Systems Co., Ltd.) ................20

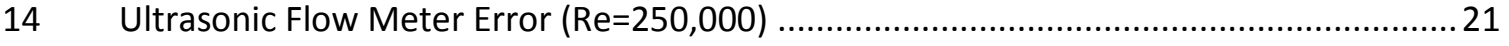

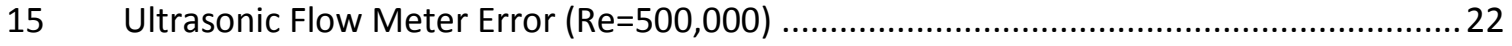

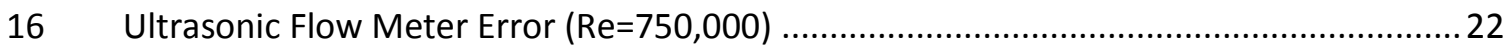

17 Ultrasonic Errors around Circumference of Pipe at 3 Diameters D/S of the Elbow ..........23

18 Cross-sectional View of Pipe Computational Mesh .....................................................25

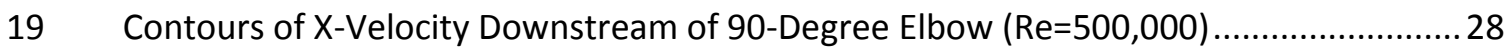

20 Cross-Sectional Velocity Contours (ft/s) Downstream of 90-Degree Elbow

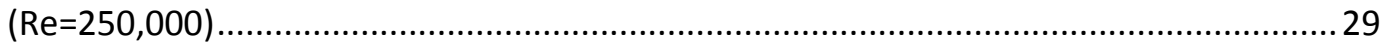


21 Cross-Sectional Velocity Contours (ft/s) Downstream of 90-Degree Elbow $(\operatorname{Re}=500,000)$.

22 Cross-Sectional Velocity Contours (ft/s) Downstream of 90-Degree Elbow $(\operatorname{Re}=750,000)$.

23 Ultrasonic Measurement Errors $(\mathrm{Re}=250,000)$.

Ultrasonic Measurement Errors $(\mathrm{Re}=750,000)$.

30 Contours of Fully Developed Velocity Profile $(\operatorname{Re}=250,000)$.......

40 Contours of $X$-Velocity at 1.5D Downstream $(\operatorname{Re}=500,000)$

41 Contours of X-Velocity at 3D Downstream $(\operatorname{Re}=500,000)$

42 Contours of $X$-Velocity at 5D Downstream $(R e=500,000)$ 


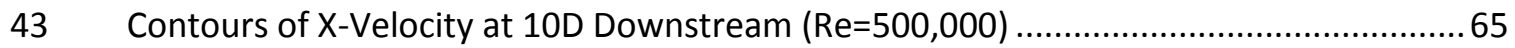

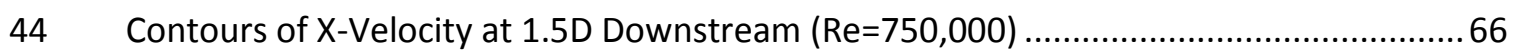

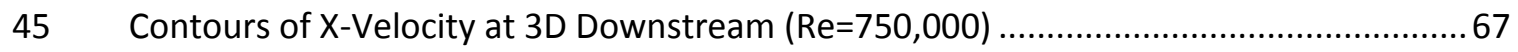

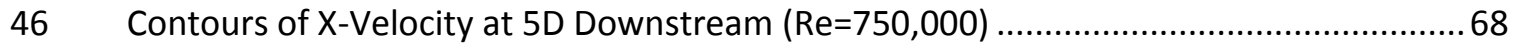

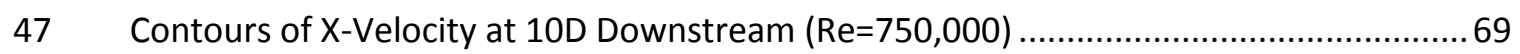




\section{NOTATION}

\begin{tabular}{|c|c|c|}
\hline $1 / n$ & $=$ & square root of the Darcy-Weisbach friction factor \\
\hline$a c-f t$ & $=$ & acre-foot \\
\hline$A_{p}$ & $=$ & cross-sectional area of pipe in feet squared \\
\hline$C F$ & $=$ & dimensionless correction factor \\
\hline$c f s$ & $=$ & cubic feet per second \\
\hline CFD & $=$ & Computational Fluid Dynamics \\
\hline$D$ & $=$ & pipe diameter \\
\hline$D$ & $=$ & pitch angle in degrees \\
\hline$D / S$ & $=$ & abbreviation for downstream \\
\hline$\varepsilon$ & $=$ & rate of turbulent kinetic energy dissipation \\
\hline$\varepsilon$ & $=$ & pipe roughness height \\
\hline$f$ & $=$ & Darcy-Weisbach friction factor \\
\hline$f t$ & $=$ & feet \\
\hline fps & $=$ & feet per second \\
\hline gpm & $=$ & gallons per minute \\
\hline$I D$ & $=$ & inside pipe diameter \\
\hline$k$ & $=$ & turbulent kinetic energy \\
\hline$k W-h r$ & $=$ & kilowatt-hour \\
\hline$L$ & $=$ & length of the ultrasonic signal path in feet \\
\hline$\pi$ & $=$ & pi term \\
\hline P1 & $=$ & centrally located pressure tap on insert velocity probe \\
\hline$P 2$ & $=$ & yaw pressure tap on insert velocity probe \\
\hline P23 & $=$ & the average of $P 2$ and $P 3$ \\
\hline
\end{tabular}




\begin{tabular}{|c|c|c|}
\hline P3 & $=$ & yaw pressure tap on insert velocity probe \\
\hline P4 & $=$ & pitch pressure tap on insert velocity probe \\
\hline P5 & $=$ & pitch pressure tap on insert velocity probe \\
\hline$P A P C$ & $=$ & pitch angle pressure coefficient \\
\hline Ps & $=$ & static pressure \\
\hline$P t$ & $=$ & total pressure \\
\hline$q$ & $=$ & mass flow rate in a plane in feet squared per second \\
\hline$Q$ & $=$ & mass flow rate in cubic feet per second \\
\hline$Q_{\text {actual }}$ & $=$ & actual mass flow rate \\
\hline$Q_{U S F M}$ & $=$ & mass flow rate measured by ultrasonic flow meter \\
\hline$r$ & $=$ & radial distance from the center of the pipe \\
\hline$R$ & $=$ & inside radius of pipe \\
\hline RANS & $=$ & Reynolds-Averaged Navier-Stokes equations \\
\hline$R e$ & $=$ & Reynolds number \\
\hline$S$ & $=$ & ultrasonic correction factor \\
\hline$u$ & $=$ & local velocity of the fluid \\
\hline$u_{\max }$ & $=$ & maximum velocity of the fluid \\
\hline USFM & $=$ & abbreviation for ultrasonic flow meter \\
\hline$V$ & $=$ & velocity of fluid in feet per second \\
\hline$V_{a}$ & $=$ & average-area velocity in feet per second \\
\hline$V_{l}$ & $=$ & average fluid velocity along the signal path in feet per second \\
\hline$V P C$ & $=$ & velocity pressure coefficient \\
\hline$y$ & $=$ & distance from the pipe wall \\
\hline$y+$ & $=$ & average wall distance (dimensionless) \\
\hline
\end{tabular}




\section{CHAPTER I}

\section{INTRODUCTION}

\section{Purpose}

In the arid west, water is among the most valuable of resources. One of the most critical aspects of water resource management is that of flow measurement. Accurate flow measurement data is needed to effectively manage any water distribution system, whether for culinary or irrigation use. For this reason and others, irrigation companies, power companies, and other entities that measure flow rates are interested in information and technology that improves the accuracy of flow measurements. More accurate flow measurement ultimately improves the allocation of water rights, system management, and water conservation.

The portable ultrasonic flow meter is a commonly used flow meter for field flow measurements in closed conduits. This type of flow meter has many advantages for field use. It is easy to temporarily install and does not produce any head loss in the system. Additionally, since the flow meter is not limited to a permanent installation, it is possible to use the same ultrasonic flow meter device in multiple locations.

There are two main types of ultrasonic flow meters: Transit-time and Doppler. Transittime ultrasonic flow meters emit two ultrasonic signals across the cross-section of the pipe. One signal travels with the direction of the flow and the other travels against the flow. The difference in signal travel time is then used along with the known geometry of the pipe to calculate the average flow velocity of the fluid.

Doppler ultrasonic meters also emit an ultrasonic signal across the pipe. However, this type of flow meter requires that the fluid contain particles which reflect the ultrasonic signal. These reflections cause a frequency shift, which is used to calculate the average flow velocity of the fluid. 


\section{Ultrasonic Flow Meter Installation Requirements}

In order to successfully and accurately measure a flow rate using any type of flow meter, several requirements must be met. In irrigation piping, it is generally recommended that a straight section of pipe be installed immediately upstream from the flow meter to avoid distorted flow patterns and extreme turbulence. Some research has been conducted in the past with regards to this issue. Among others, Hanson and Schwankl (1998) studied the error in flow rate measurements resulting from non-ideal conditions caused by several flow-disturbing devices. They were able to confirm that the performance of the types of flow meters studied suffered with regards to accuracy when used in non-ideal piping scenarios.

Additional requirements must be met in order to successfully and accurately measure a flow rate using an ultrasonic flow meter in irrigation pipes. The pipe must be full of fluid, in good condition, and should be mostly free of rust and other abnormalities. Another very important factor that affects ultrasonic meter accuracy and functionality is the placement of the meter transducers on the pipe. Ultrasonic flow meter manufacturers usually publish placement requirements in their user's manuals. These requirements specify how much straight piping should exist both upstream and downstream from the metering station where the ultrasonic meter is placed. In addition, elements such as pumps, valves, etc. should be a certain distance from the metering location to prevent disturbed flow at the metering location. In horizontal piping installations, the location where the ultrasonic flow meter is placed on the circumference of the pipe is also limited to certain mounting positions.

In the case that any of the specified requirements are not met, error may be introduced into the system and the accuracy of the measurement may suffer. The internal software used by a transit-time ultrasonic flow meter assumes that the velocity profile of the fluid at the 
location of the measurement is fully developed and symmetrical about the centerline of the pipe. The minimum requirements for straight piping upstream and downstream of the metering location allow adequate distance and time for the flow to stabilize and approach uniformity. The necessary length of straight piping is based on pipe size, and is usually given in terms of pipe diameter. While there is some variance amongst the requirements given by the different flow meter manufacturers, most flow meter manufacturers recommend at least 10 diameters of straight pipe upstream of the metering location and 5 diameters of straight pipe downstream of the metering location.

For new designs where ultrasonic flow measurement is to be used, these installation requirements must be met to ensure accurate flow measurement. In many existing field piping situations, however, such flow conditions are impossible to achieve. A very small percentage of all field piping contains adequate straight upstream length between the metering location and disturbances caused by throttling valves, pipe elbows, or pumps. This can be due to inadequate room to install straight piping, lack of money, or other changes made over time to a given water distribution system. Sometimes, flow conditioners such as tube bundles or vanes can be used to aid in developing the velocity profile, but such applications are not always possible or economically feasible. When adequate straight piping is not available, the velocity profile will not be fully developed, and chances are that meter readings in these physical configurations will be inaccurate. Several examples of poor approach conditions upstream of ultrasonic flow meters are shown in Figures 1 and 2. In both scenarios, the ultrasonic flow meters are placed very close to both non-straight piping and pump intakes.

With regards to flow measurement in non-ideal conditions, little research has been conducted specifically on the performance of ultrasonic flow meters. Johnson et al. (2001) 
studied the performance of an ultrasonic flow meter in disturbed flow conditions. Errors in flow rates as high as $36.5 \%$ were observed in some situations, while measurement accuracy was within $\pm 5 \%$ at the location 10 diameters downstream from any flow disturbances. By applying a correctional multiplier to some of the flow disturbing devices, flow measurement was improved to within $\pm 4 \%$ at locations at least 4.5 pipe diameters from the disturbance. They also found that the performance of the ultrasonic flow meter was not significantly different between the different pipe sizes, materials and flow rates used.

\section{$\underline{\text { Use of Computational Fluid Dynamics to Model Fluid Flow }}$}

The use of Computational Fluid Dynamics (CFD) is an increasingly popular way to numerically study and model fluid flow. Several commercial CFD codes currently available put powerful resources in the hands of engineers that are interested in modeling various types of

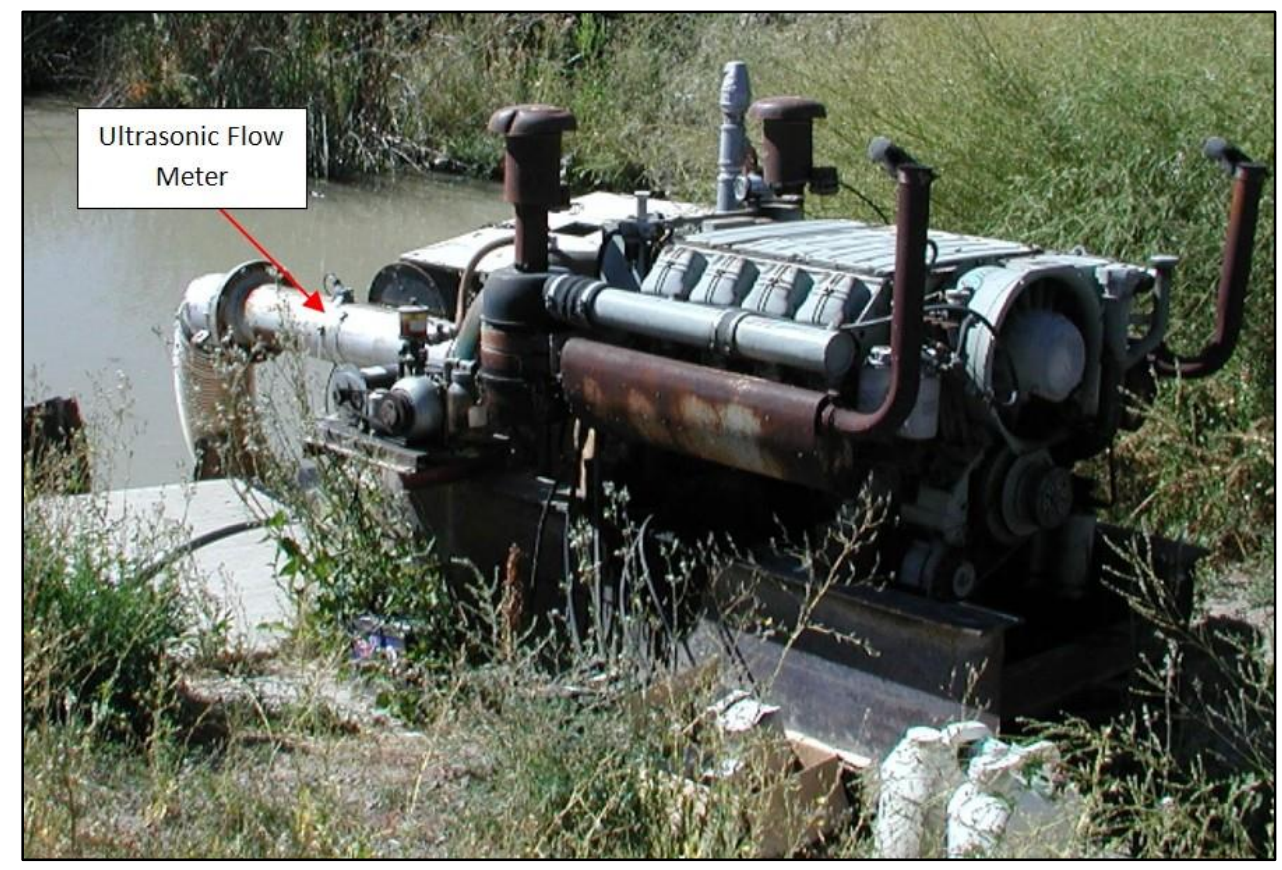

Figure 1. Bullen Farms Pump \#43 (Courtesy: Utah Division of Water Rights) 


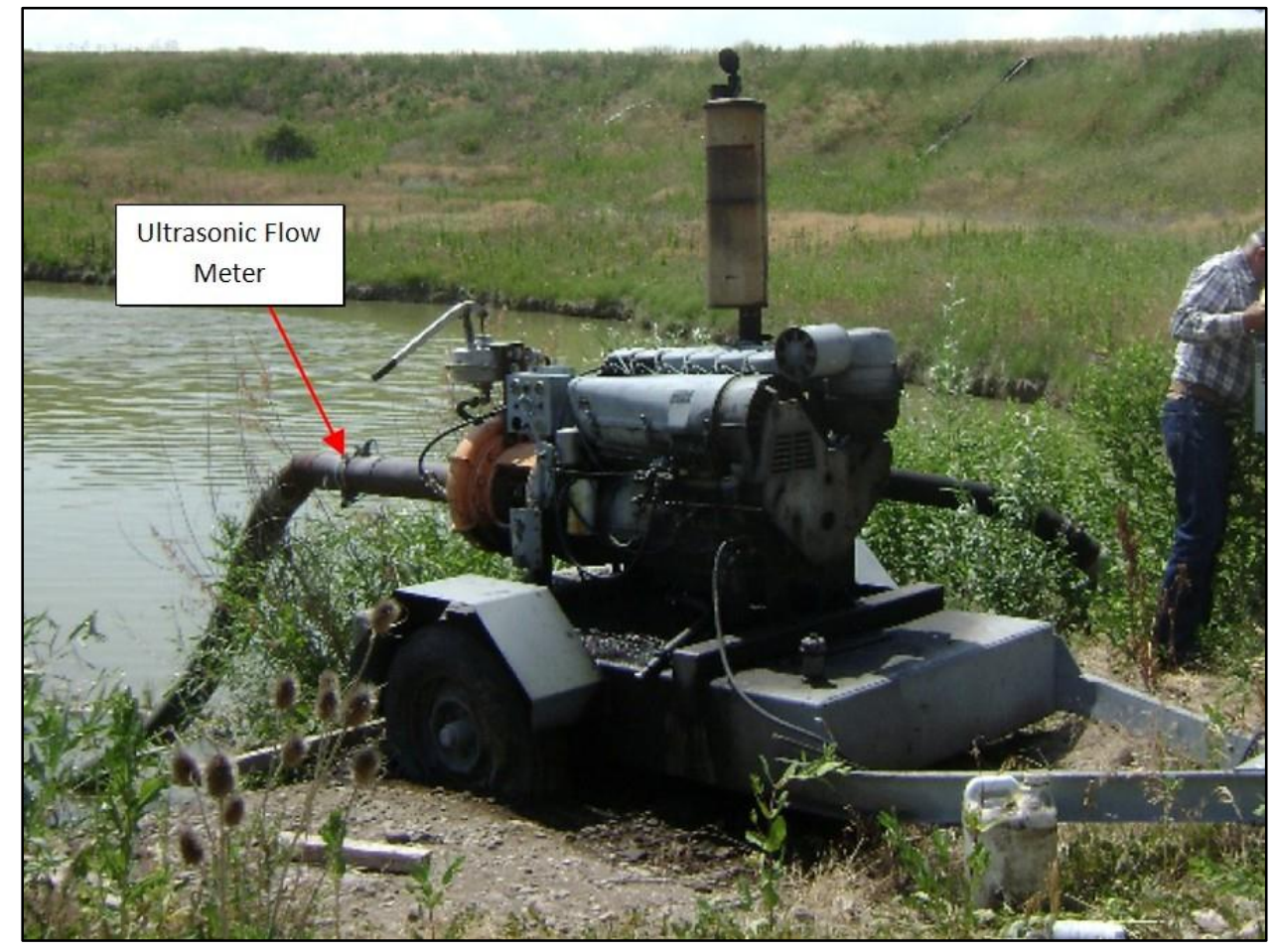

Figure 2. Irrigation Pump on the Cub River (Courtesy: Utah Division of Water Rights)

fluid flows for research and design. Because of the infinite number of possible combinations of non-ideal piping scenarios and the non-intrusive nature of ultrasonic flow metering, accurate numerical CFD representations of fluid flows could help in quantifying the inaccuracies of ultrasonic flow metering in non-ideal piping conditions. Accurate CFD solutions representing the flow in non-ideal piping scenarios could aid in better understanding the magnitude of velocity profile distortion from such geometry. If the extent of effects of the non-ideal piping on ultrasonic flow measurement can be understood and quantified, corrections can be made to ultrasonic flow meter installation procedures to account for the minimum installation requirements that are not able to be met in the field. 


\section{Objective}

The main objective of this research was to quantify the extent of the effects that a typical non-ideal piping configuration can have on ultrasonic flow measurement accuracy. This study includes both laboratory and CFD simulations. CFD was used to generalize and to better visualize the expected disturbances in velocity profiles in non-ideal piping setups, and was used as a tool in determining potential corrections and improvements to ultrasonic installation procedures. The laboratory flow measurements were used to validate the results obtained using the numerical CFD models. The specific research components for this study include the following:

1. Characterize fully developed velocity profiles in straight pipe

2. Characterize velocity profiles at various locations downstream of a 90-degree elbow

3. Test Fuji transit-time ultrasonic flow meter in straight pipe and downstream of 90degree elbow to determine flow meter accuracy in a general non-ideal piping condition

4. Develop numerical CFD models of uniform velocity profiles and velocity profiles downstream of a 90-degree elbow

5. Validate CFD results by comparing laboratory test results to numerical results

6. Use CFD results to analyze the magnitude of the flow disturbances created from the non-ideal piping geometry and to determine how said flow disturbances affect the ultrasonic flow meter capabilities

It was expected that the ultrasonic flow meter would display appreciable error at locations just downstream from the 90-degree elbow. By integrating the velocity profile of the fluid across the ultrasonic signal path, the distortion to the velocity profile from the flow disturbance can be characterized to determine potential correction factors and improved 
installation procedures. In some cases, the conclusion may be that the use of an ultrasonic flow meter is not advised if the recommended installation including sufficient straight pipe is unavailable. 
CHAPTER II

EXPERIMENTAL LABORATORY METHODS

\section{Fully Developed Velocity Profiles in Straight Pipe}

Fully developed velocity profiles in a straight 12 -inch pipe (inside diameter) were characterized for three different flow rates with Reynolds numbers of approximately 250,000, 500,000 , and 750,000 . These Reynolds numbers correspond to average pipe flow velocities of

$3.4,6.8$, and 10.3 feet per second (fps), respectively.

\section{$\underline{\text { Three-Dimensional Insert Velocity Probe Calibration }}$}

A 3-dimensional insert velocity probe manufactured by United Sensor Corporation was used to determine point velocities traversing a cross section of the 12 -inch laboratory pipe. The probe has five pressure holes on its tip, labeled in Figure 3 as P1 through P5. The centrally located pressure tap measures P1, while P2 and P3 measure the "yaw" and P4 and P5 measure the "pitch" of the direction of the fluid velocity. By following the appropriate measurement procedure, the quantities of total pressure, Pt and static pressure, Ps are found. The difference of these two pressure quantities is the velocity pressure, also called the velocity head, of the fluid flow. The procedure for obtaining point velocity measurements using the insert probe follows:

1. The probe is inserted into the flow stream at the desired measurement location and the probe is aligned so that $\mathrm{P} 1$ is pointing towards a reference position (i.e. upstream direction).

2. The probe is rotated until $\mathrm{P} 2$ equals $\mathrm{P} 3$, and the angle that the probe is rotated to in order to achieve P2=P3 is recorded as the yaw angle. 
3. The quantities P4-P5 and P1-P23 (where P23 is the average of $\mathrm{P} 2$ and $\mathrm{P} 3$ ) are measured and recorded.

4. The recorded measurement P4-P5 is divided by P1-P23. This value is called the Pitch Angle Pressure Coefficient.

5. The pitch angle is determined using the Pitch Angle Pressure Coefficient vs. Pitch Angle calibration curve for the individual probe.

6. Using the pitch angle, the Velocity Pressure Coefficient is found using the Velocity Pressure Coefficient vs. Pitch Angle calibration curve for the individual probe.

7. The Velocity Pressure Coefficient is multiplied by the recorded measurement of P1-P23. The result is the velocity pressure (Pt-Ps), also called the velocity head, of the fluid flow at the measurement point.

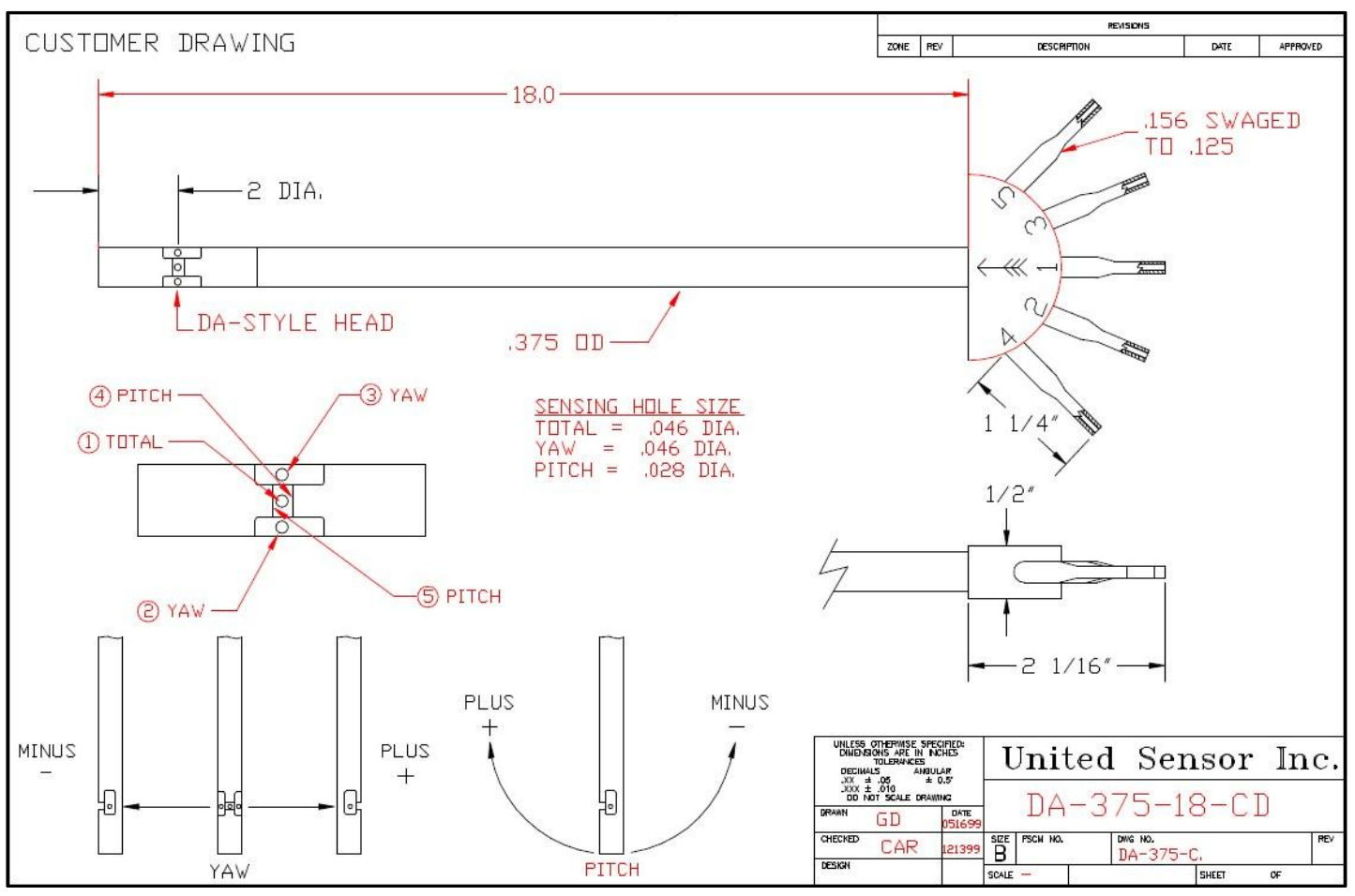

Figure 3. Customer Drawing for United Sensor 3-D Insert Velocity Probe 
United Sensor Corporation provided a single 9-point pitch calibration with the 3dimensional insert velocity probe, ranging from \pm 40 degrees in 10 -degree increments. The provided calibration included the necessary plots of the Pitch Angle Pressure Coefficient and the Velocity Pressure Coefficient. The calibration, however, was achieved in a wind tunnel capable of a minimum air velocity of $95 \mathrm{fps}$. To ensure successful measurements in the hydraulics lab at the Utah Water Research Laboratory, different calibration curves were necessary for water.

A similar 11-point pitch calibration was conducted in the hydraulics lab at the Utah Water Research Lab with the 3-dimensional insert velocity probe, by ranging the pitch values from \pm 40 degrees in 10 -degree increments and including 0 degrees and \pm 5 degrees. This was achieved by welding compression fittings onto the outside of the pipe wall at $0,5,10,20,30$, and 40 degrees from perpendicular. Figure 4 shows how the positive pitch angle calibrations were conducted. For the negative pitch values, the pipe was simply reinstalled in the opposite longitudinal direction. To achieve a fully developed velocity profile in both installations, there were more than 40 diameters of straight pipe upstream from the measurement locations.

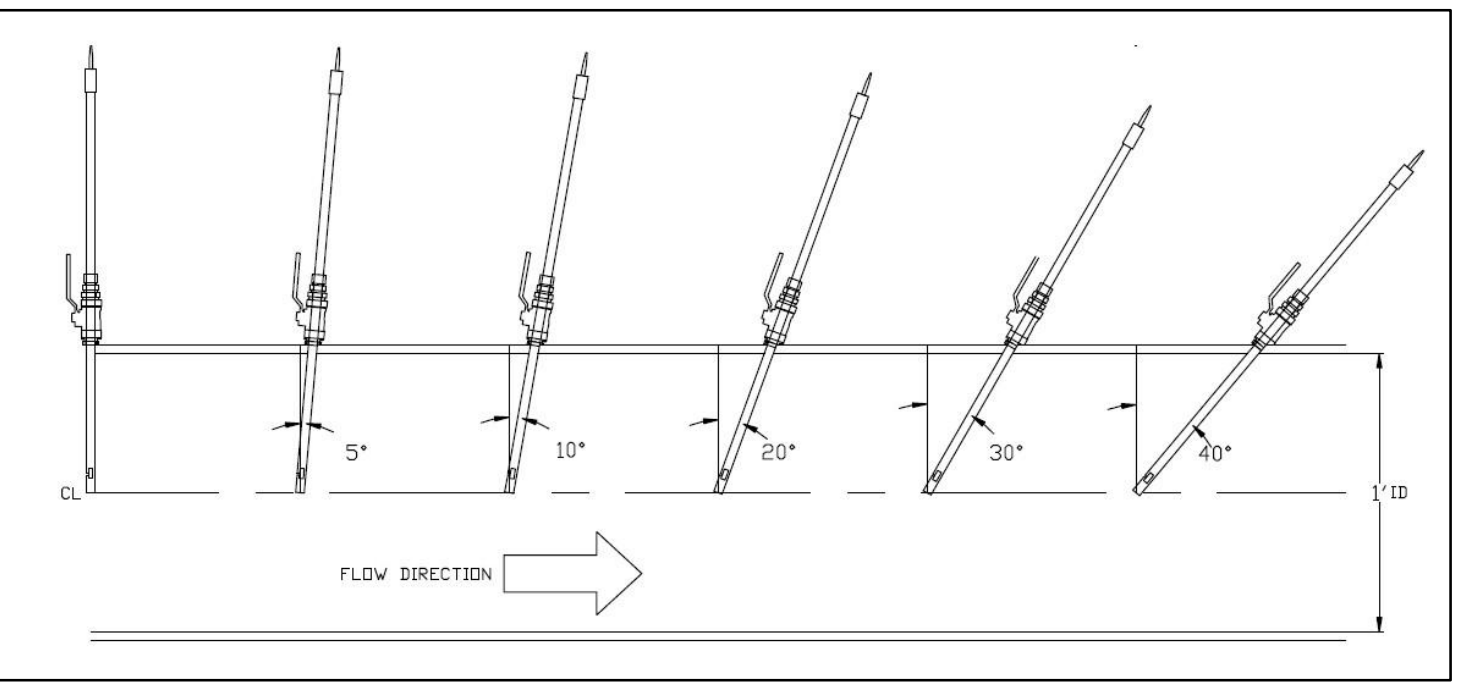

Figure 4. Positive Pitch Calibration in Laboratory 
Laboratory flow rates for the calibration were obtained using the laboratory magnetic meter, which was checked periodically against a weight tank for accuracy. The maximum difference seen between the weight tank and the magnetic meter during the calibration was 0.15\%. The quantities P2-P3, P1-P23, P2-Ps, and P4-P5 were measured for each pitch angle using Omega PX2300 Series Bi-Directional Differential Pressure Transducers for the following average pipe flow velocities: $3.4,6.8,10.3$, and $11.9 \mathrm{fps}$. The velocity head, or the difference between the total pressure and the static pressure, is equal to P1-P23. Pitch Angle Pressure Coefficients were obtained by dividing P4-P5 by P1-P23 for each flow rate and pitch angle. Figure 5 shows the Pitch Angle Pressure Coefficients that were determined when plotted against pitch angle for each of the four flow rates, as well as the average of the values for each pitch angle.

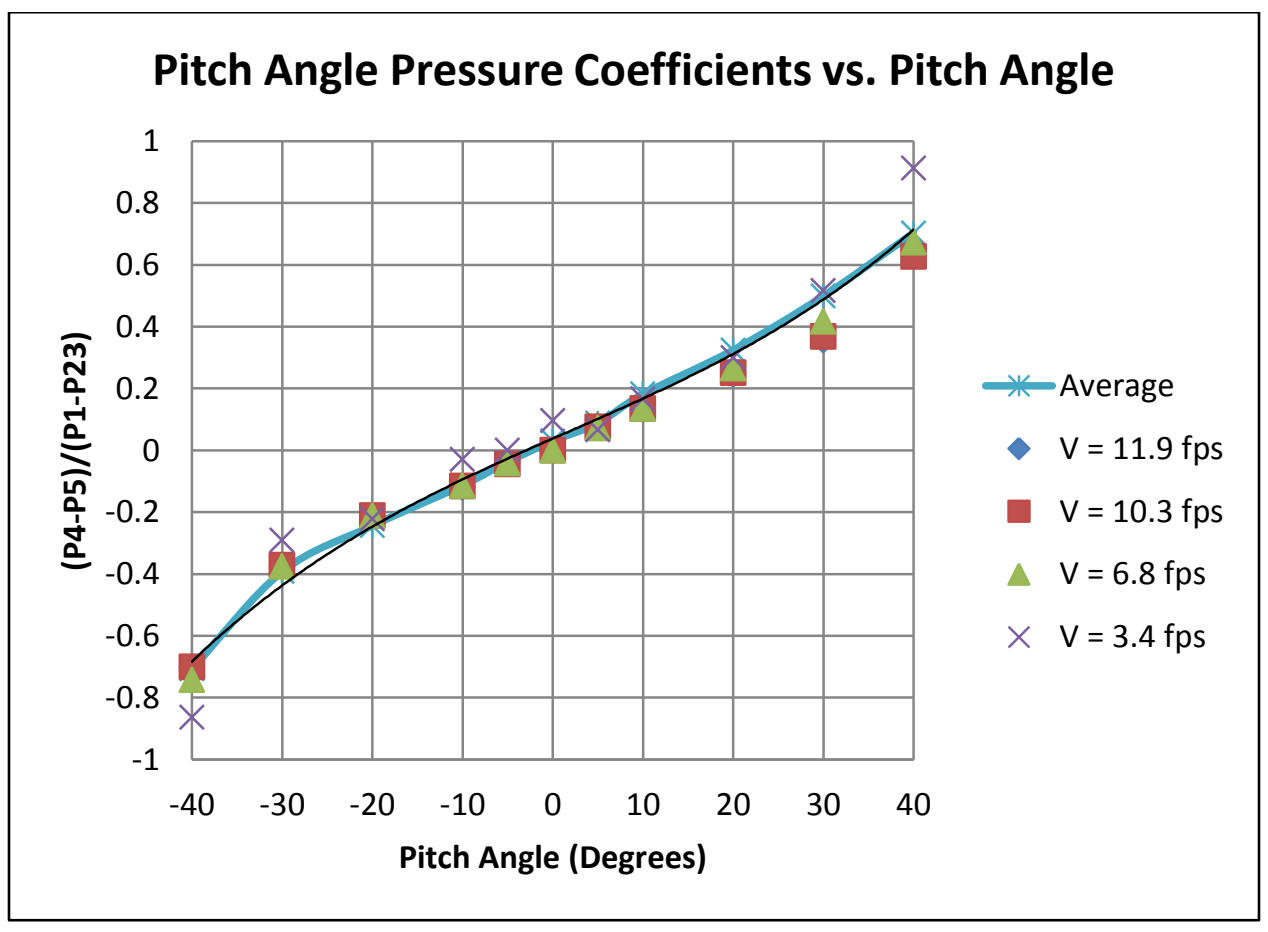

Figure 5. Pitch Angle Pressure Coefficients vs. Pitch Angle 
Equation (1) is a third-order polynomial that was fit to the average of the Pitch Angle Pressure Coefficients, with an $\mathrm{R}^{2}$ value of 0.9976 .

$$
P A P C=3 \times 10^{-6} \times D^{3}-1 \times 10^{-5} \times D^{2}+0.0128 \times D+0.0381
$$

where $P A P C$ is the Pitch Angle Pressure Coefficient and $D$ is the pitch angle in degrees. Equation (1) shows no asymptotes in the range of \pm 40 degrees. As the probe was to be used only in straight pipe, pitch angles were not expected to deviate from zero by more than a few degrees in either direction at most. Therefore, the fitted equation should serve well for the purposes of this study. The largest individual deviations visible in Figure 5 come from some of the lower velocities that were measured. As the flow rate increases, the data appears to converge on a single curve.

In addition to the Pitch Angle Pressure Coefficients, Velocity Pressure Coefficients were obtained by dividing Pt-Ps by P1-P23 for each flow rate and pitch angle. Figure 6 shows the Velocity Pressure Coefficients that were determined plotted against pitch angle for each of the four flow rates, as well as the average of the values for each pitch angle.

Due to the shape of the curve, two separate third-order polynomials were fit to the average of the Velocity Pressure Coefficients: one for pitch angles less than zero, and one for pitch angles greater than and including zero. They are shown in Equations (2) and (3), and have $R^{2}$ values of 0.9927 and 0.9986 , respectively.

$$
\begin{aligned}
& V P C_{\text {negative }}=-4 \times 10^{-6} \times D^{3}+7 \times 10^{-5} \times D^{2}+0.0026 \times D+1.1251 \\
& V P C_{\text {positive }}=1 \times 10^{-5} \times D^{3}+0.0004 \times D^{2}+0.0024 \times D+1.0835
\end{aligned}
$$




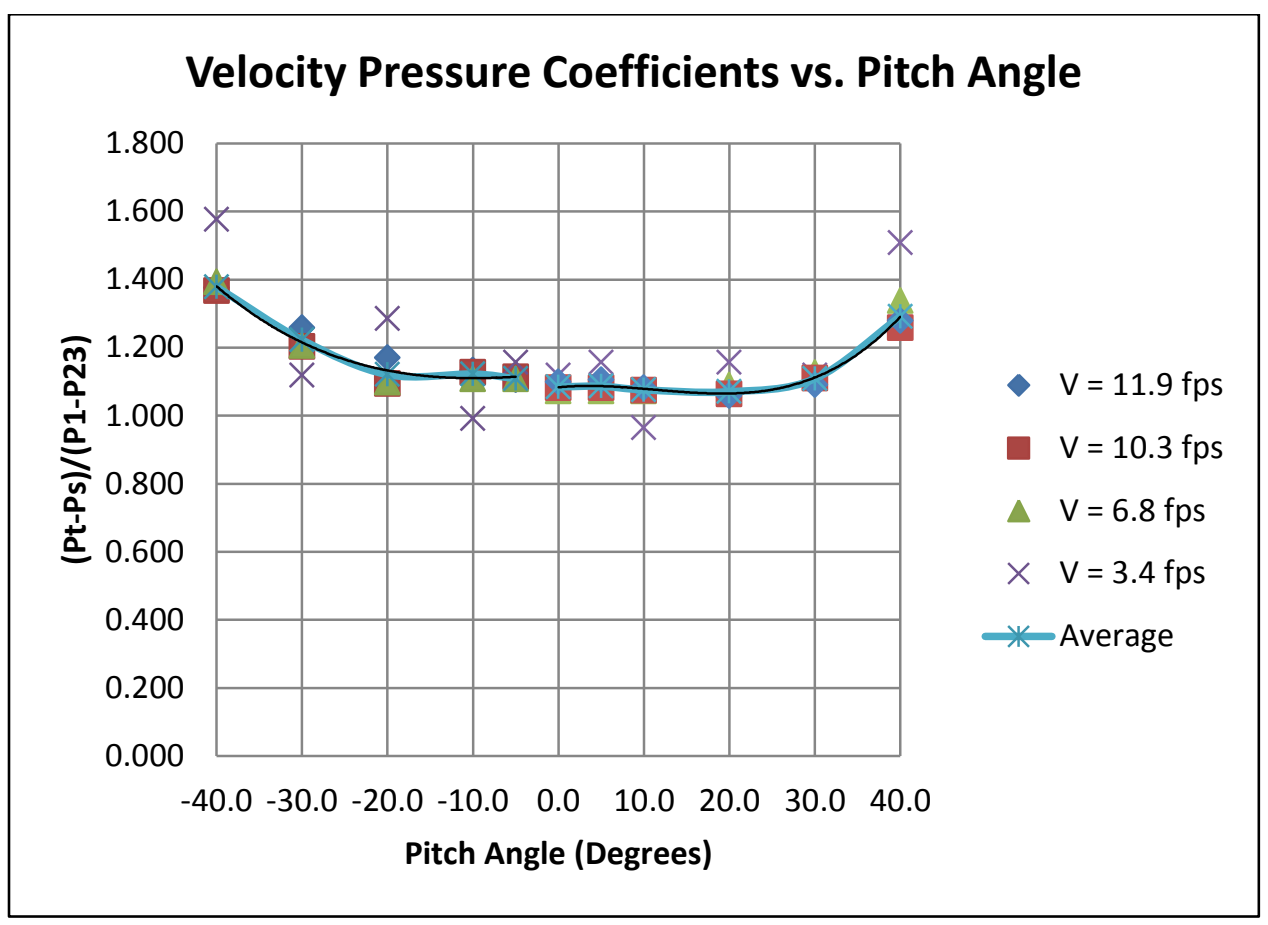

Figure 6. Velocity Pressure Coefficients vs. Pitch Angle

where $V P C_{\text {negative }}$ is the Velocity Pressure Coefficient for pitch angles less than zero, $V P C_{\text {positive }}$ is the Velocity Pressure Coefficient for pitch angles greater than or equal to zero, and $D$ is the pitch angle in degrees. Equations (2) and ( 3 ) show no asymptotes in the range of \pm 40 degrees. As the probe was to be used only in straight pipe, pitch angles were not expected to deviate from zero by more than a few degrees in either direction. Therefore, the fitted equations should serve well for the purposes of this study. As with the Pitch Angle Pressure Coefficient data, the largest individual deviations visible in Figure 6 come from some of the lower velocities that were measured. With the higher velocities, the data appears to converge on a single curve.

Performing the pitch angle calibration in the laboratory also provided an opportunity to assess the physical limitations of the velocity probe. In order to operate the probe as designed 
and to avoid any excessive vibrations or breaking of the probe, the fluid flow velocities were limited to approximately $10 \mathrm{fps}$.

\section{Fully Developed Velocity Profiles in Straight Pipe}

Having obtained new probe calibration curves for water, the probe was then used to obtain point velocity measurements in straight pipe using the same procedure described previously. For each flow rate, a 5-point test (including a point on the centerline of the pipe) was completed and the point velocities were measured across a vertical traverse and again across a horizontal traverse, as seen in Figure 7.

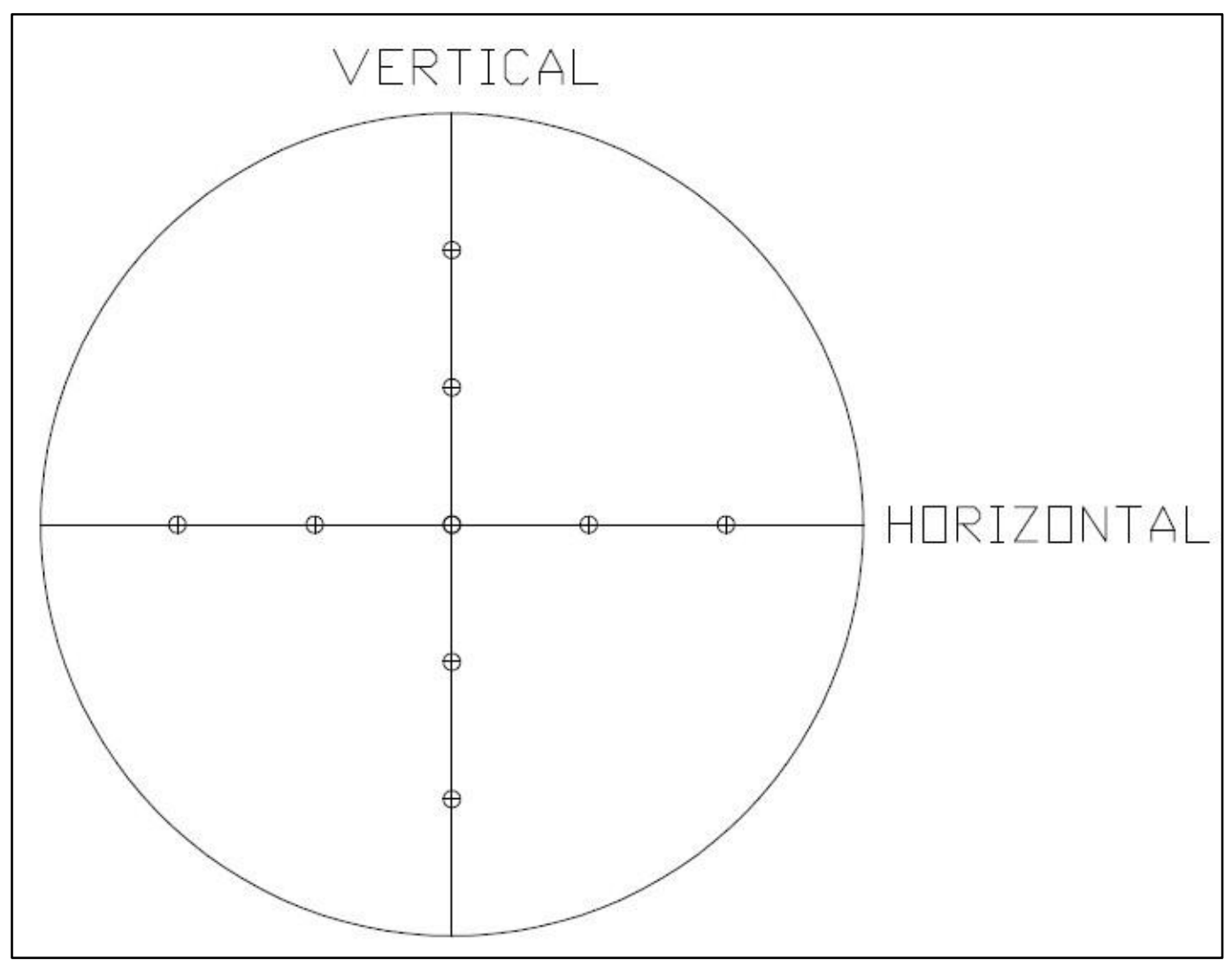

Figure 7. Cross-Sectional View of Point Measurement Traverses 
More than 40 diameters of straight pipe were installed upstream from the measurement locations in order to achieve fully developed velocity profiles. Measurement locations were normalized by dividing the distance from the pipe wall to the point of measurement, $y$, by the inside pipe diameter, D. Point velocities were normalized by dividing the measured point velocity by the average pipe flow velocity for each measurement. Figure 8 shows the fully developed velocity profiles that were measured. The noticeable yet relatively insignificant deviations across the traverses are thought to originate in part from the turbulent fluctuations in the fluid flow over time. Each point velocity measurement was averaged over a time of several minutes, and the fluctuations might have been minimized further with longer averaging times. These velocity profiles were then used to validate the fully developed velocity profiles obtained from numerical CFD models.

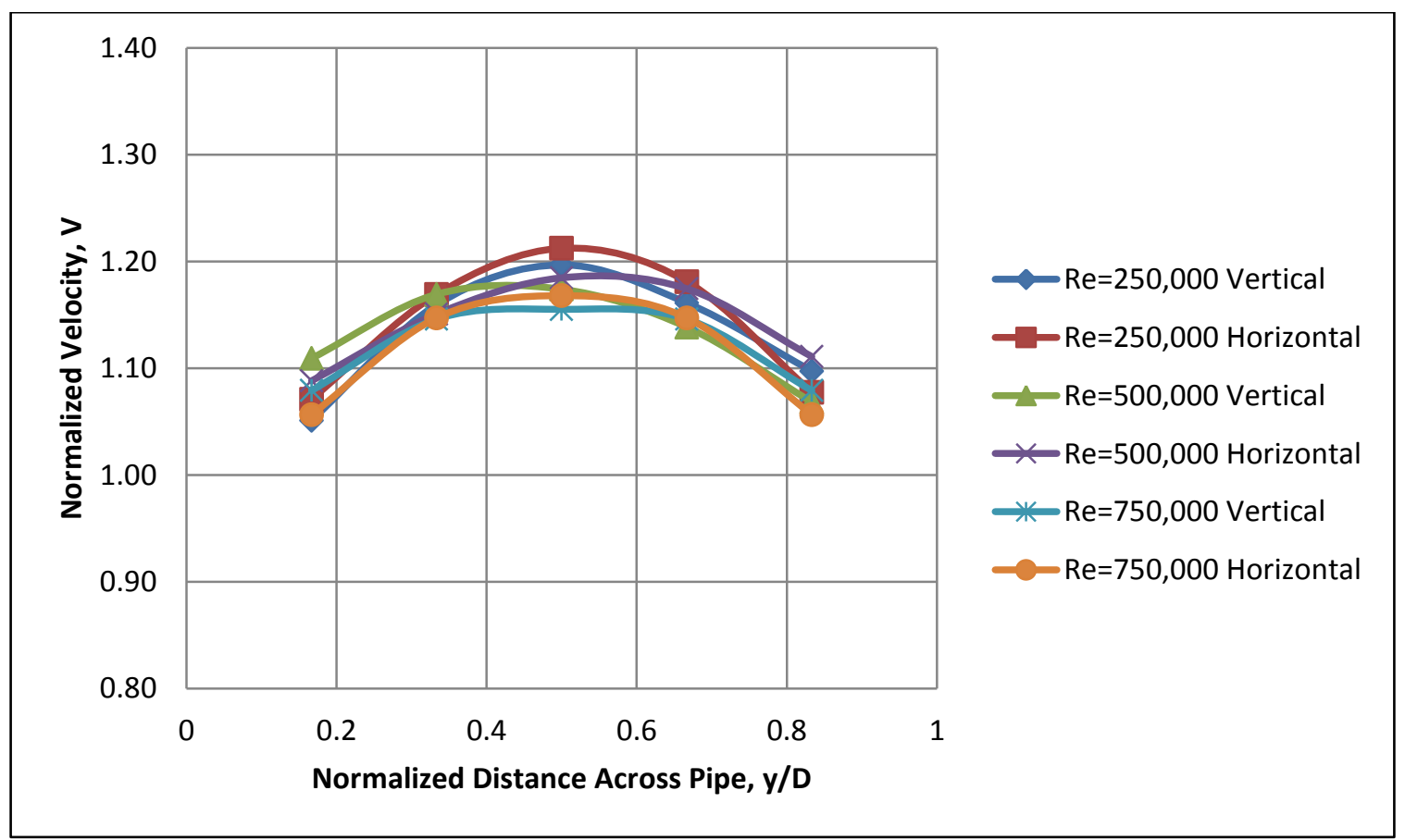

Figure 8. Fully Developed Velocity Profiles 


\section{Ultrasonic Flow Measurements in Straight Pipe}

The Fuji PortaflowX is a transit-time portable ultrasonic flow meter. The accuracy of the PortaflowX was verified in the physical conditions as specified by the manufacturer. This was done on the same straight 12.00 -inch inside diameter pipe with more than 40 diameters of straight pipe upstream of the measurement location. All other suggested conditions were met according to the manufacturer's provided recommendations (Fuji Electric Systems Co., Ltd., 2009).

Three flow conditions were tested with Reynolds numbers of approximately 250,000, 500,000 , and 750,000 . For each flow rate, the ultrasonic flow was measured against the laboratory magnetic flow meter twice and against the laboratory weight tank once. The measurements that were taken are tabulated in Table 1, along with the calculated percent deviation. The average deviation of the ultrasonic flow meter was $-0.47 \%$, which is generally considered to be within the acceptable range of error for field flow measurements.

Table 1. Laboratory Ultrasonic Flow Meter Measurements

\begin{tabular}{|c|c|c|c|c|}
\hline $\begin{array}{c}\text { Reynolds } \\
\text { Number }\end{array}$ & $\begin{array}{c}\text { Mag Meter } \\
\text { Flow } \\
\text { (gpm) }\end{array}$ & $\begin{array}{c}\text { Weigh Tank } \\
\text { Flow } \\
\text { (gpm) }\end{array}$ & $\begin{array}{c}\text { Ultrasonic } \\
\text { Flow } \\
\text { (gpm) }\end{array}$ & $\begin{array}{c}\text { Percent } \\
\text { Deviation } \\
(\%)\end{array}$ \\
\hline \hline \multirow{3}{*}{250,000} & 1195.0 & - & 1189.4 & $-0.47 \%$ \\
\cline { 2 - 5 } & 1195.1 & - & 1189.4 & $-0.48 \%$ \\
\cline { 2 - 5 } & - & 1197.0 & 1189.4 & $-0.63 \%$ \\
\hline \multirow{3}{*}{500,000} & 2413.0 & - & 2412.5 & $-0.02 \%$ \\
\cline { 2 - 5 } & 2428.0 & - & 2412.5 & $-0.64 \%$ \\
\cline { 2 - 5 } & - & 2429.2 & 2412.5 & $-0.69 \%$ \\
\hline \multirow{3}{*}{750,000} & 3634.0 & - & 3615.9 & $-0.50 \%$ \\
\cline { 2 - 5 } & 3626.0 & - & 3610.3 & $-0.43 \%$ \\
\cline { 2 - 5 } & - & 3624.8 & 3610.3 & $-0.40 \%$ \\
\hline
\end{tabular}




\section{Ultrasonic Flow Measurement Downstream of 90-Degree Elbow}

The accuracy of the Fuji Ultrasonic Flow Meter downstream of a flow disturbance was then studied. A simple yet common flow disturbance found in field situations is a single longradius 90 -degree elbow coming out of a pump to supply flow to an irrigation line. Flow meter

manufacturers specify a necessary length of straight pipe that is required between an upstream elbow and the ultrasonic measurement location. In general, manufacturers state that at least 10 diameters of straight pipe are required to achieve a fully developed velocity profile at the measurement location. Due to the countless number of possible non-ideal piping configurations that could result in disturbed ultrasonic flow measurements, it was impractical to study every possible scenario for this study. The single 90-degree elbow was chosen for simplicity and to demonstrate how ultrasonic flow measurements might be improved for a general disturbed flow condition. The laboratory and CFD results do not accurately represent the flow patterns that would occur downstream of any other flow disturbing device or combination of devices.

\section{Description of Laboratory Installation}

In the hydraulics laboratory, a long-radius 90-degree elbow having an inside diameter of 12.00 inches was installed upstream of a long length of straight pipe on which the ultrasonic flow meter would be used to measure the effects of the elbow on the ultrasonic flow meter accuracy. Upstream of the elbow, another 20 diameters of straight pipe was installed in addition to a flow conditioner installed with the objective of obtaining a fully developed velocity profile entering the elbow. The laboratory installation and setup described is shown in Figures 9-11. 


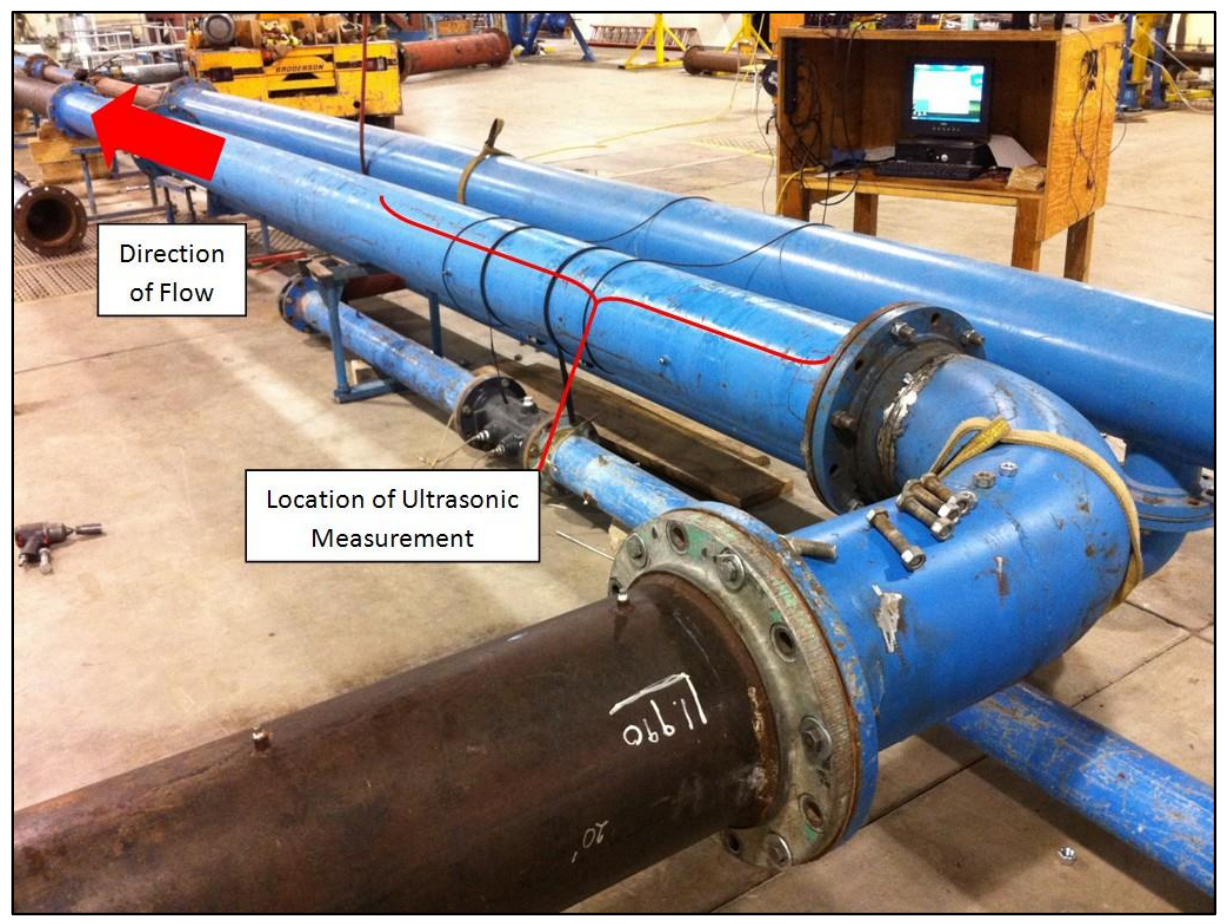

Figure 9. Laboratory Installation of 90-Degree Elbow

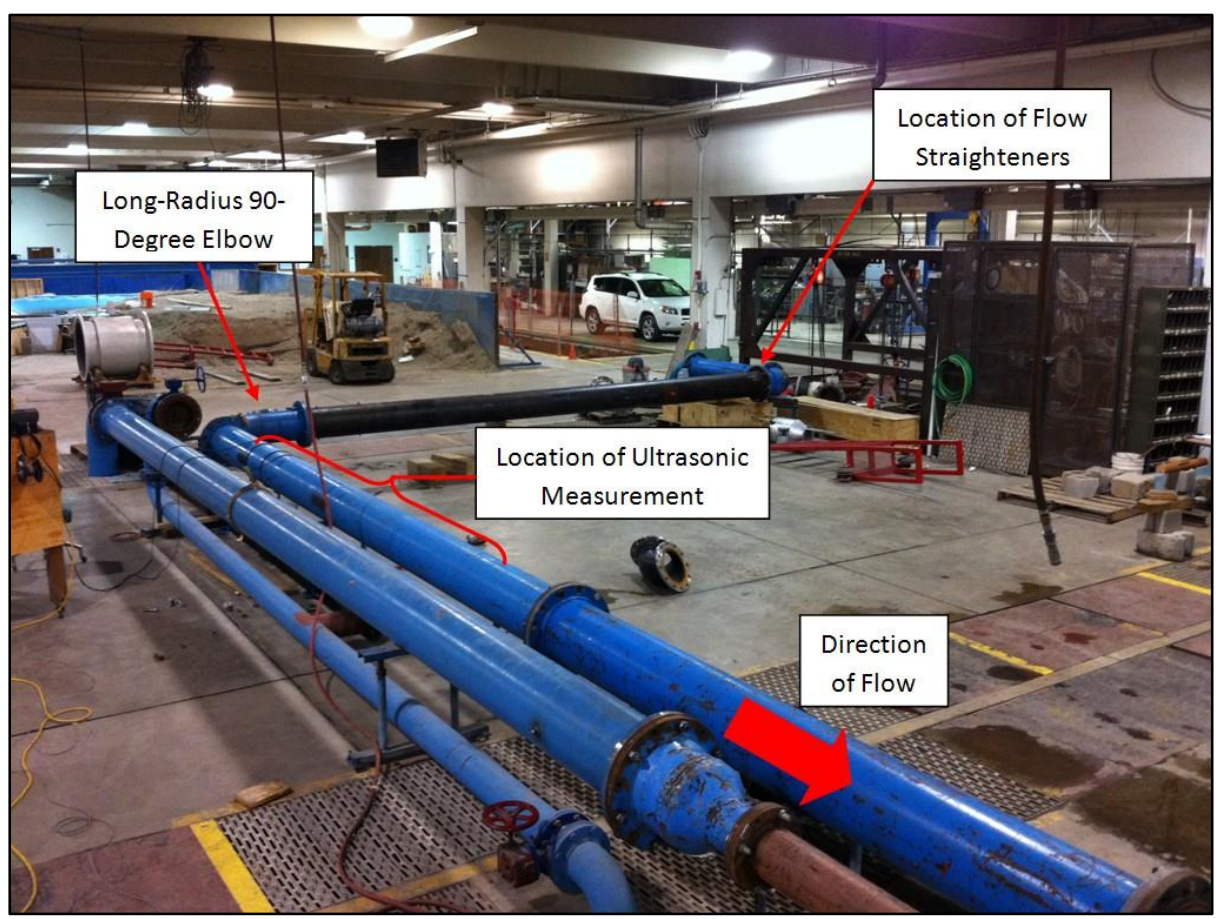

Figure 10. Laboratory Installation of 90-Degree Elbow 


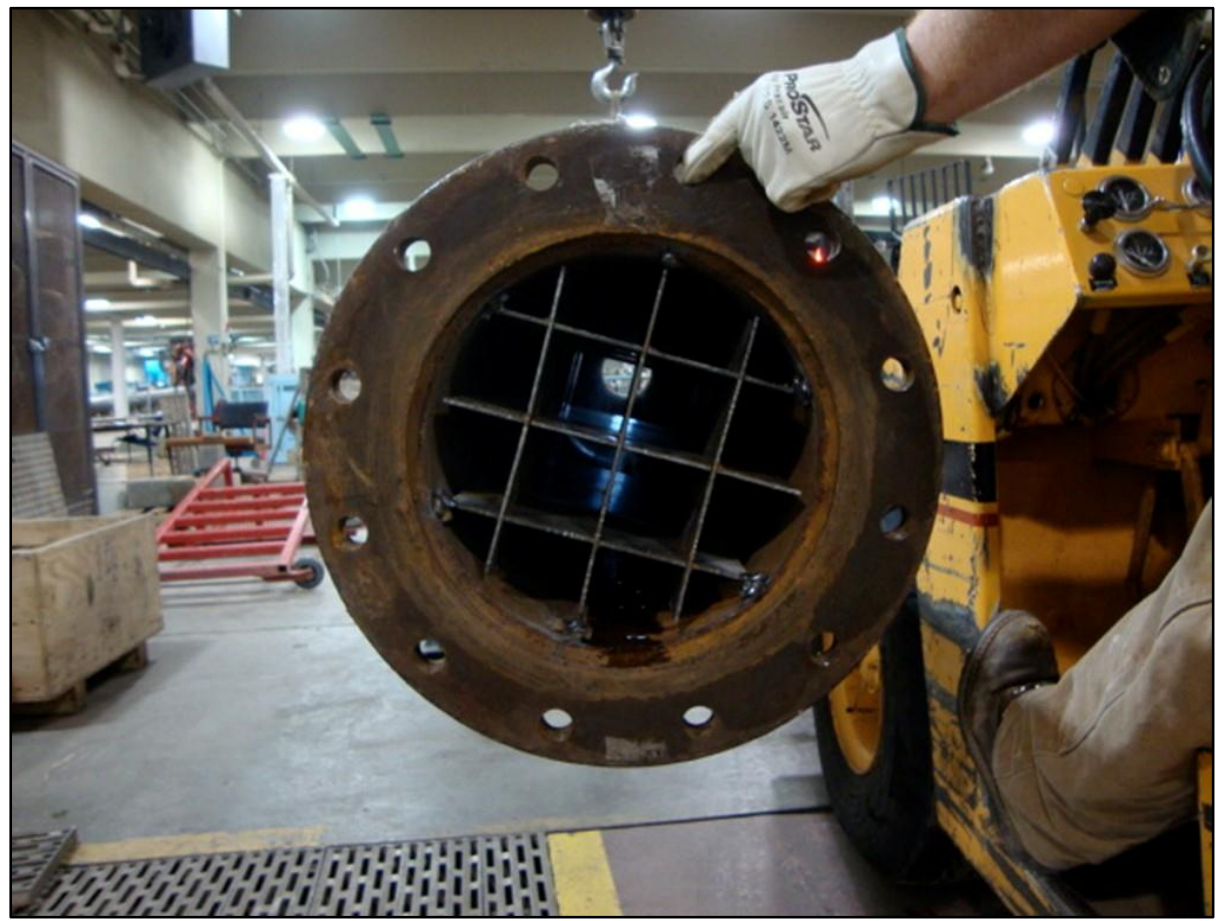

Figure 11. Flow Conditioner Used Upstream of Elbow

\section{$\underline{\text { Measurement Locations }}$}

The ultrasonic flow meter was installed and tested at four different locations

downstream from the elbow. In terms of pipe diameter, the measurements were taken at the following downstream locations: 1.5D, 3D, 5D, and 10D downstream from the downstream edge of the elbow, as seen in Figure 12. At each of these four downstream locations, the ultrasonic flow meter was installed at three different orientations around the circumference of the pipe: $-45^{\circ}, 0^{\circ}$, and $+45^{\circ}$ from horizontal, as seen in Figure 13.

\section{Ultrasonic Flow Measurements Downstream} of 90-Degree Elbow

For each orientation and at each measurement location, the flow rate measured by the ultrasonic flow meter was recorded two times against the laboratory magnetic meter. The 
percent error was then calculated for each data point. As was done with the insert velocity probe tests, the accuracy of the magnetic meter was periodically verified with weight tank measurements.

Figures 14-16 plot the percent error of the ultrasonic flow meter measurement against measurement location for each flow rate and installation orientation. It is noted that the

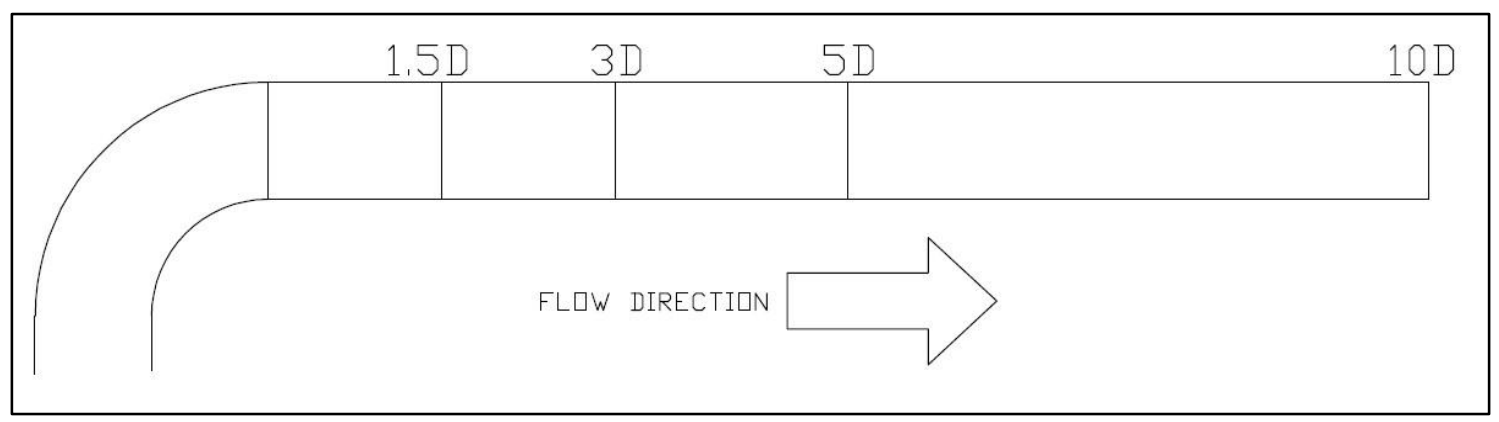

Figure 12. Downstream Measurement Locations

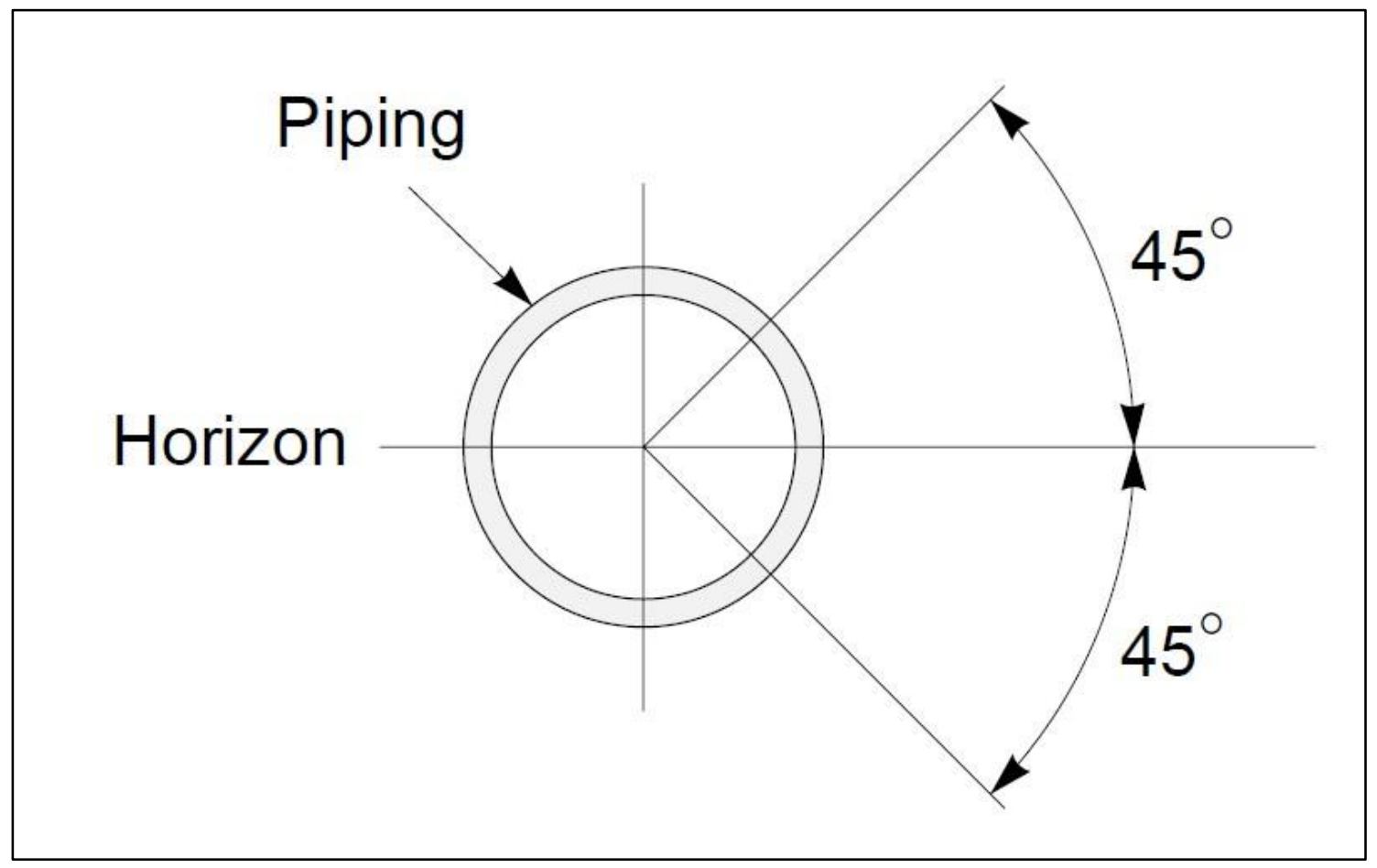

Figure 13. Ultrasonic Installation Orientations (Courtesy: Fuji Electric Systems Co., Ltd.) 
ultrasonic flow meter error is always negative, indicating that the ultrasonic flow meter underpredicts the actual flow in the pipe when it is installed in a disturbed-flow region. The ultrasonic flow meter measurement error is decreased the further it is placed downstream from the flow disturbance. This trend coincides with the recommended installation practices involving straight piping upstream from the measurement location.

\section{Full Profile of Ultrasonic Flow Measurements}

In addition to the measurement locations mentioned previously, measurements around the full circumference of the pipe were taken for the $\mathrm{Re}=500,000$ flow rate at the measurement location three diameters downstream from the elbow. The percent error of the ultrasonic flow measurements can be seen around the entire circumference of the pipe at their respective

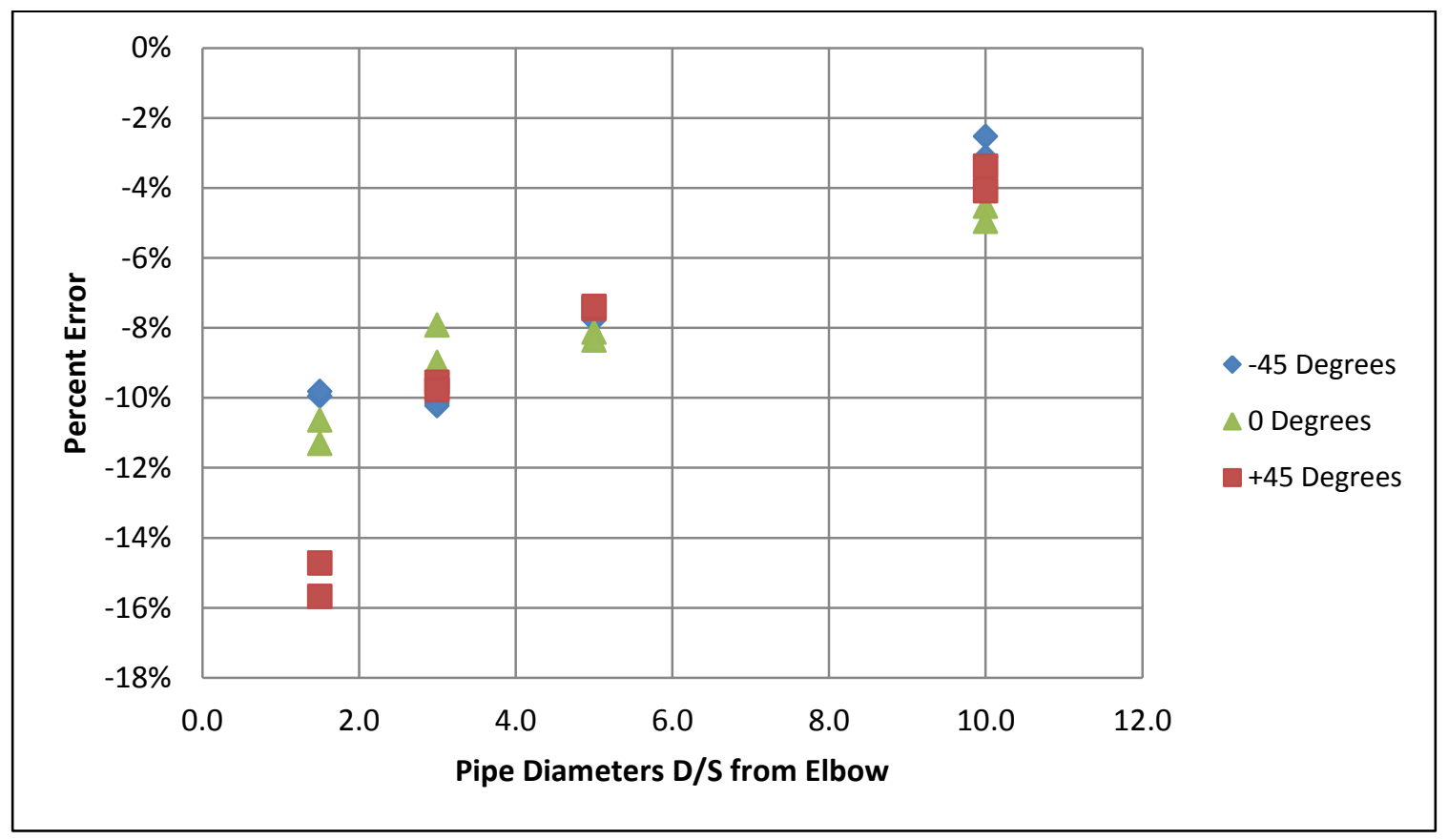

Figure 14. Ultrasonic Flow Meter Error $(\operatorname{Re}=250,000)$ 


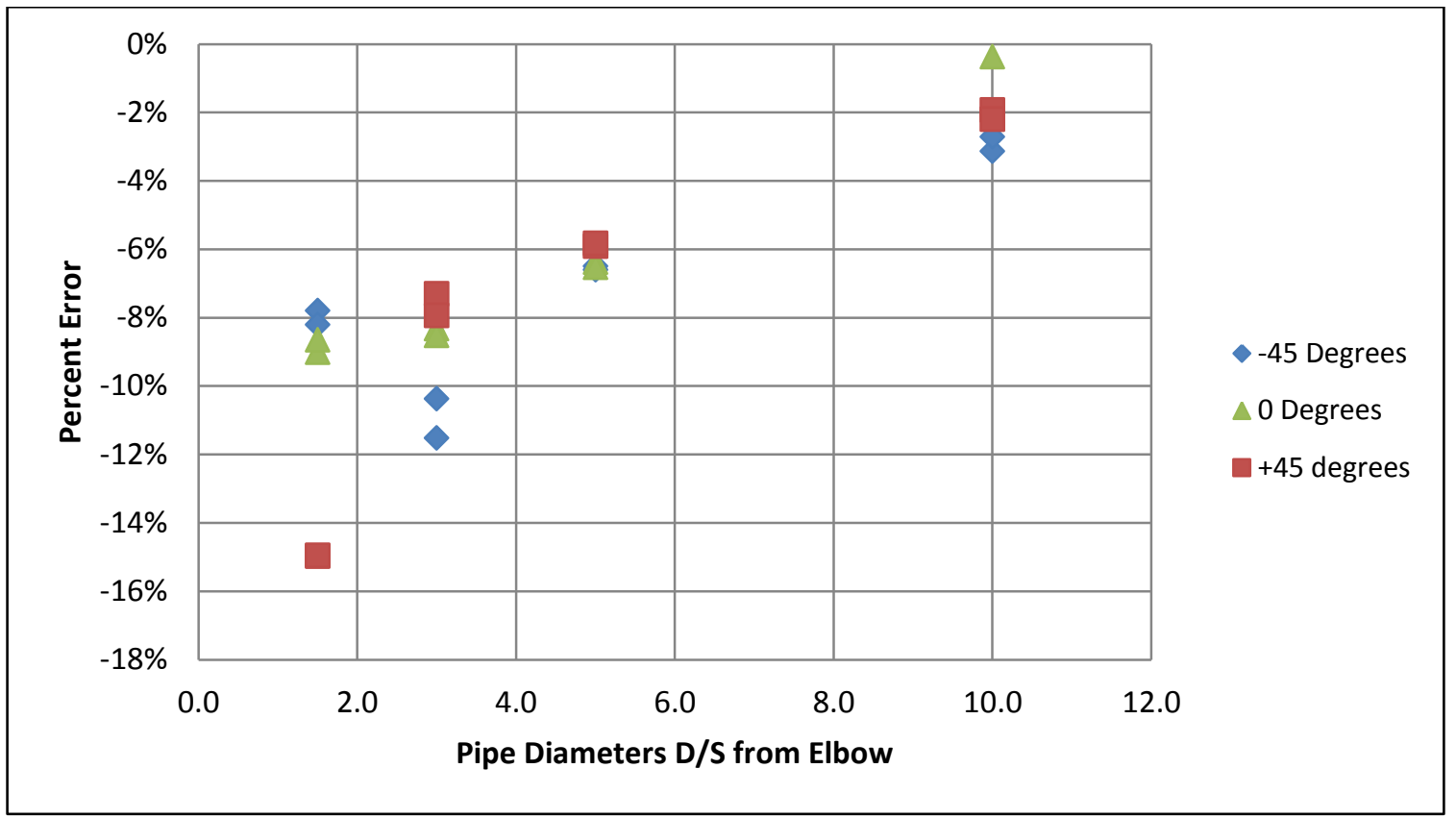

Figure 15. Ultrasonic Flow Meter Error $(\operatorname{Re}=500,000)$

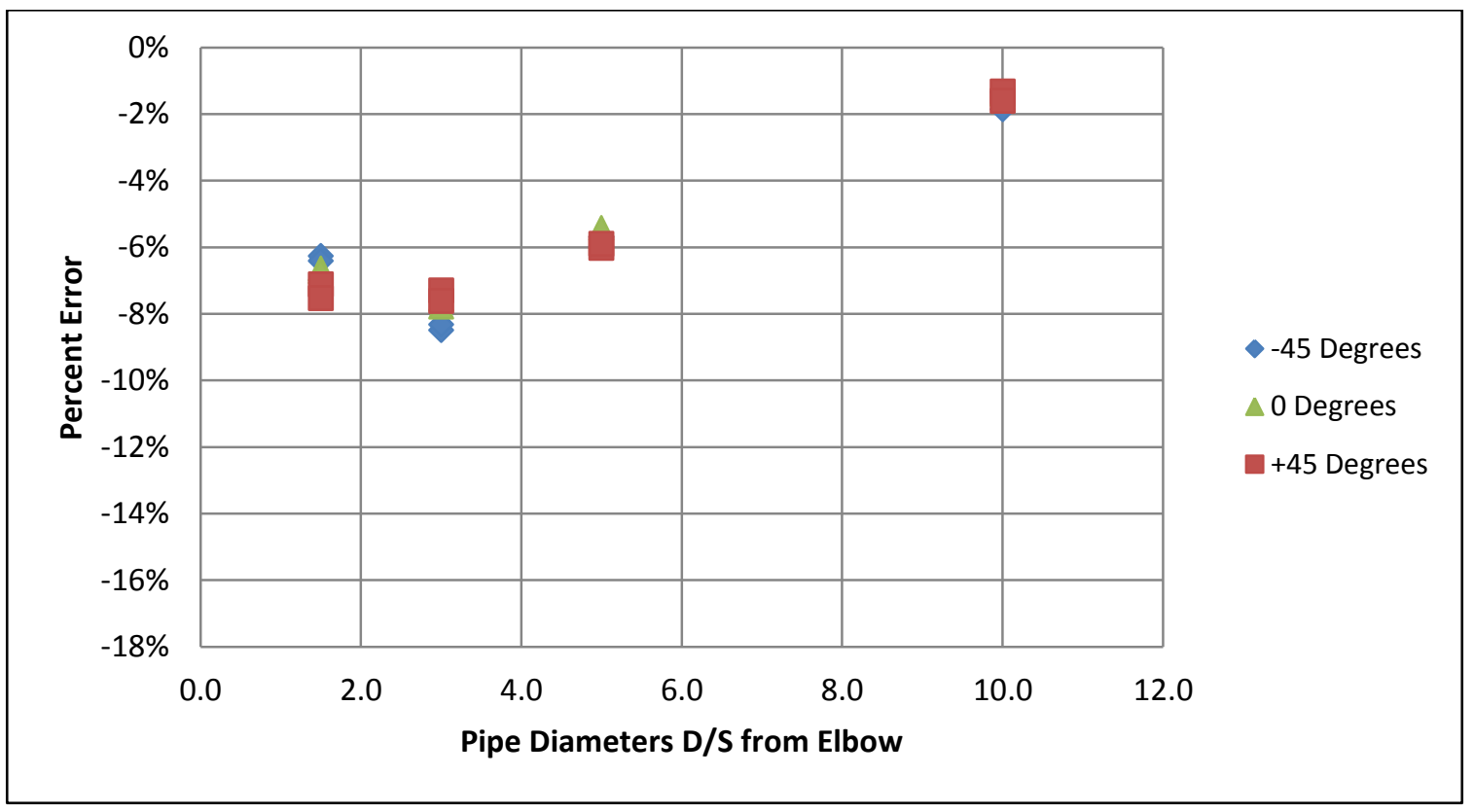

Figure 16. Ultrasonic Flow Meter Error $(\operatorname{Re}=750,000)$ 
installation locations in Figure 17. From this data, it is apparent that the flow patterns inside the pipe downstream of the long-radius elbow are not exactly symmetrical about the plane in which the elbow lies. This is a notable observation related to the fact that the turbulent fluctuations and eddies in the fluid flow may not display a single flow pattern over a given period of time.

Only as time approaches infinity will the mean flow patterns appear constant in turbulent flow.

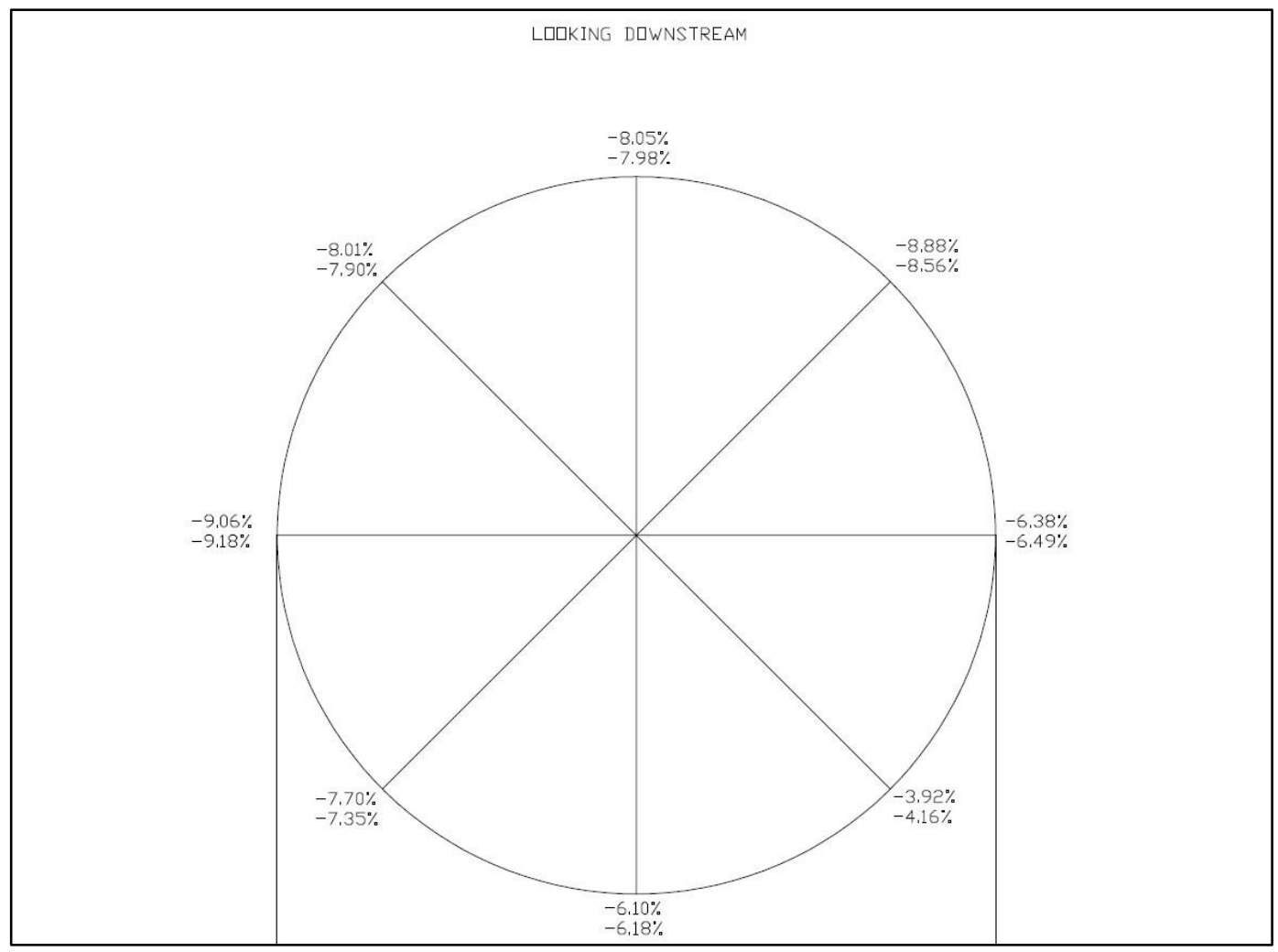

Figure 17. Ultrasonic Errors around Circumference of Pipe at 3 Diameters D/S of the Elbow 
CHAPTER III

COMPUTATIONAL FLUID DYNAMICS

\section{Description of Numerical Models}

Accurate CFD solutions representing the flow in non-ideal piping scenarios could potentially aid in better understanding magnitude of velocity profile distortion from such geometry. If the extent of effects of the non-ideal piping on ultrasonic flow measurement can be understood and quantified, corrections can be made in ultrasonic flow meter installation procedures. CFD was used to generalize and to better visualize the expected disturbances in velocity profiles in non-ideal piping setups, and was also used as a tool in determining potential correction factors and improvements to ultrasonic installation procedures. It is anticipated that the approach used in this study might also be applied to other non-ideal piping configurations.

\section{Grid Generation}

ANSYS GAMBIT version 2.4.6 was used to generate the finite-volume computational grid for the long-radius 90-degree elbow with an ID of 12.00 inches. For the mesh used in this study, the wall boundary layer was created by placing the first layer from the wall to a height of 0.005 inches. More layers were added (for a total of 20 layers) by increasing the distance of each layer from the previous layer by 20 percent. These values were chosen by trial-and-error to ensure that the average wall distance y+ would be within the desired range (Yuan, 1967; ANSYS, Inc., 2009). The circumference of the pipe was then meshed, and a face created consisting of quadrilateral prisms, as seen in Figure 18. By replicating and revolving the face in 3-dimensional space, the complete volume was created. Two diameters of straight pipe were included upstream of the elbow to provide some distance from the inlet boundary to the leading edge of 


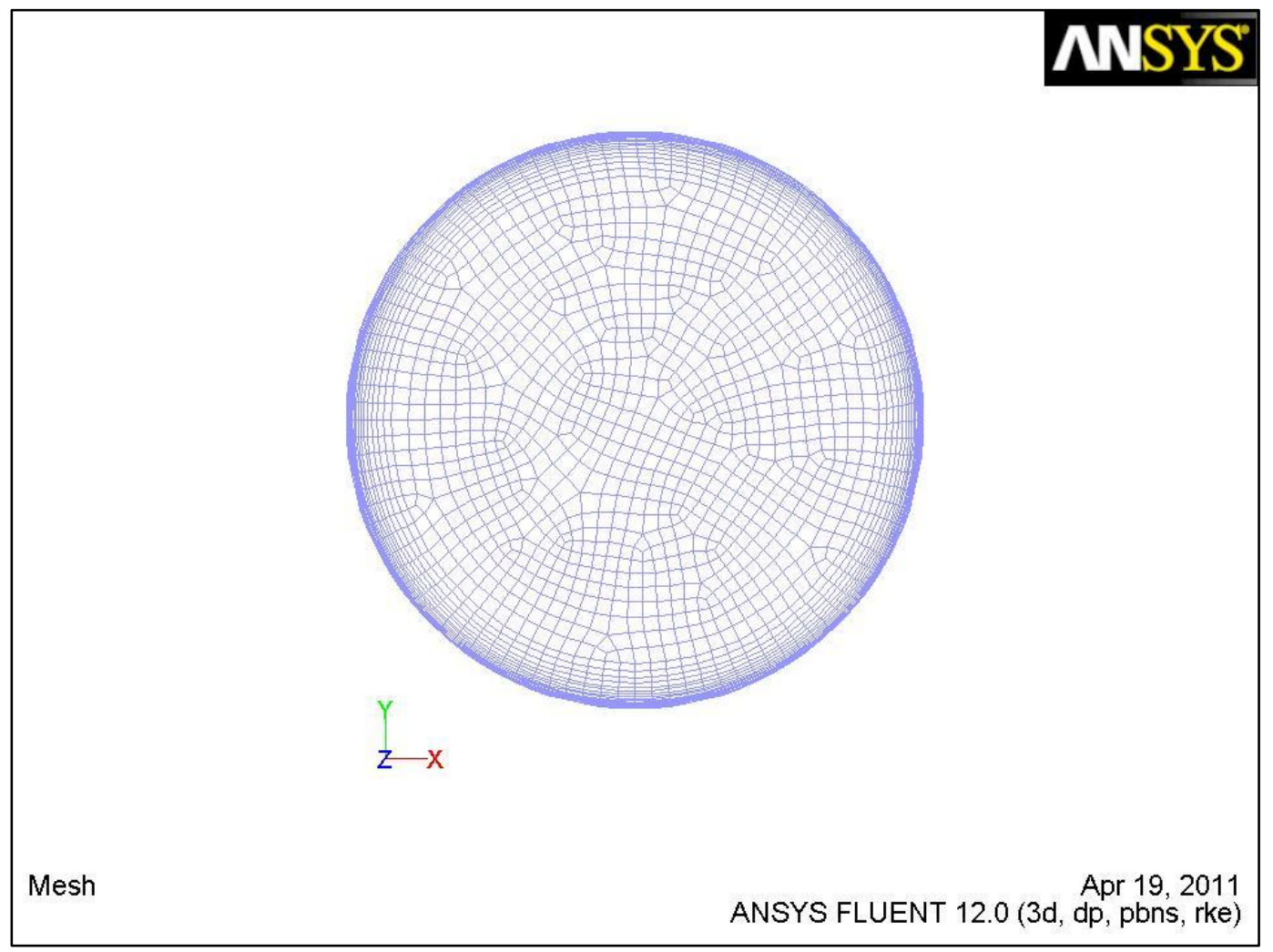

Figure 18. Cross-sectional View of Pipe Computational Mesh

the elbow, and twenty diameters of straight pipe were included downstream of the elbow.

\section{Numerical Method}

The fluid flow was solved using version 12.0.6 of FLUENT CFD code (ANSYS, Inc., 2009). The two-equation realizable k- $\varepsilon$ eddy viscosity model was selected to solve the Reynoldsaveraged Navier-Stokes (RANS) equations. While the standard $k-\varepsilon$ model is widely-used in practical engineering and CFD flow modeling, some improvements have been made to improve its performance. The realizable $k-\varepsilon$ model improves on the standard version of the model by using a new dissipation rate equation and a new realizable eddy viscosity formulation (Shih et al., 1995). As a result, the realizable $k-\varepsilon$ model generally performs better for flows with separation zones and flow rotation. One weakness of the $k-\varepsilon$ model lies in the fact that it is a 
steady state model, and thus cannot compute any time-dependent turbulent fluctuations of fluid flow. This limitation is considered when comparing any experimental laboratory data to the CFD computations.

Default values from the FLUENT materials database were used for the fluid properties (water-liquid). Relaxation factors of 0.9 for pressure and 0.4 each for momentum, turbulent kinetic energy, and turbulent dissipation rate were used. Pressure-velocity coupling was accomplished using the SIMPLEC method. For the convective terms, the second-order upwind method was used to interpolate variables to cell faces, and the diffusive terms were discretized using the second-order central differencing method. Iterative convergence was achieved when the residuals of all the discretized model equations were decreased by 5 orders of magnitude.

The results from the realizable $k-\varepsilon$ model were qualitatively compared to the flow solution from a different RANS turbulence $k-\omega$ model and were found to be practically identical. This was done to make certain that the $k-\varepsilon$ model turbulence model did not introduce any substantial sources of error due to mesh generation or numerical methods used.

\section{Boundary Conditions}

Fully developed and symmetric velocity profiles were needed to evaluate against any disturbed velocity profiles and to use as a boundary condition upstream of the 90-degree elbow. Using periodic boundary conditions, flow was modeled in a short section of pipe with a length of 2 feet for each of the three flow rates $(\operatorname{Re}=250,000,500,000$, and 750,000$)$ until convergence was achieved. Outlet flow profiles from the periodic pipe section, including $x, y$, and $z$ velocity components, as well as the necessary $\mathrm{k}-\varepsilon$ turbulence parameters, were then exported and used as fully developed inlet flow profiles for the inlet boundary condition upstream of the 90-degree 
elbow. Contours of the developed velocity profiles for each flow rate are presented in Appendix A.

\section{Velocity Profiles Downstream of 90-Degree Elbow}

Using the fully developed velocity profiles from the periodic case as upstream boundary conditions, the flow disturbances downstream of a 90-degree elbow were determined. The $x, y$, and $z$ velocity components, as well as the necessary $k-\varepsilon$ turbulence parameters obtained from the periodic models were transferred and used upstream of the elbow. An outflow type boundary condition was specified at the outlet, which was located 20 feet downstream from the elbow, as it was a fair distance downstream from any separation zones created by the elbow geometry. Figure 19 shows contours of velocity in the $\mathrm{x}$-direction on the plane in which the 90degree elbow lies for the $\mathrm{Re}=500,000$ flow rate. The figure provides a rough idea of the velocity profile distortion downstream from the elbow. Similar plots for all three flow rates are presented in Appendix B.

During the grid generation and solution process, mesh independence was assessed by adapting several meshes of varying sizes and numbers of nodes. Meshes containing approximately 1.5 million, 2.4 million, and 3.3 million cells each were generated and the fluid properties from the results were studied at various points in the fluid continuum. The flow profiles for the 2.4 million and 3.3 million cell grids showed little to no visible change in the results.

Ultimately, the 3.3 million cell grid was selected as the principal mesh used for the CFD computations due to the solution independence and for mesh considerations regarding the wall treatment. In all of the CFD models, the enhanced wall treatment option was used, which was 


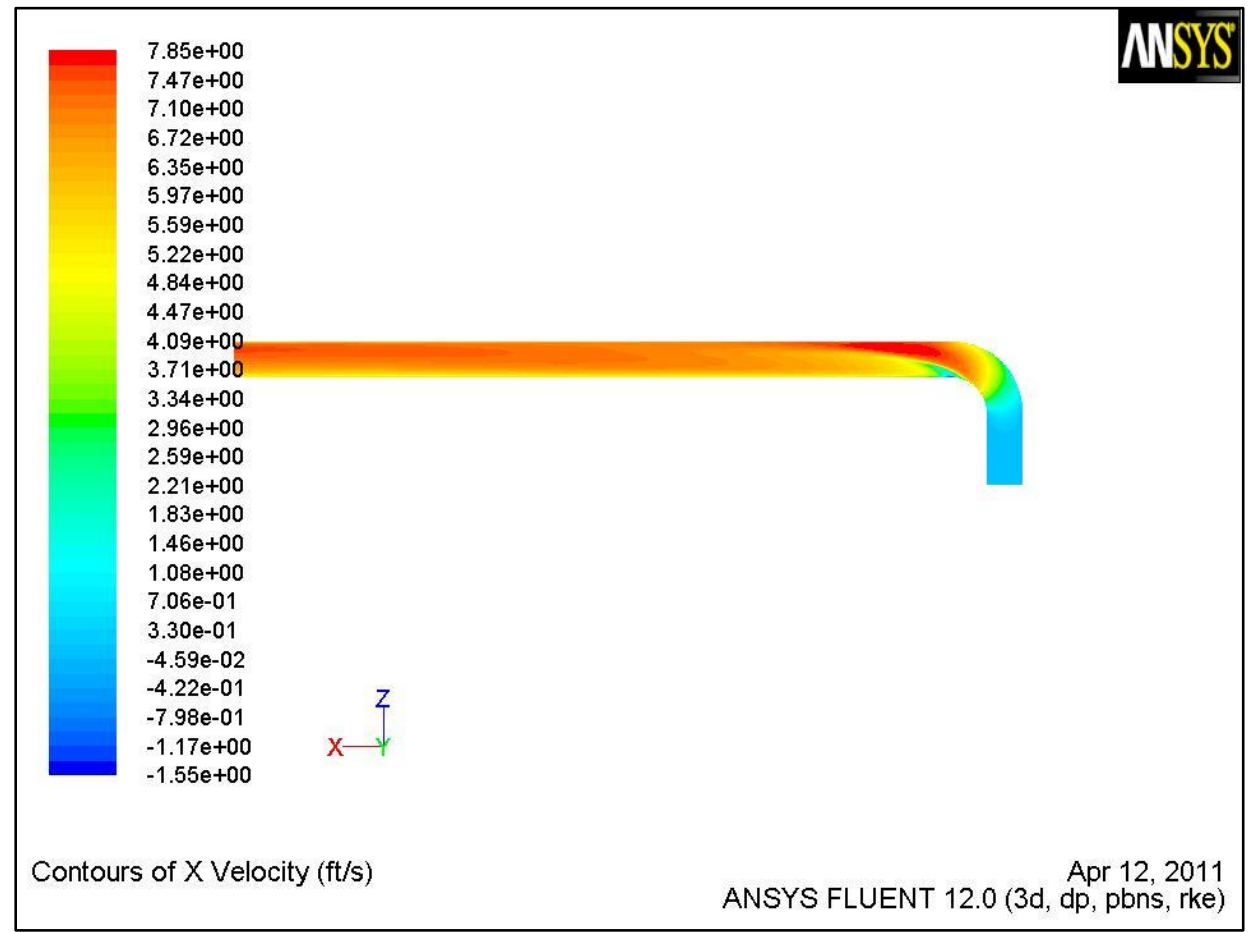

Figure 19. Contours of X-Velocity Downstream of 90-Degree Elbow $(\operatorname{Re}=500,000)$

designed to better resolve the laminar viscous sublayer. For all CFD computations, the average wall $y+$ was determined by calculating the area-weighted average of $y+$ over the wall boundary. The calculated values of $y+$ were 1.37, 2.62 and 3.71, respectively, which are all below the suggested limit for the viscous sublayer ( $y+<5$ ) (Yuan, 1967; ANSYS, Inc., 2009).

All of the FLUENT models were computed by means of Utah State University's Center for High Performance Computing. For each model, eight quad-core processors were employed for the necessary jobs. The resulting velocity profiles for each of the flow rates at each measurement location are shown in Figures 20-22. Larger individual velocity contour plots are also presented in Appendix B. It is worth noting that the CFD results obtained are timeindependent. As mentioned previously, the k- $\varepsilon$ model is a steady state model, and thus cannot compute any time-dependent turbulent fluctuations of fluid flow. 


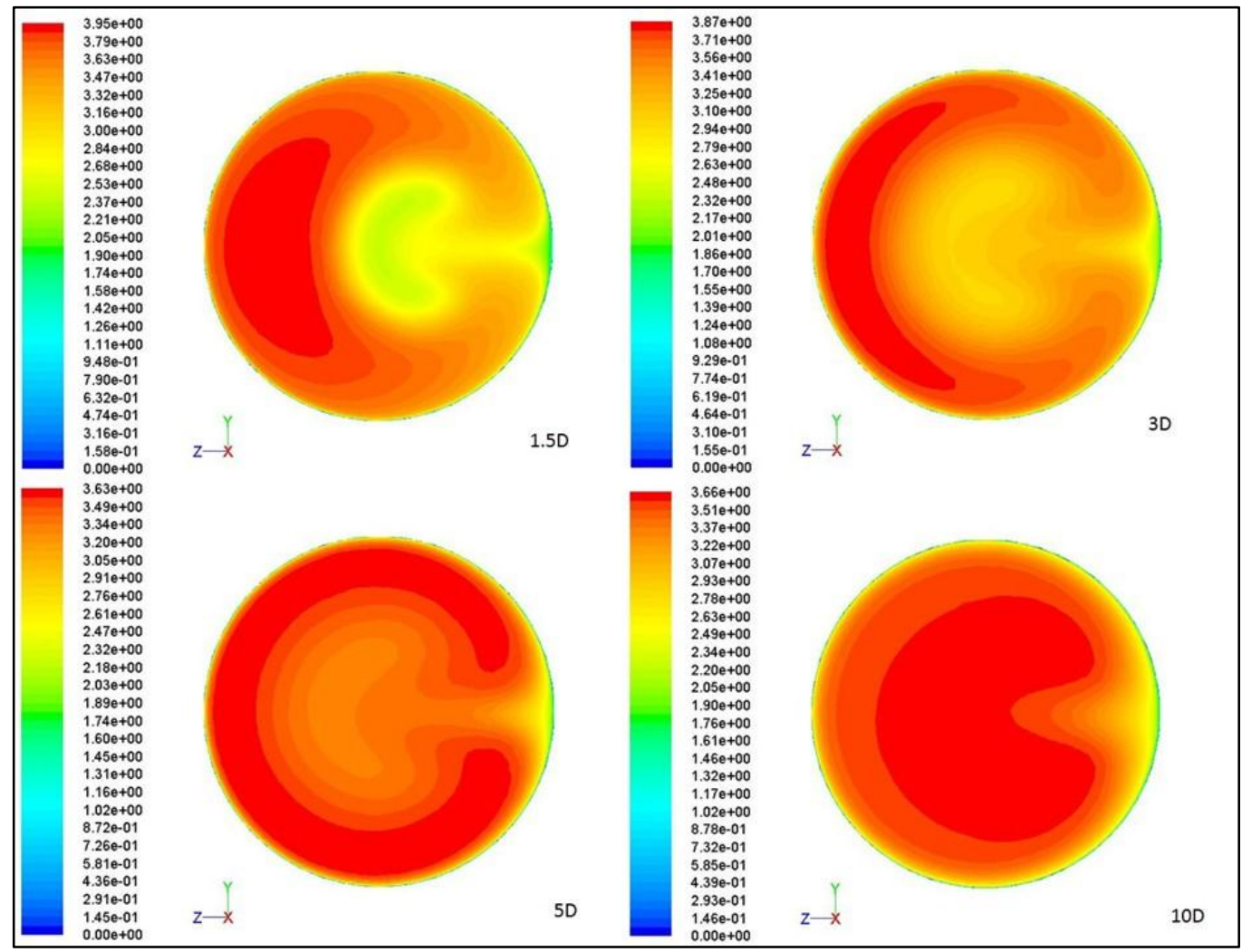

Figure 20. Cross-Sectional Velocity Contours (ft/s) Downstream of 90-Degree Elbow $(\operatorname{Re}=250,000)$ 


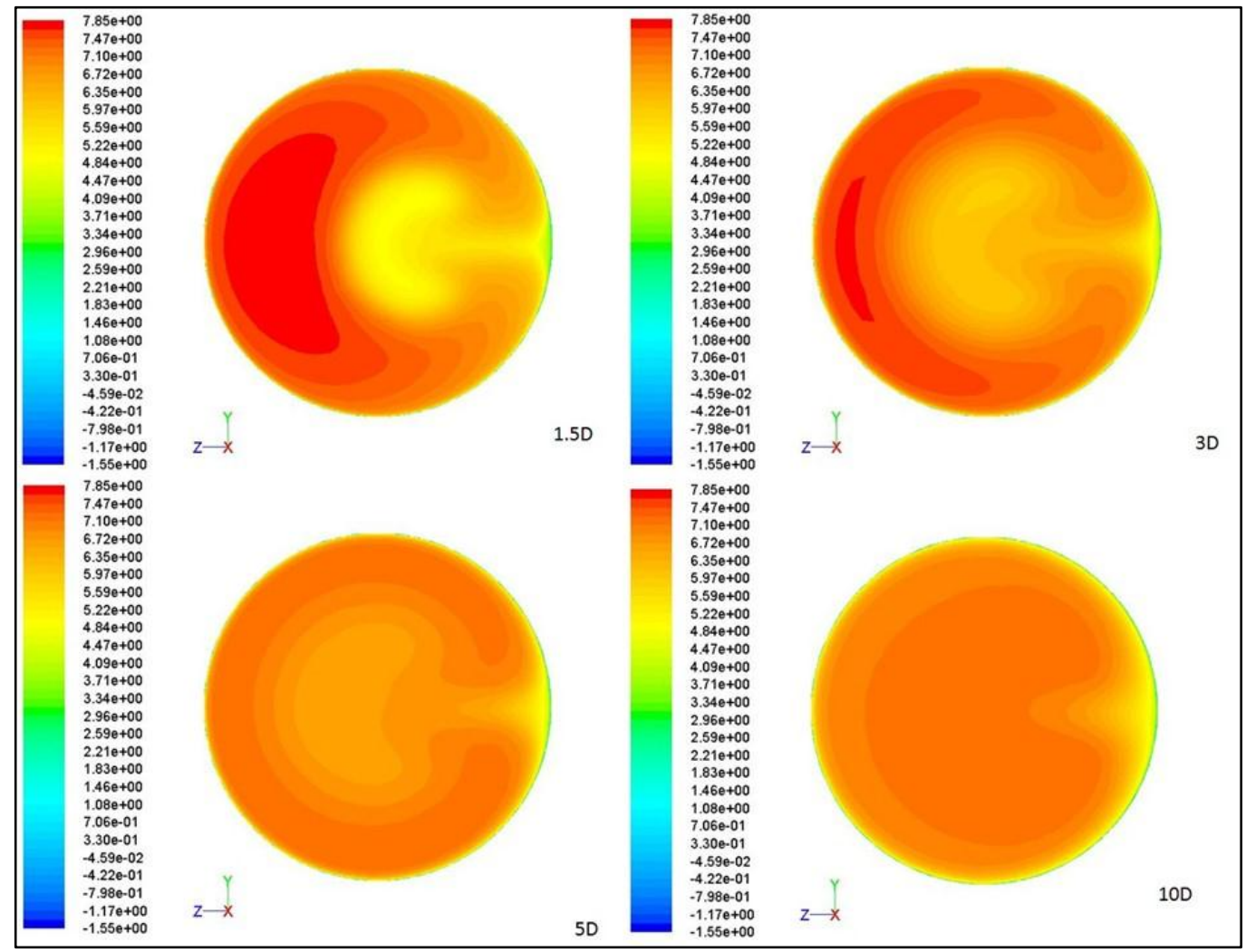

Figure 21. Cross-Sectional Velocity Contours (ft/s) Downstream of 90-Degree Elbow $(\operatorname{Re}=500,000)$ 


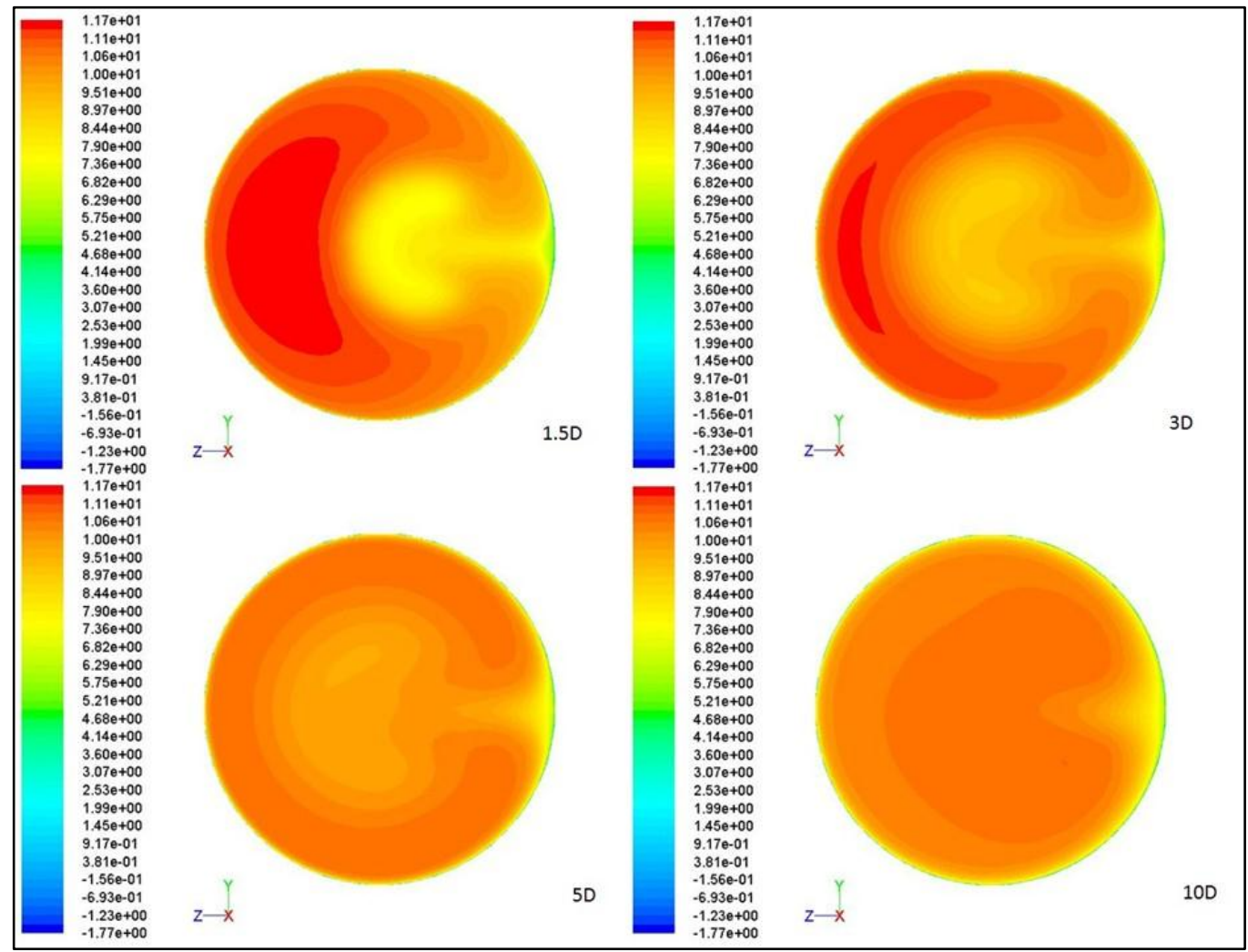

Figure 22. Cross-Sectional Velocity Contours (ft/s) Downstream of 90-Degree Elbow $(\operatorname{Re}=750,000)$ 
CHAPTER IV

RESULTS \& DISCUSSION

\section{Fully Developed Velocity Profile (Lab vs. CFD)}

The fully developed velocity profiles obtained from the periodic CFD models were verified by comparing them to the velocity profiles obtained in the straight pipe in the laboratory. This was done using the fundamental Power Law profile for turbulent and laminar pipe flow, where the fluid velocity at a point is described by Equation (4).

$u=u_{\max } \times\left(1-\frac{r}{R}\right)^{\frac{1}{n}}$

where $u$ is the local velocity of the fluid, $u_{\max }$ is the maximum velocity of the fluid at the center of the pipe, $r$ is the distance from the center of the pipe in the radial direction, $R$ is the radius of the pipe, and $1 / n$ is equal to the square root of the Darcy-Weisbach friction factor $f$. The friction factor $f$ can be solved for directly using the Swamee-Jain equation, shown as Equation (5).

$$
f=\frac{0.25}{\left[\log _{10}\left(\frac{\varepsilon}{3.7 D}+\frac{5.74}{\operatorname{Re}^{0.9}}\right)\right]^{2}}
$$

where $\varepsilon$ is the roughness height, $D$ is the diameter of the pipe, and $R e$ is the Reynolds number. For all calculations that were completed, roughness height $\varepsilon$ is approximated as $0.00085 \mathrm{ft}$ (Tullis, 1989) and the pipe diameter $D$ is $1.0 \mathrm{ft}$. By integrating the velocity across the distance from the centerline of the pipe to the pipe wall, the 2-dimensional flow in that plane, $q\left(\mathrm{ft}^{2} / \mathrm{s}\right)$, can be calculated using Equation (6). 
$q=\int_{0}^{R} u(r) d r$

By doubling the resulting value for $q$, the 2-dimensional flow in a plane, from one pipe wall to the opposite pipe wall passing through the center of the pipe, can be obtained. This 2-

dimensional power law summation was compared to the same 2-dimensional flow plane in the numerical CFD results using the same integration procedure for each flow rate and traverse orientation. The results are compared in Table 2.

The maximum difference between the laboratory and CFD data is $-2.03 \%$, with most values within $\pm 1 \%$. Similarly, the comparison between the laboratory and CFD flow profiles was analyzed in three dimensions by comparing the mass flow rate specified in FLUENT to the total laboratory flow rate, $Q\left(\mathrm{ft}^{3} / \mathrm{s}\right)$, which is obtained by integrating the flow plane from the center of the pipe to the pipe wall about the axis of the pipe, as shown in Equation (7).

$Q=\int_{0}^{R} 2 \pi r \times u(r) d r$

where $2 \pi r$ is the circumference of the circular pipe and the Power Law profile, shown in Equation (4), is substituted as $u$ into Equation (7). The results of the laboratory and CFD profiles are tabulated in Table 3.

Similarly to the 2-dimensional flow comparison, most of the compared values fall within the range of $\pm 1 \%$. The maximum difference between the laboratory and CFD data is $-2.02 \%$.

These results indicate the CFD models used were capable of accurately predicting flow in a pipe to within approximately 1 to $2 \%$ of the actual physical flow. When considering the typical uncertainty associated with laboratory measurements (and even more so with field measurements), this level of accuracy is encouraging. 
Table 2. 2-Dimensional Flow Profile Comparison (Lab vs. CFD)

\begin{tabular}{|c|c|c|c|c|}
\hline $\begin{array}{c}\text { Reynolds } \\
\text { Number }\end{array}$ & $\begin{array}{c}\text { Traverse } \\
\text { Orientation }\end{array}$ & $\begin{array}{c}\text { 2-D Power Law } \\
\text { Summation } \\
\left(\mathrm{ft}^{2} / \mathrm{s}\right)\end{array}$ & $\begin{array}{c}\text { 2-D CFD } \\
\text { Summation } \\
\left(\mathrm{ft}^{2} / \mathrm{s}\right)\end{array}$ & $\begin{array}{c}\text { Percent } \\
\text { Difference } \\
(\%)\end{array}$ \\
\hline \hline \multirow{2}{*}{250,000} & Vertical & 3.54 & 3.51 & $0.84 \%$ \\
\cline { 2 - 5 } & Horizontal & 3.58 & 3.51 & $1.93 \%$ \\
\hline \multirow{2}{*}{500,000} & Vertical & 6.98 & 7.02 & $-0.59 \%$ \\
\cline { 2 - 5 } & Horizontal & 7.04 & 7.02 & $0.27 \%$ \\
\hline \multirow{2}{*}{750,000} & Vertical & 10.33 & 10.54 & $-2.03 \%$ \\
\cline { 2 - 5 } & Horizontal & 10.44 & 10.54 & $-0.91 \%$ \\
\hline
\end{tabular}

Table 3. 3-Dimensional Flow Profile Comparison (Lab vs. CFD)

\begin{tabular}{|c|c|c|c|c|}
\hline $\begin{array}{c}\text { Reynolds } \\
\text { Number }\end{array}$ & $\begin{array}{c}\text { Traverse } \\
\text { Orientation }\end{array}$ & $\begin{array}{c}\text { 3-D Power Law } \\
\text { Integration } \\
\left(\mathrm{ft}^{3} / \mathrm{s}\right)\end{array}$ & $\begin{array}{c}\text { 3-D CFD } \\
\text { Flow Rate } \\
\left(\mathrm{ft}^{3} / \mathrm{s}\right)\end{array}$ & $\begin{array}{c}\text { Percent } \\
\text { Difference } \\
(\%)\end{array}$ \\
\hline \hline \multirow{2}{*}{250,000} & Vertical & 2.68 & 2.65 & $0.85 \%$ \\
\cline { 2 - 5 } & Horizontal & 2.68 & 2.63 & $1.93 \%$ \\
\hline \multirow{2}{*}{500,000} & Vertical & 5.37 & 5.41 & $-0.59 \%$ \\
\cline { 2 - 5 } & Horizontal & 5.37 & 5.36 & $0.27 \%$ \\
\hline \multirow{2}{*}{750,000} & Vertical & 8.08 & 8.24 & $-2.02 \%$ \\
\cline { 2 - 5 } & Horizontal & 8.08 & 8.15 & $-0.91 \%$ \\
\hline
\end{tabular}

\section{Ultrasonic Performance Downstream of 90-Degree Elbow}

The laboratory ultrasonic measurements downstream of the elbow were then

compared to the CFD results obtained from the numerical models of the elbow. This was done in order to explore the possibility of using CFD codes to improve installation methods and the corresponding flow measurement results of clamp-on ultrasonic metering devices.

Volumetric flow rates in pipelines can be calculated using the common continuity equation, seen in Equation (8).

$Q=V_{a} A_{p}$ 
where $Q$ is volumetric flow rate $\left(\mathrm{ft}^{3} / \mathrm{s}\right), V_{a}$ is the average-area velocity $(\mathrm{ft} / \mathrm{s})$, and $A_{p}$ is the crosssectional area of the pipe $\left(\mathrm{ft}^{2}\right) . V_{a}$ can be calculated using Equation (9).

$V_{a}=\frac{1}{A_{p}} \int_{0}^{A_{p}} V d A$

where $V$ is the velocity at any point in the cross section of the pipe area $(\mathrm{ft} / \mathrm{s})$ and $d A$ is the differential area section.

Transit-time ultrasonic flow meters utilize a similar approach to determine the flow through a pipe. Instead of integrating with respect to differential areas, however, the velocity is integrated across the flow meter's signal path. In pipe flow, the velocity of the fluid through the pipe is not constant across the pipe diameter. Transit-time ultrasonic flow meters determine the volumetric flow rate by comparing the speed of ultrasonic signals moving downstream with speed of ultrasonic signals moving upstream (ASME, 1985). The equation used for velocity of the fluid along the signal path is shown as Equation (10).

$V_{l}=\frac{1}{L} \int_{0}^{L} V d l$

where $V_{l}$ is the average fluid velocity along the signal path $(\mathrm{ft} / \mathrm{s}), L$ is the length of the signal path $(\mathrm{ft})$, and $d l$ is the differential path length $(\mathrm{ft})$. A correction factor $S$ is then used to convert the signal path velocity, $V_{l}$, to an average-area velocity, $V_{a}$, seen in Equation (11) (ASME, 1985).

$V_{a}=S V_{l}$

This corrected value for fluid velocity is then combined with known pipe dimensions internally in the ultrasonic flow meter's computer to determine the volumetric flow rate at the location of 
the ultrasonic flow meter installation. Typical values for $S$ for fully developed velocity profiles range from 0.75 for laminar flow to 1.0 for plug flow (ASME, 1985).

While ultrasonic flow meter manufacturers do not publish the exact algorithms and correction factors that are used in their flow meters, the ultrasonic flow meter's accuracy can be studied by comparing the integrated velocity path downstream of a flow disturbance with the same integrated velocity path of a fully developed and symmetrical velocity profile. This is the approach that was taken to compare the CFD results to the physical laboratory data that has been obtained for the purposes of this research.

The average fluid velocity in the main direction of flow along the signal path at each measurement location and orientation downstream of the elbow was compared to the average fluid velocity in the flow direction along an identical signal path for a fully developed and uniform velocity profile to determine the error associated with the flow disturbance created by the elbow. Figures 23-25 display the deviations in the measurement from the actual flow rate that were determined for the laboratory ultrasonic flow meter measurements and from the CFD model results for each flow rate. The same data can also be grouped according to ultrasonic flow meter installation orientation around the circumference of the pipe for all flow rates, seen in Figures 26-28.

There are several observations that can be made from these results:

1. The error in the ultrasonic flow meter measurement decreases as the distance from the flow disturbance to the measurement location increases.

2. The turbulence located just downstream from the flow disturbance creates a wider range of scatter in laboratory data points and CFD flow profiles. 


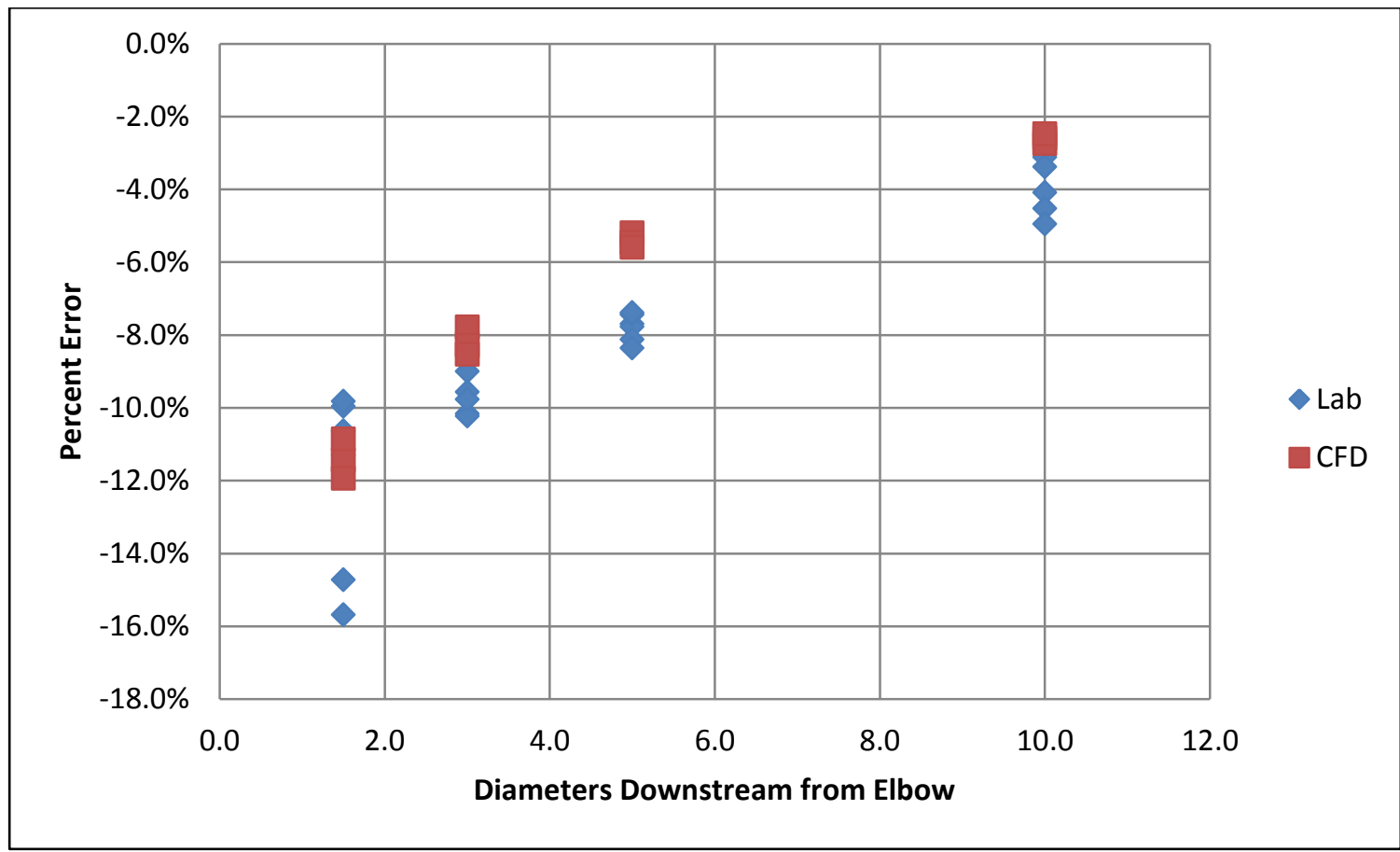

Figure 23. Ultrasonic Measurement Errors $(\operatorname{Re}=250,000)$

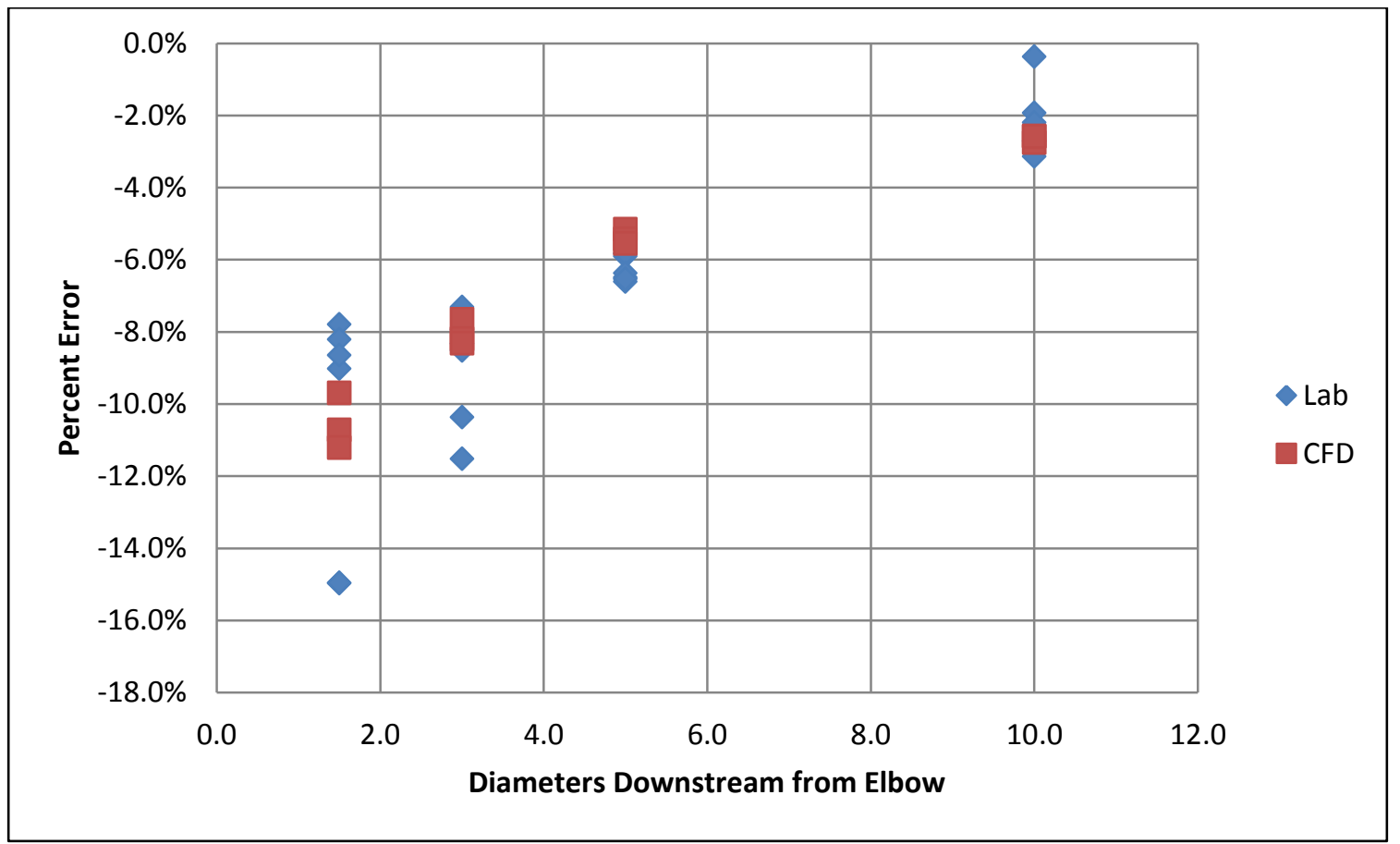

Figure 24. Ultrasonic Measurement Errors $(\operatorname{Re}=500,000)$ 


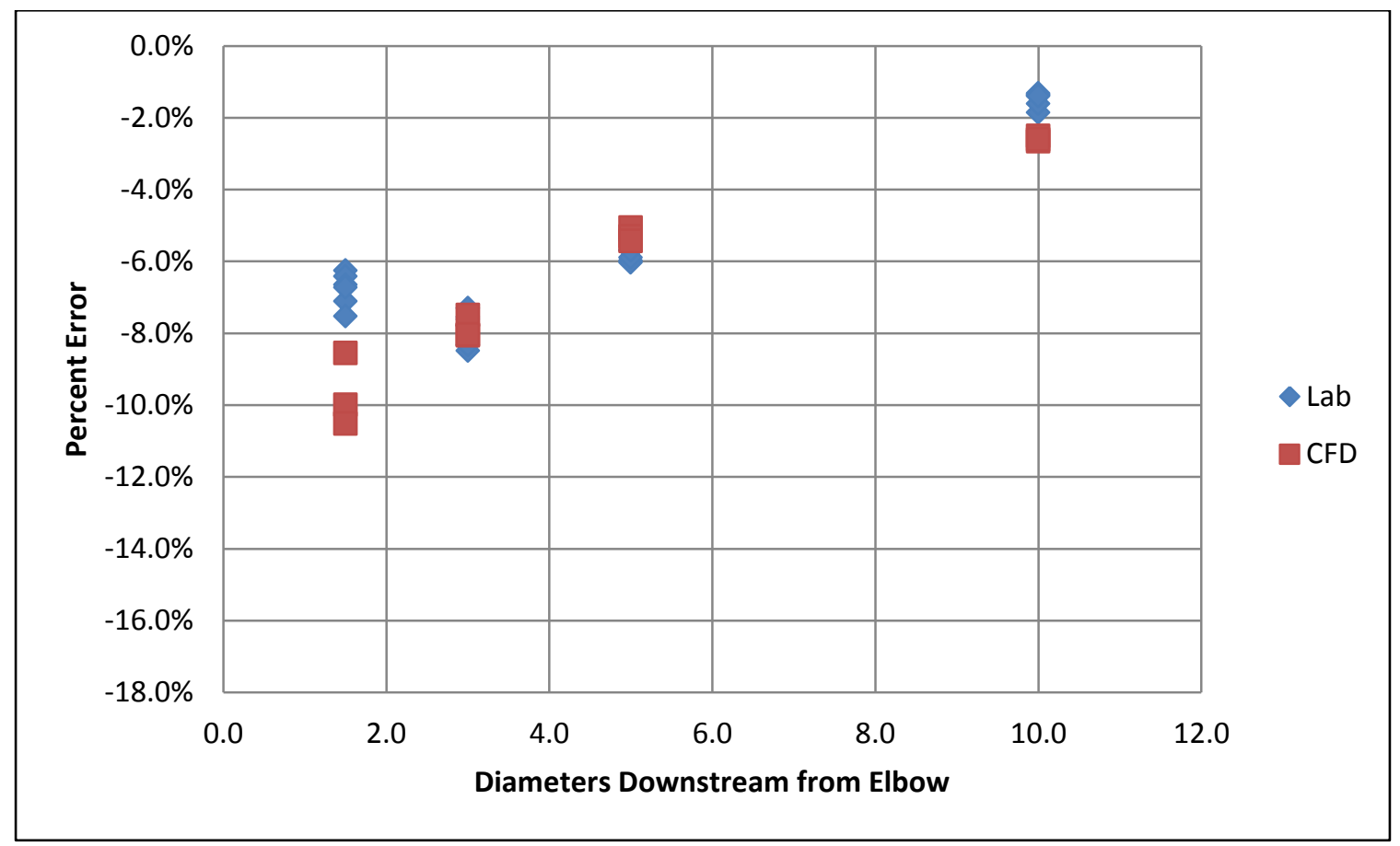

Figure 25. Ultrasonic Measurement Errors $(\mathrm{Re}=750,000)$

With the exception of a few outliers, there is no clear indication that the orientation of the ultrasonic flow meter with respect to the circumference of the pipe helps or hinders the accuracy of the meter itself. Regardless of the orientation, the distance from the flow disturbance is a much more significant factor that affects the accuracy of the ultrasonic flow meter. Also notable from the results is the apparent nonsymmetry in the physical laboratory measurements about the plane in which the 90-degree elbow lies. In the time-averaged numerical models, the flow on either side of the elbow's plane is virtually identical, while physical measurements indicate that other factors may be at play, including: time-dependent turbulent fluctuations, irregularities in the pipe surface and roughness and measurement errors.

It is noted that the ultrasonic flow meter always measured a flow rate lower than the actual flow rate downstream of the flow disturbance created by the elbow. This observation 


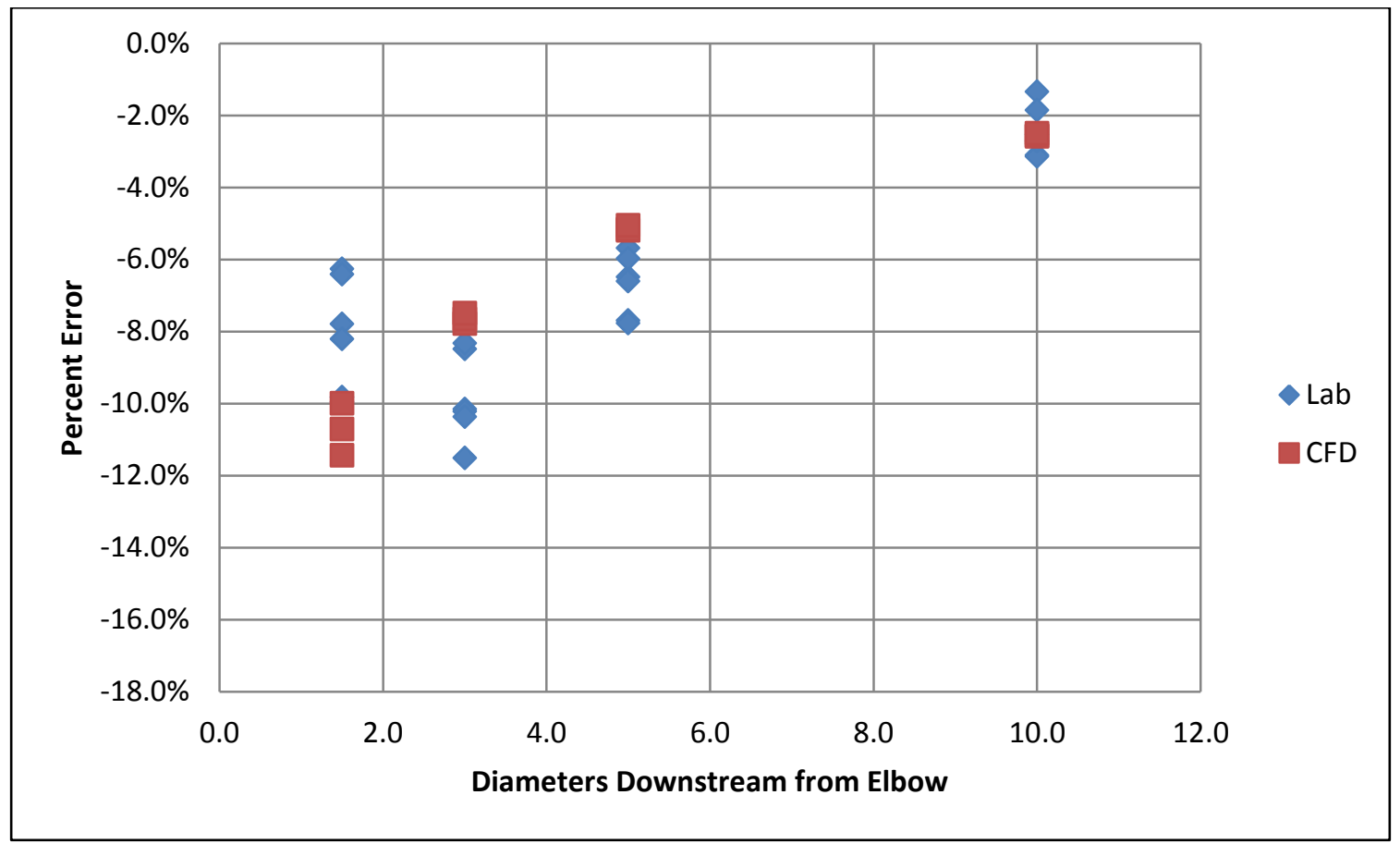

Figure 26. Ultrasonic Measurement Errors (-45 Degree Orientation)

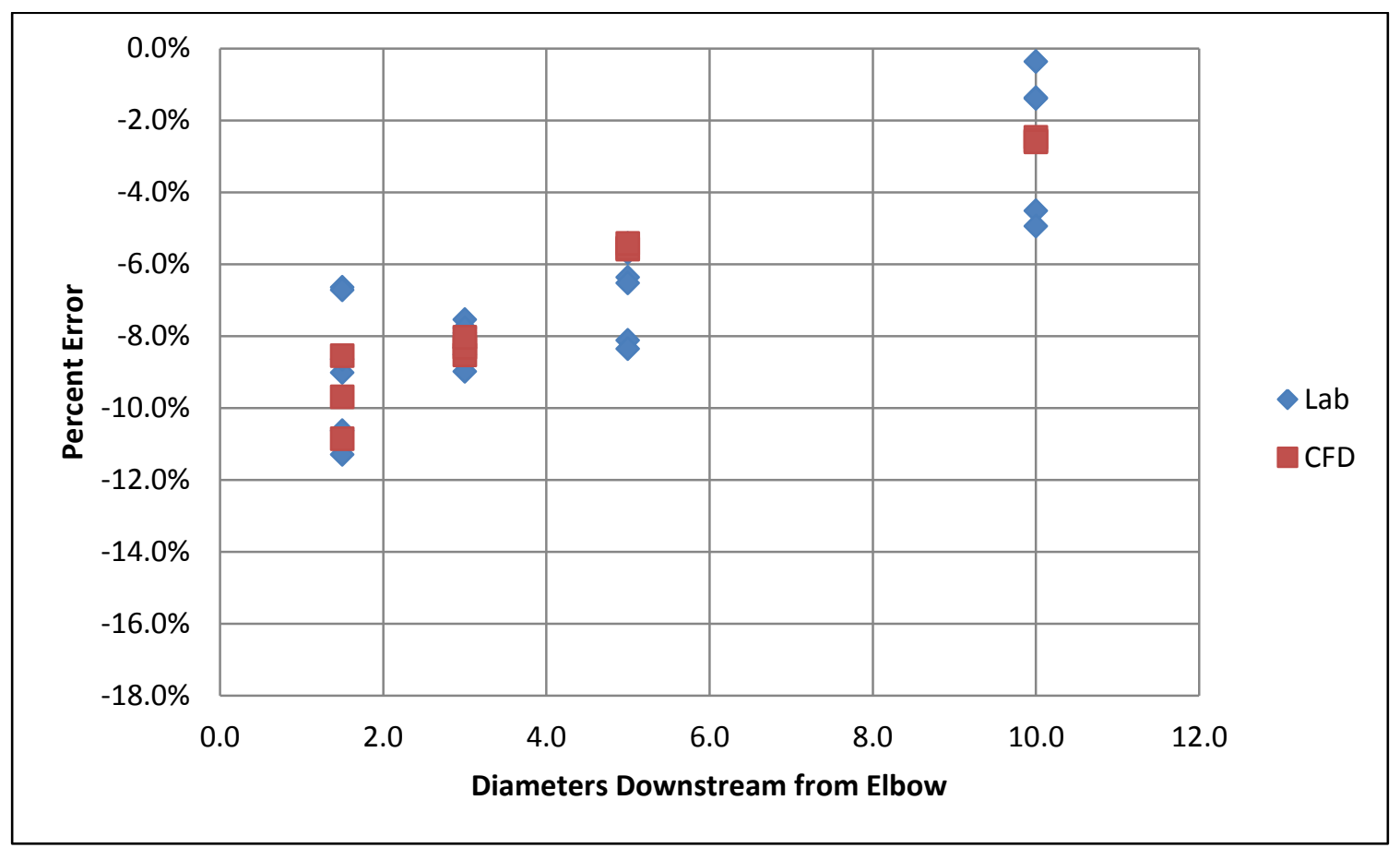

Figure 27. Ultrasonic Measurement Errors (0 Degree Orientation) 


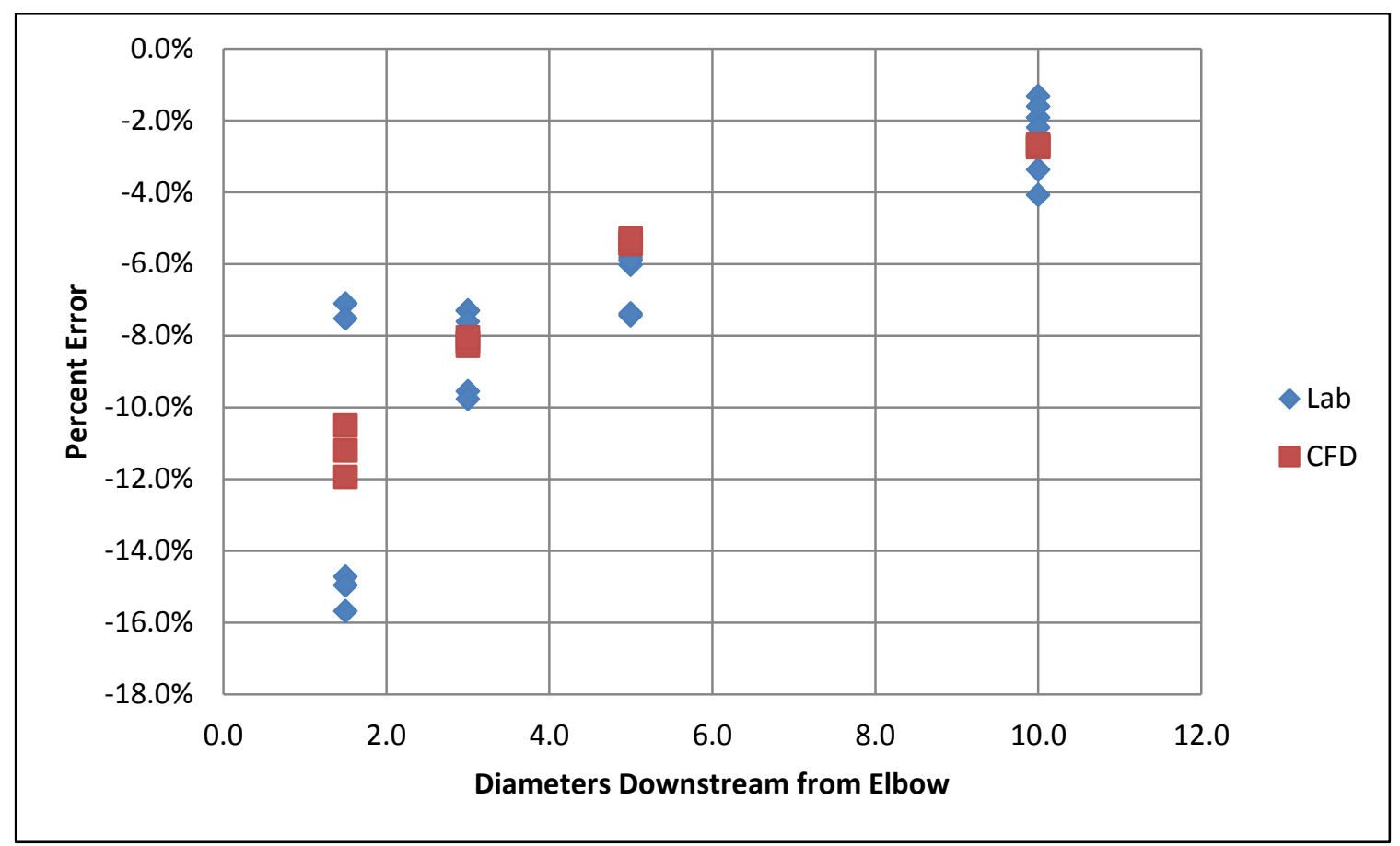

Figure 28. Ultrasonic Measurement Errors (+45 Degree Orientation)

seems to indicate than any velocity profile on which the ultrasonic signal path travels, other than a fully developed and symmetrical profile, will cause the ultrasonic flow meter to underestimate the actual mass flow rate. This is especially true if the ultrasonic signal path crosses a region of flow separation or rotation, where the local flow could actually be flowing in the upstream direction, causing the ultrasonic flow meter to calculate the flow incorrectly.

In addition to the ultrasonic flow measurements that were taken in the $0-10 \mathrm{D}$ range downstream from the elbow, several additional measurements were made at a point over 40D downstream from the elbow to confirm that the velocity profile eventually reached its fully developed shape. The ultrasonic flow meter at the downstream location measured a flow rate approximately $-0.5 \%$ lower than the actual flow rate for all conditions and flows. 
The Fuji PortaflowX Ultrasonic Flow Meter claims to perform to within $\pm 1.0 \%$ for the given physical conditions of this study (Fuji Electric Systems Co., Ltd., 2009). The internal calculations that the meter performs use the piping material, size and angle of sound wave propagation, and other factors to determine the flow rate. There are several input parameters that become potential factors in producing error, including: piping material, piping size (inside diameter and thickness), sensor mounting length, and change in water temperature. Any uncertainty associated with these parameters carry with them the potential to translate into error in the flow measurement.

\section{Correction to Ultrasonic Flow Meter Measurements}

A correction procedure was applied to the ultrasonic measurements that were collected. The reader is reminded that the following correction procedure is valid only for the physical scenario that was used for this study, including all geometric parameters, flow rates, and equipment used. Any variations to the physical setup (i.e. different pipe size or geometry, different ultrasonic flow meter) may produce somewhat comparable results, but such a determination cannot be made without an in-depth examination of the different physical scenario.

A logarithmic curve was fit to the deviations in measurement of the CFD results, as seen in Figure 29, with an $R^{2}$ value of 0.9664 . The correction curve is given as Equation (12).

$C F=0.0426 \ln (D)-0.124$

where $C F$ is a dimensionless correction factor and $D$ is the distance downstream from the elbow in terms of pipe diameter ( 1 foot $=1 \mathrm{D}$ for 12 -inch pipe). Equation (12) always gives a negative value for the correction factor $C F$ in the range of $0-10 D$ downstream from the elbow. The 
equation was limited to this range as most flow meter manufacturers recommend at least 10 diameters of straight pipe upstream of the metering location. The correction factor can be applied to the measured ultrasonic flow rate using Equation (13).

$Q_{\text {actual }}(C F+1)=Q_{U S F M}$

where $Q_{\text {actual }}$ is the actual flow rate through the pipe and $Q_{\text {USFM }}$ is the measured flow rate given by the ultrasonic flow meter. By combining Equations (12) and (13) and rearranging terms, Equation (14) gives the actual flow rate in terms of ultrasonic flow rate measurement and distance downstream from the elbow.

$Q_{\text {actual }}=\frac{Q_{U S F M}}{(0.0426 \ln (D)+0.876)} \quad$ for $1.5 \leq \mathrm{D} \leq 10$

When Equation (11) was applied to all of the ultrasonic flow meter measurements that were conducted in the laboratory, the errors in measurement were reduced by nearly $90 \%$. Table 4 shows the average ultrasonic measurement error before and after applying the correction, as well as the percent improvement in measurement accuracy for each downstream measurement location.

In general, there is more scatter amongst the data points taken in the laboratory versus the error associated with the numerical models. In large part, this is likely due to the timedependant and turbulent nature of the flows. Fuji Electric Systems Co. (2009) states in their ultrasonic meter reference documentation that not only will there be appreciable error in the flow measurement when the flow profile is skewed, but also that the calculated flow value will fluctuate in disturbed flow. The standard deviations from the given correction curve of the 


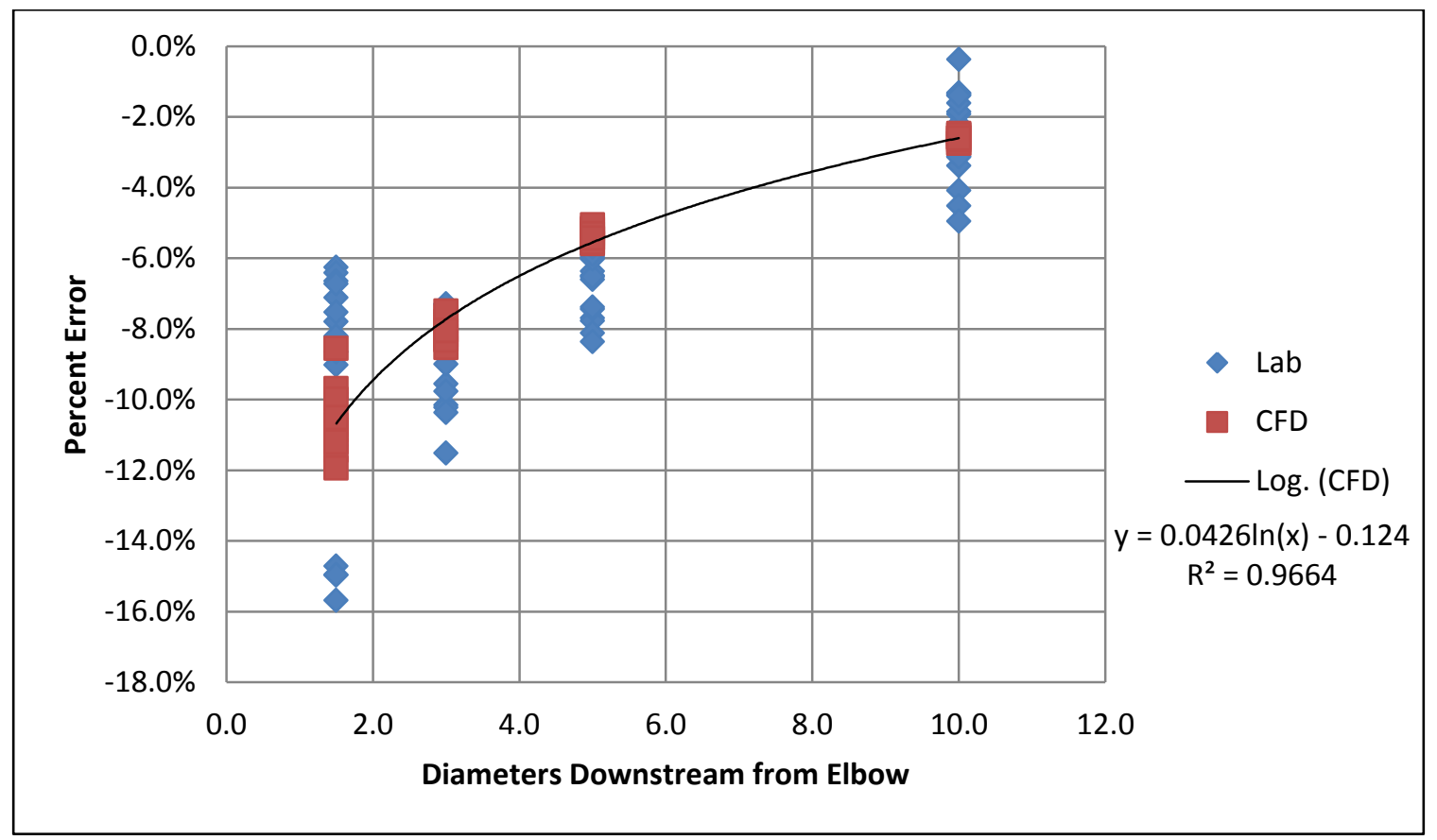

Figure 29. Ultrasonic Measurement Errors for All Flow Rates \& Orientations

Table 4. Ultrasonic Flow Measurement Error Before \& After Correction

\begin{tabular}{|c|c|c|c|}
\hline $\begin{array}{c}\text { Measurement } \\
\text { Location } \\
\text { (Pipe Diameters D/S) }\end{array}$ & $\begin{array}{c}\text { Average } \\
\text { Measurement Error } \\
(\%)\end{array}$ & $\begin{array}{c}\text { Average Measurement } \\
\text { Error After Correction } \\
(\%)\end{array}$ & $\begin{array}{c}\text { Percent } \\
\text { Improvement } \\
(\%)\end{array}$ \\
\hline \hline 1.5 & $-9.8 \%$ & $-0.9 \%$ & $91.1 \%$ \\
\hline 3.0 & $-8.8 \%$ & $1.0 \%$ & $88.1 \%$ \\
\hline 5.0 & $-6.6 \%$ & $1.1 \%$ & $83.7 \%$ \\
\hline 10.0 & $-2.3 \%$ & $-0.3 \%$ & $88.1 \%$ \\
\hline
\end{tabular}

ultrasonic measurement error for both laboratory and CFD results are shown in Table 5 and Table 6, grouped by flow rate and ultrasonic installation orientation, respectively. The average standard deviation from the correction curve of the laboratory ultrasonic measurement errors is $1.1 \%$, with a maximum of $3.4 \%$ when grouped by flow rate and the average standard deviation is $1.4 \%$ with a maximum of $4.0 \%$ when grouped by orientation. 
Table 5. Standard Deviations of USFM Measurement Error from Correction Curve

\begin{tabular}{|c|c|c|c|}
\hline $\begin{array}{c}\text { Flow } \\
\text { Rate }\end{array}$ & $\begin{array}{c}\text { Measurement } \\
\text { Location }\end{array}$ & $\begin{array}{c}\text { Standard } \\
\text { Deviation of } \\
\text { USFM Lab } \\
(\%)\end{array}$ & $\begin{array}{c}\text { Standard } \\
\text { Deviation of } \\
\text { USFM CFD } \\
\text { (Pipe Diameters D/S) }\end{array}$ \\
\hline \hline \multirow{3}{*}{250,000} & 1.5 & $2.5 \%$ & $0.5 \%$ \\
\cline { 2 - 4 } & 3.0 & $0.9 \%$ & $0.4 \%$ \\
\cline { 2 - 4 } & 5.0 & $0.4 \%$ & $0.2 \%$ \\
\hline \multirow{3}{*}{500,000} & 10.0 & $0.9 \%$ & $0.1 \%$ \\
\cline { 2 - 4 } & 1.5 & $3.4 \%$ & $0.8 \%$ \\
\cline { 2 - 4 } & 3.0 & $1.6 \%$ & $0.3 \%$ \\
\hline \multirow{3}{*}{750,000} & 5.0 & $0.3 \%$ & $0.2 \%$ \\
\cline { 2 - 4 } & 10.0 & $1.3 \%$ & $0.1 \%$ \\
\cline { 2 - 4 } & 1.5 & $0.5 \%$ & $1.0 \%$ \\
\cline { 2 - 4 } & 3.0 & $0.5 \%$ & $0.3 \%$ \\
\hline & 5.0 & $0.2 \%$ & $0.2 \%$ \\
\hline & 10.0 & $0.2 \%$ & $0.1 \%$ \\
\hline
\end{tabular}

Table 6. Standard Deviations of USFM Measurement Error from Correction Curve

\begin{tabular}{|c|c|c|c|}
\hline $\begin{array}{c}\text { US } \\
\text { Installation } \\
\text { Orientation } \\
\text { (Degrees) }\end{array}$ & $\begin{array}{c}\text { Measurement } \\
\text { Location }\end{array}$ & $\begin{array}{c}\text { Standard } \\
\text { Deviation of } \\
\text { USFM Lab } \\
(\%)\end{array}$ & $\begin{array}{c}\text { Standard } \\
\text { Deviation of } \\
\text { USFM CFD } \\
(\%)\end{array}$ \\
\hline \hline \multirow{4}{*}{-45} & 1.5 & $1.6 \%$ & $0.7 \%$ \\
\cline { 2 - 4 } & 3.0 & $1.2 \%$ & $0.1 \%$ \\
\cline { 2 - 4 } & 5.0 & $0.9 \%$ & $0.1 \%$ \\
\hline \multirow{4}{*}{0} & 10.0 & $0.7 \%$ & $0.0 \%$ \\
\cline { 2 - 4 } & 1.5 & $1.9 \%$ & $1.2 \%$ \\
\cline { 2 - 4 } & 3.0 & $0.5 \%$ & $0.2 \%$ \\
\hline \multirow{4}{*}{45} & 5.0 & $1.2 \%$ & $0.1 \%$ \\
\cline { 2 - 4 } & 10.0 & $2.2 \%$ & $0.1 \%$ \\
\cline { 2 - 4 } & 1.5 & $4.0 \%$ & $0.7 \%$ \\
\cline { 2 - 4 } & 3.0 & $1.1 \%$ & $0.1 \%$ \\
\hline & 5.0 & $0.8 \%$ & $0.1 \%$ \\
\hline
\end{tabular}




\section{CHAPTER V}

\section{CONCLUSIONS}

Laboratory experiments and numerical CFD simulations confirmed that the distorted velocity profiles that exist downstream of a 90-degree elbow adversely affect ultrasonic flow measurement accuracy. The numerical computational models were verified against the physical measurements to a reasonable level of confidence. In addition, the performance of a clamp-on transit-time ultrasonic flow meter suffered with regards to accuracy as a result of the disturbances in the flow region downstream of the elbow. The trends observed in the measured velocity profiles and in the numerical CFD simulations coincide with the recommendations of straight pipe lengths and installation instructions given by flow meter manufacturers of ultrasonic flow meters.

\section{Applications}

The numerical models that were built and solved were used as a tool to determine potential correctional measures to apply to ultrasonic flow meter installation. This was done by integrating the velocity profile of the fluid across the ultrasonic signal path and comparing the resulting total velocity to the same velocity for a fully developed and symmetric velocity profile. A similar integration of the velocity profile downstream of other non-ideal piping configurations may provide similar information about the ultrasonic flow measurement accuracy. For the physical scenario modeled in this study, flow measurement error was reduced by nearly $90 \%$ by applying the correction equation presented. While the correction equation should only be applied to the flow rates and piping scenario that have been presented herein, a similar process may prove valuable for other non-ideal piping scenarios where ultrasonic flow measurement 
accuracy suffers due to lack of recommended lengths of straight piping. Indeed, CFD appears to be a viable tool for studying flow disturbances and making appropriate corrections for ultrasonic flow measurement in pipes.

The results of the physical scenario studied herein show that the ultrasonic flow meter always underpredicted the true flow rate when installed downstream of the flow disturbance created by the elbow. This is notable as it is a common scenario seen in field flow measurement. Historical discharge and power consumption records for the years 2000-2010 were provided by the Idaho Department of Water Resources (Corbin Knowles, personal communication, June 6,2011 ) for seven wells with 12-inch piping and volumetric flow rates similar to those that were tested in the laboratory for this study. The mean discharge during this time period was 816 ac-ft per well per irrigation season. Using an estimated cost of water of $\$ 15$ per ac-ft, a reduction in flow measurement error from $-10 \%$ to $-1 \%$ equates to a savings of $\$ 1,100$ per well per irrigation season.

Even more significantly, additional savings can also be estimated in terms of electrical power required in order to pump the groundwater out of the well. The mean power consumption during the same time period was $734,000 \mathrm{~kW}$-hr per well per irrigation season. Using Idaho Power's current power cost of 6.8 cents per kW-hr (Quentin Nesbitt, personal communication, June 6,2011$)$, a reduction in flow measurement error from $-10 \%$ to $-1 \%$ equates to a savings of approximately $\$ 4,500$ per well per irrigation season. This cost is separate from the demand cost to operate a pump; it considers only the potential savings from being able to operate the pump for fewer hours during a season in order to obtain the same quantity of water from a given well. When considering the abundance of potential well 
locations where similar flow measurement corrections might be applied, these cost savings are significant.

\section{Need for Future Research}

The physical scenario that was studied is a fairly typical and simplistic condition, yet still non-ideal for ultrasonic flow measurement. There are a large number of possible non-ideal installation scenarios (different flow disturbing devices, pipe sizes, pipe materials, flow rates, etc.) which could be studied more in-depth using CFD. More complex piping installations upstream of ultrasonic flow meters could produce more complex flow patterns, and therefore affect the accuracy of said ultrasonic flow meter. For any given physical piping scenario there is potential to find an installation location or correction procedure that might improve the meter's performance.

While not likely to happen in the near future, the modeling of time-dependent turbulent fluctuations seen in non-ideal piping scenarios could improve and allow for an increased understanding of the flow patterns downstream of flow disturbing devices such as elbows, tees, and valves. With improved modeling capabilities, quicker and less expensive solutions can present themselves to correct for erroneous flow measurement. Improved flow measurement will help protect and manage water as the valuable resource that it is. 


\section{REFERENCES}

ANSYS, Inc. 2009. ANSYS FLUENT 12.0 Theory Guide. ANSYS, Inc.

ASME. 1985. Measurement of Liquid Flow in Closed Conduits Using Transit-Time Ultrasonic Flowmeters. New York, N.Y.: American Society of Mechanical Engineers.

Fuji Electric Systems Co., Ltd. 2009. Portable Ultrasonic Meter PORTAFLOW X. Quick Reference. Fuji Electric Systems Co., Ltd.

Hanson, B. R., and L. J. Schwankl. 1998. Error analysis of flowmeter measurements. J. Irrigation and Drainage Eng., ASCE, 124 (5): 248-256.

Johnson, A. L., B. L. Benham, D. E. Eisenhauer, and R. H. Hotchkiss. 2001. Ultrasonic water measurement in irrigation pipelines with disturbed flow. Transactions of the ASAE, 44 (4): 899910.

Shih, T. -H., W. W. Liou, A. Shabbir, Z. Yang, and J. Zhu. 1995. A New k- $\varepsilon$ Eddy Viscosity Model For High Reyholds Number Turbulent Flows. Computers and Fluids, 24 (3): 227-238.

Tullis, J. P. 1989. Hydraulics of Pipelines: Pumps, Valves, Cavitation, Transients. New York, N.Y.: John Wiley \& Sons.

Yuan, S. 1967. Foundations of Fluid Mechanics. Englewood Cliffs, N.J.: Prentice Hall. 
APPENDICES 
Appendix A. CFD Velocity Contour Plots of Fully Developed Profiles 


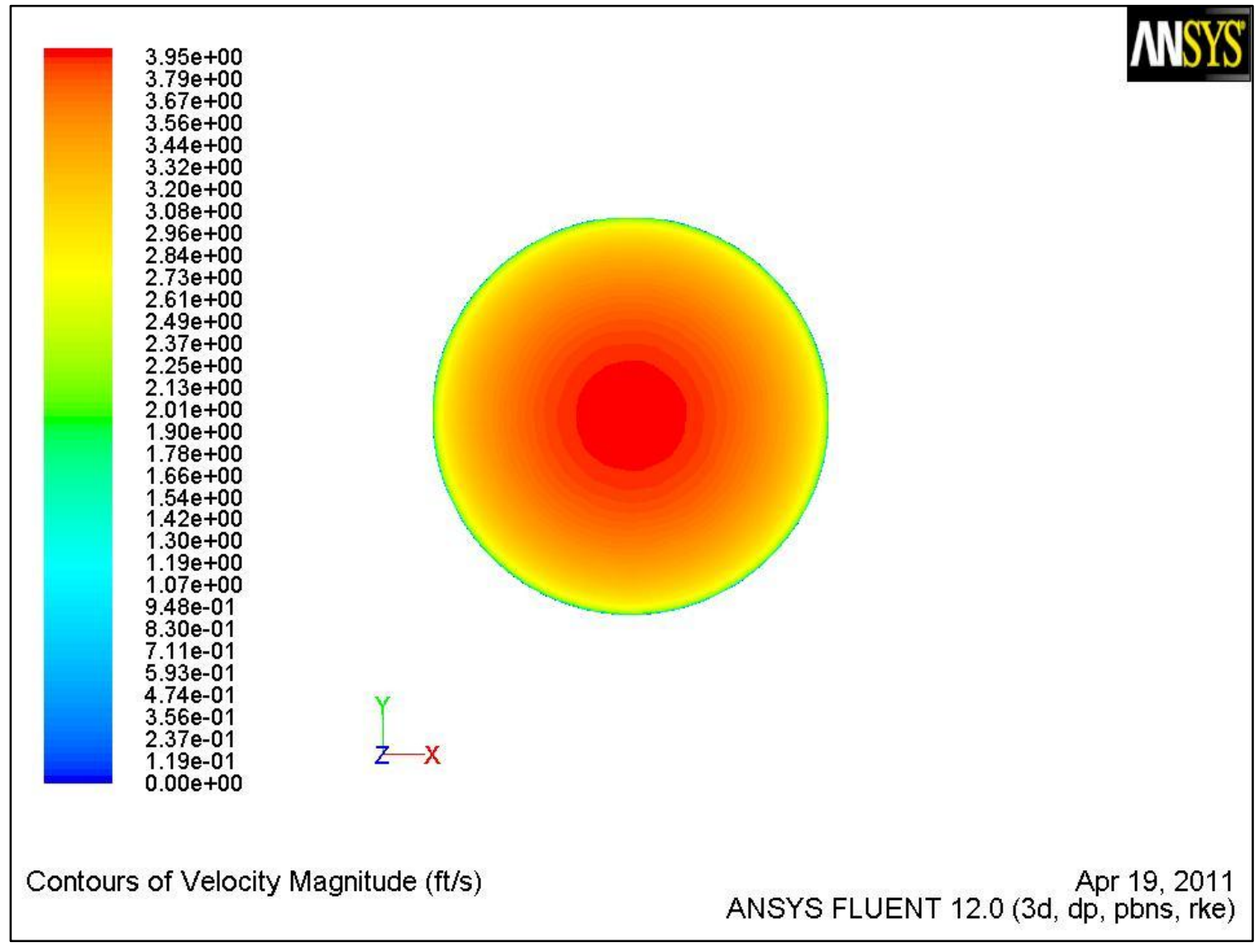

Figure 30. Contours of Fully Developed Velocity Profile $(\operatorname{Re}=250,000)$ 


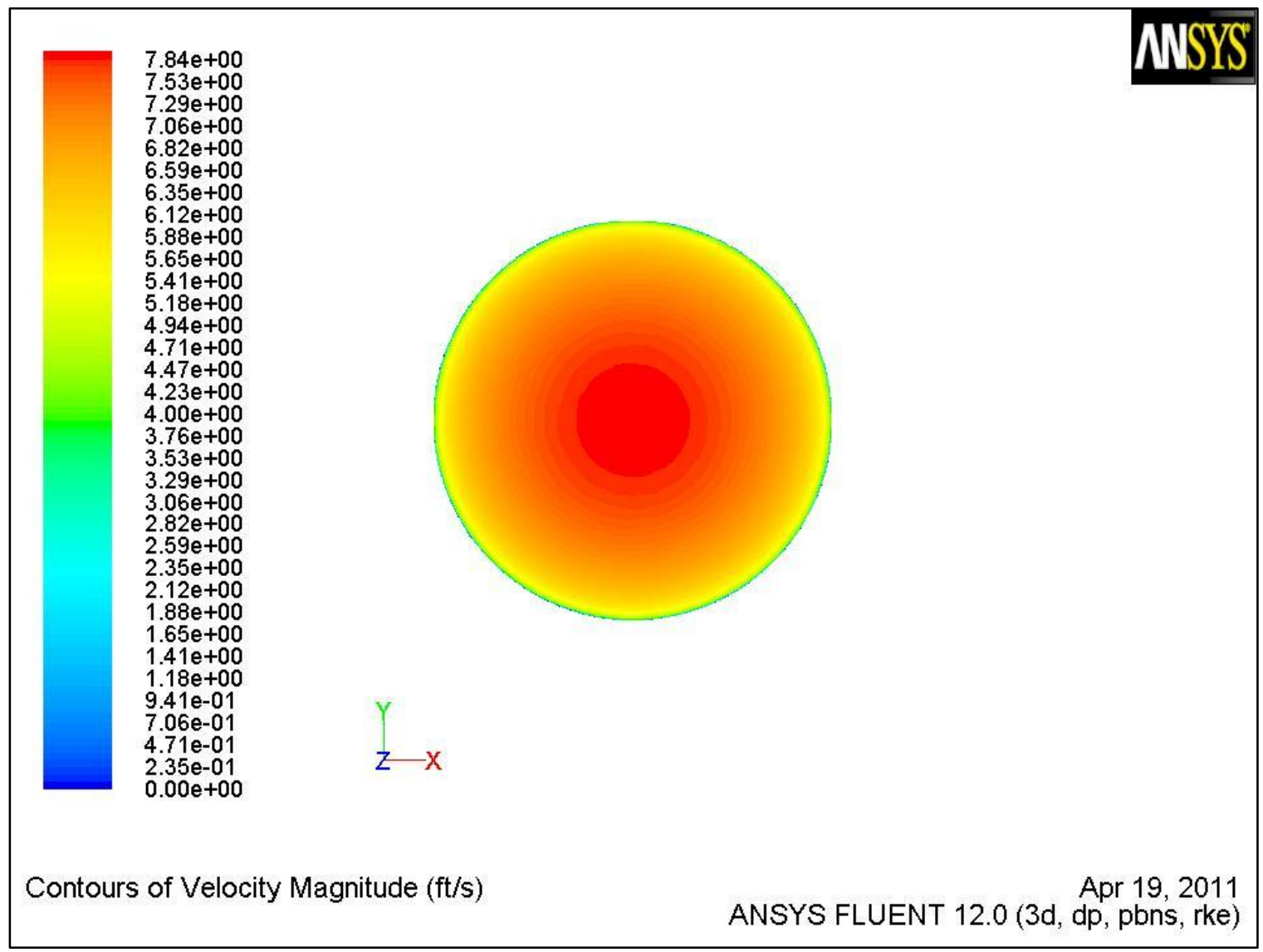

Figure 31. Contours of Fully Developed Velocity Profile $(\operatorname{Re}=500,000)$ 


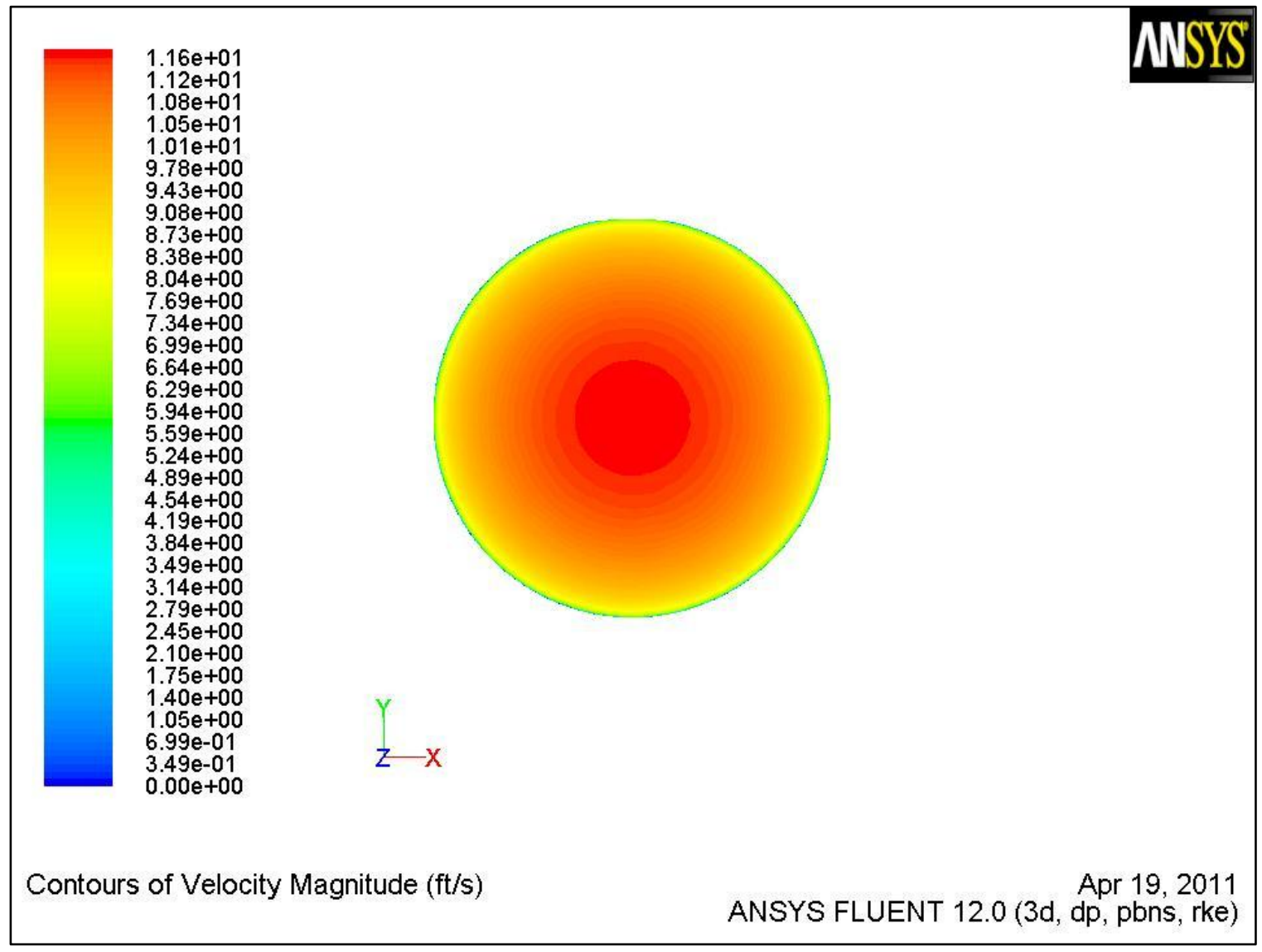

Figure 32. Contours of Fully Developed Velocity Profile $(\operatorname{Re}=750,000)$ 
Appendix B. CFD Velocity Contour Plots of Flow Profiles Downstream of 90-Degree Elbow 


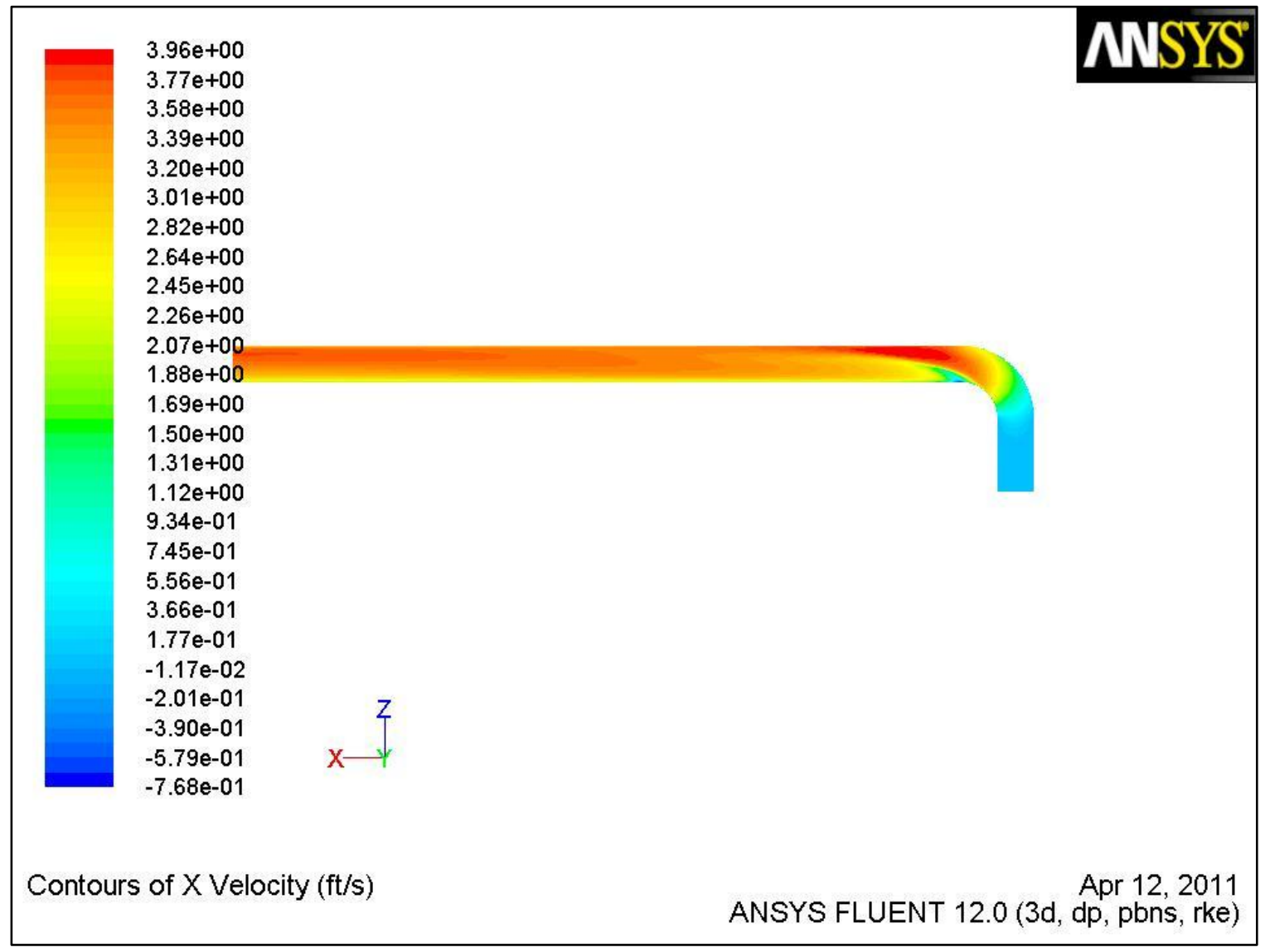

Figure 33. Contours of X-Velocity Downstream of 90-Degree Elbow $(\operatorname{Re}=250,000)$ 


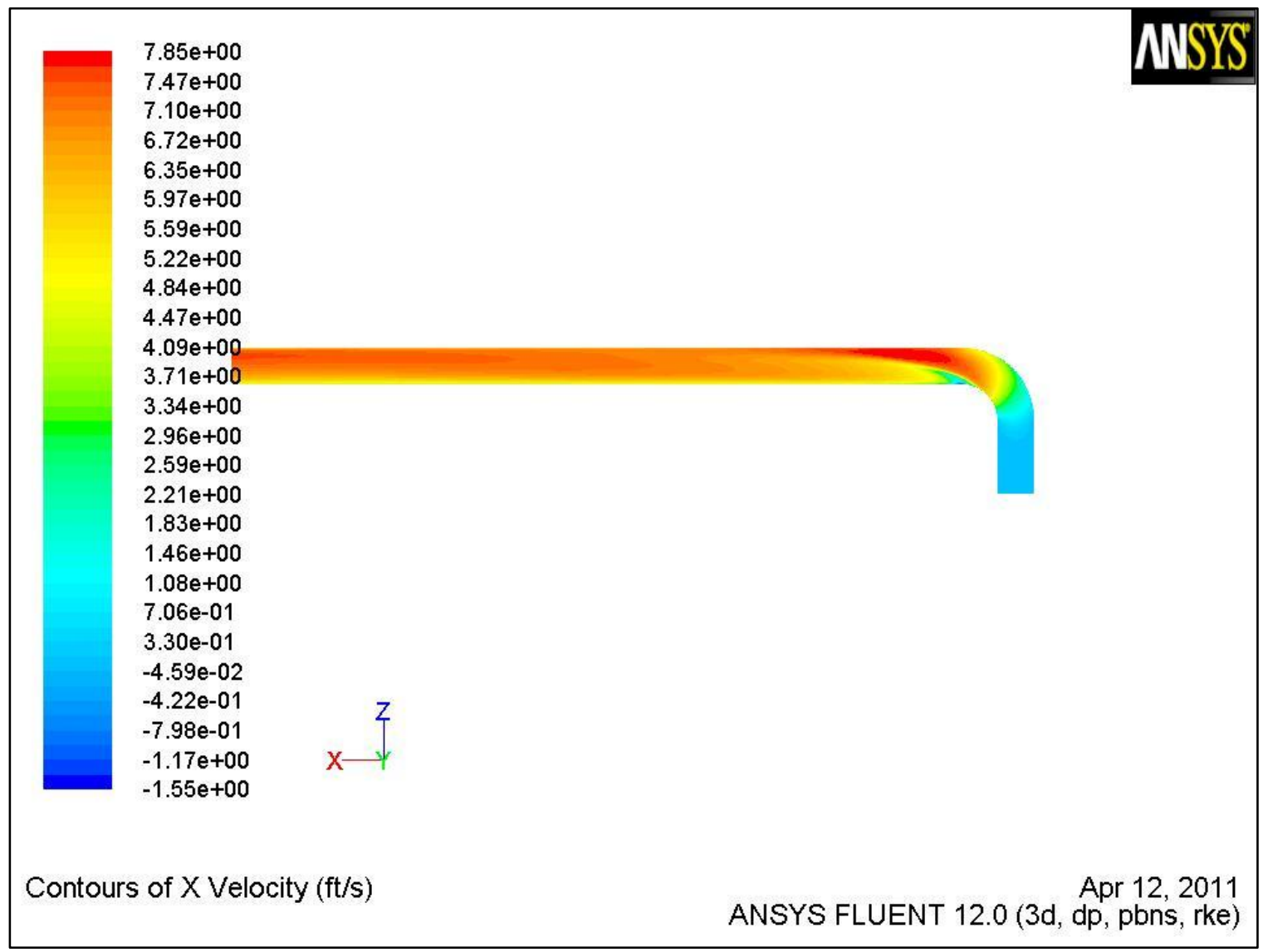

Figure 34. Contours of X-Velocity Downstream of 90-Degree Elbow $(\operatorname{Re}=500,000)$ 


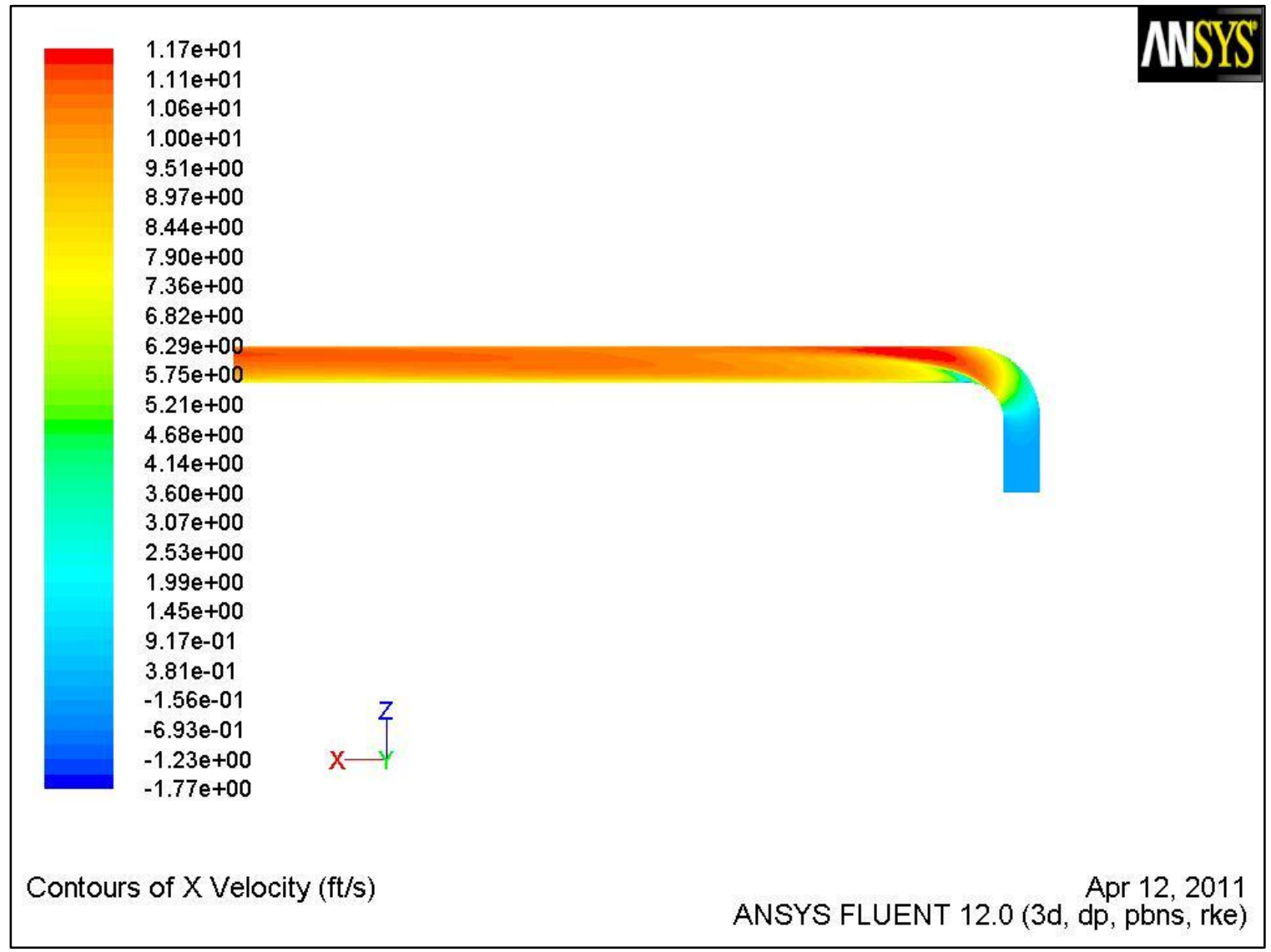

Figure 35. Contours of X-Velocity Downstream of 90-Degree Elbow $(\operatorname{Re}=750,000)$ 


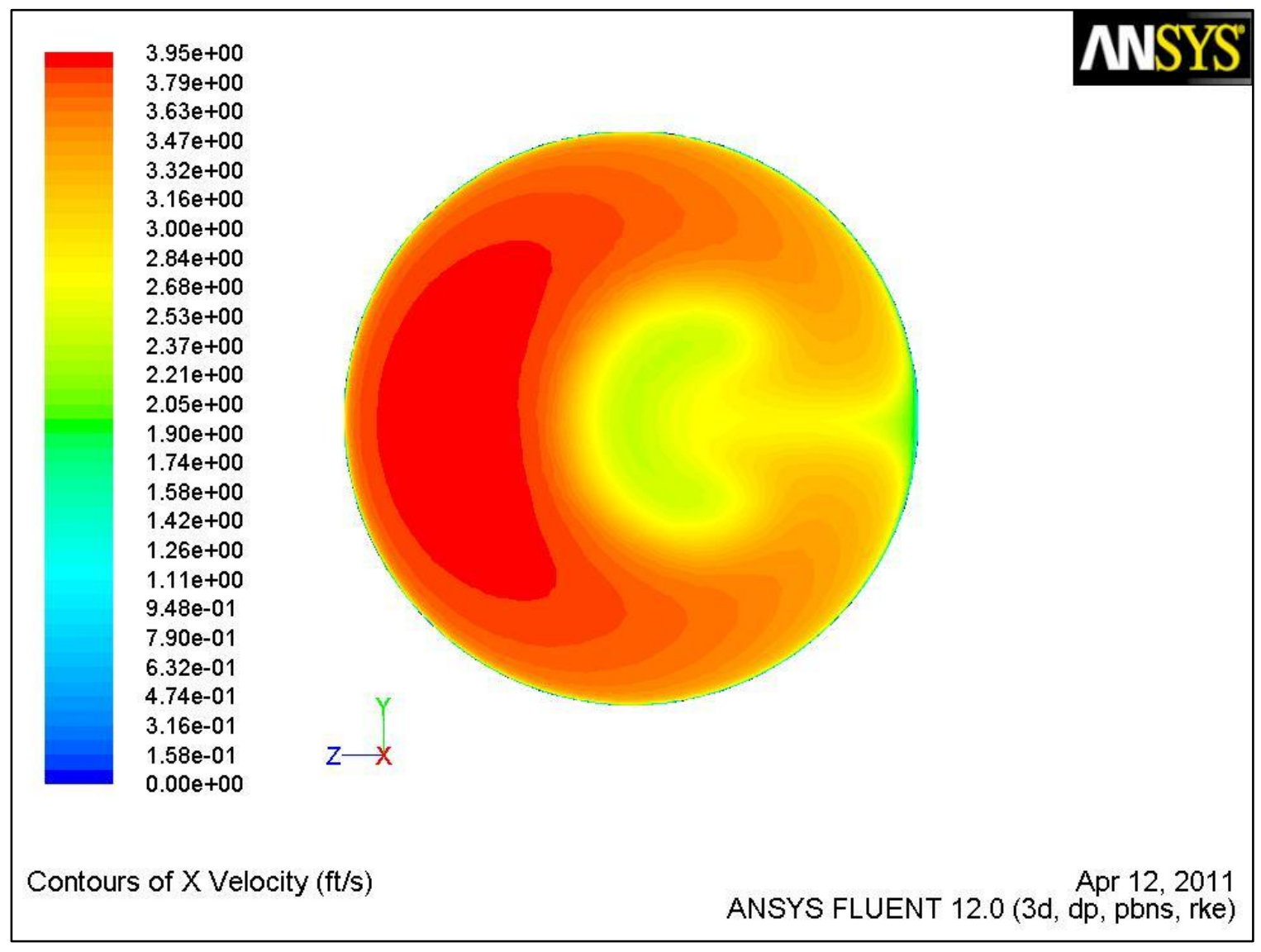

Figure 36. Contours of X-Velocity at 1.5D Downstream $(\operatorname{Re}=250,000)$ 


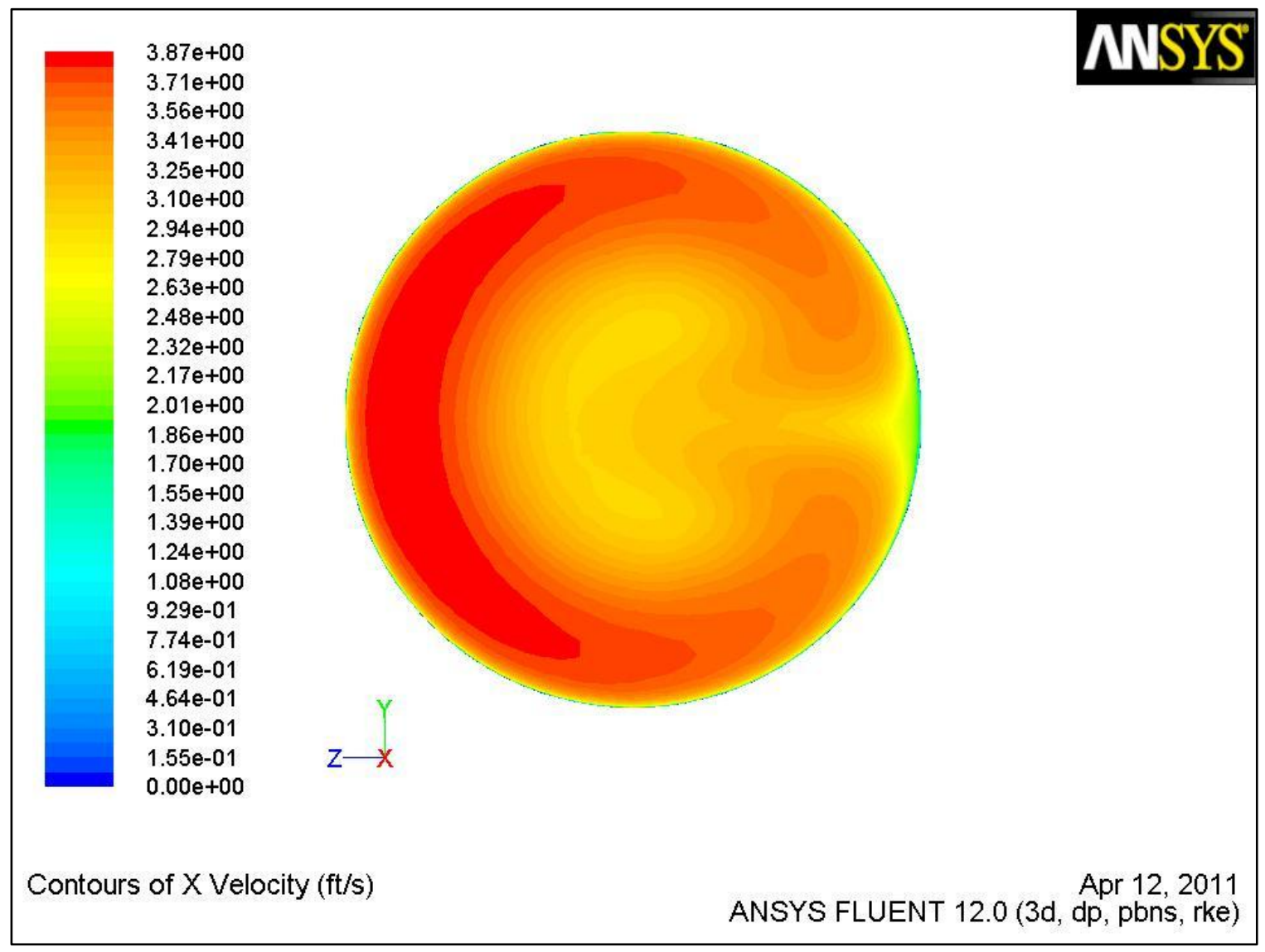

Figure 37. Contours of X-Velocity at 3D Downstream $(\operatorname{Re}=250,000)$ 


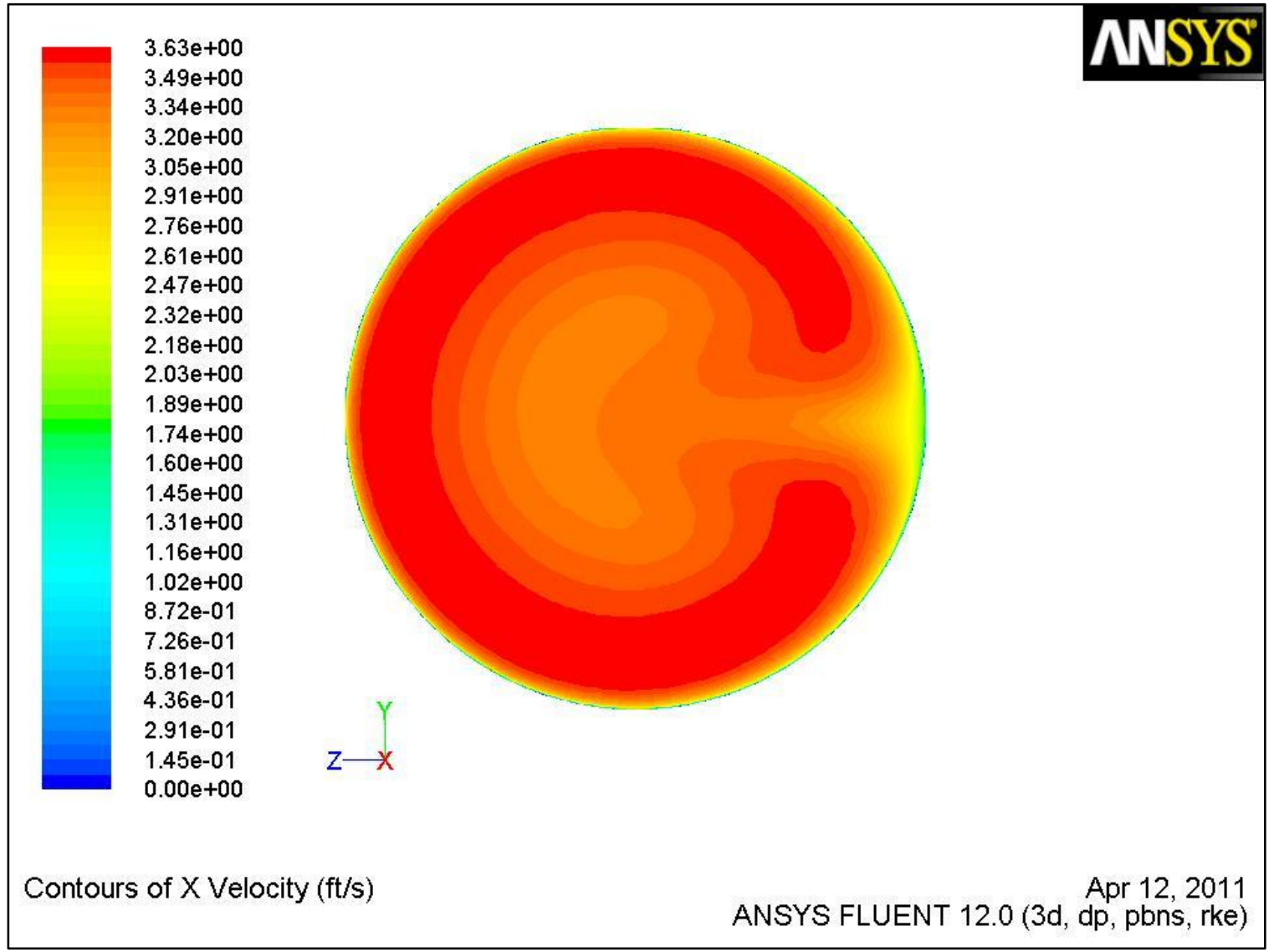

Figure 38. Contours of X-Velocity at 5D Downstream $(R e=250,000)$ 


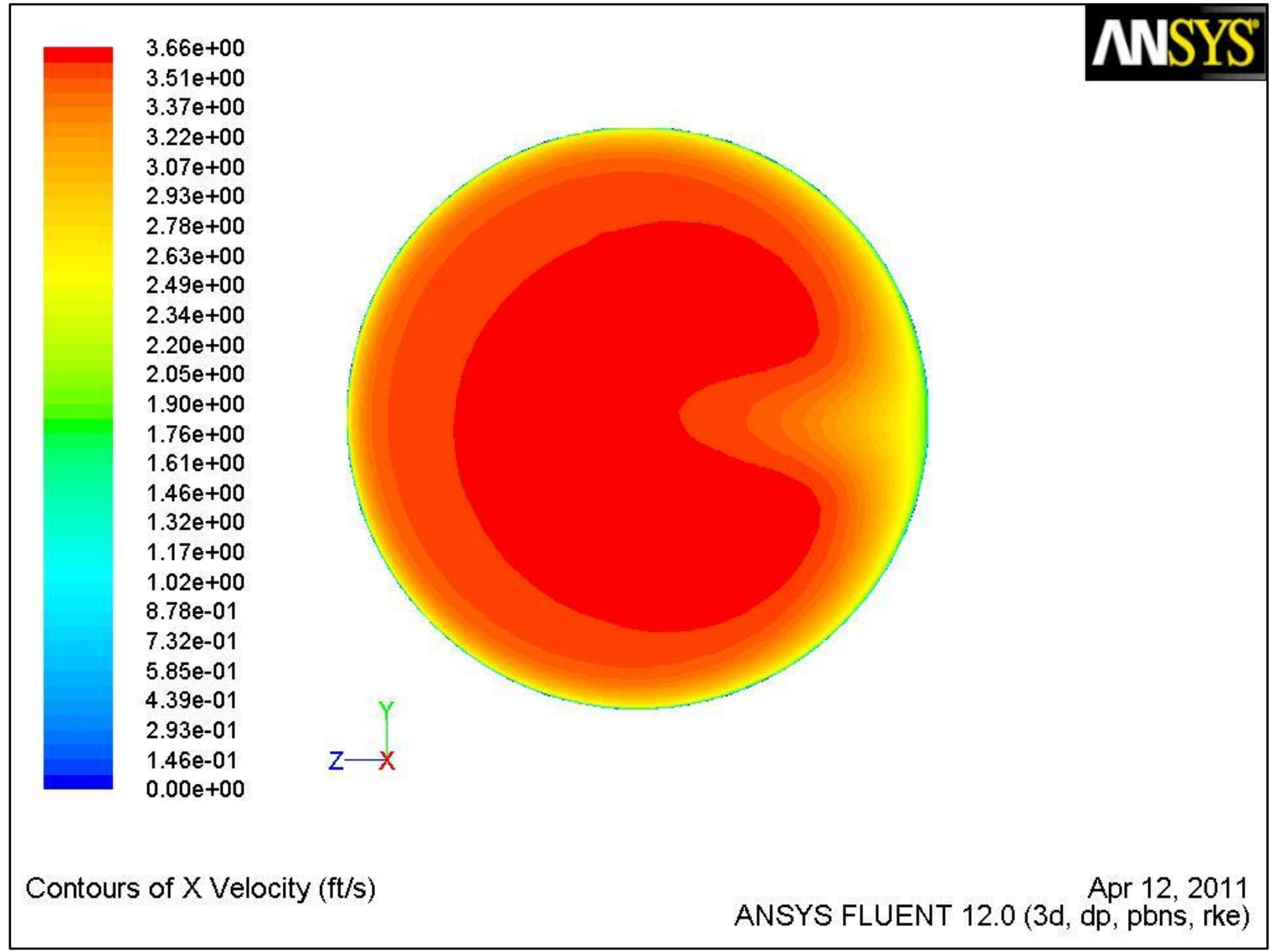

Figure 39. Contours of X-Velocity at 10D Downstream $(\operatorname{Re}=250,000)$ 


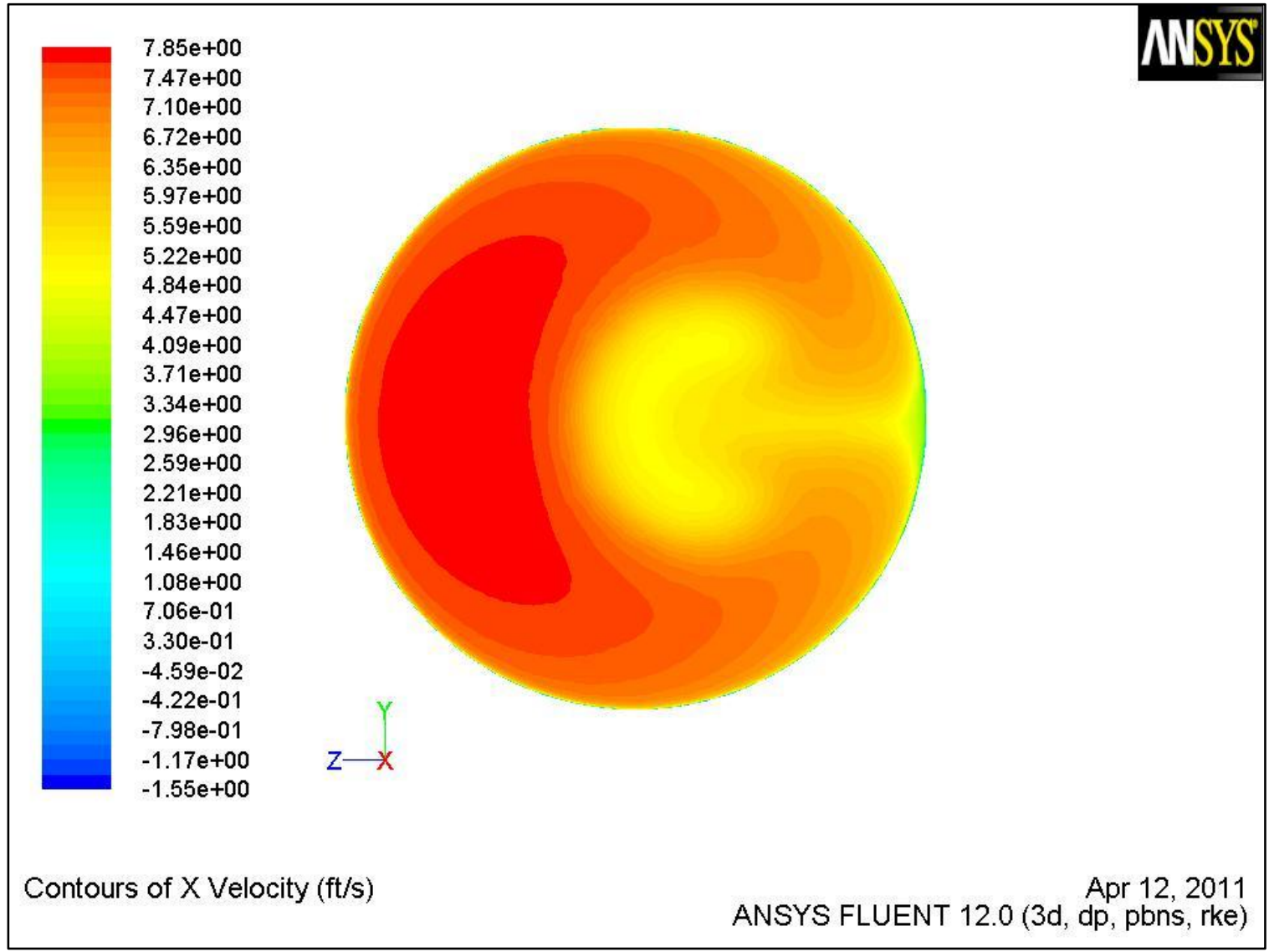

Figure 40. Contours of X-Velocity at 1.5D Downstream $(\operatorname{Re}=500,000)$ 


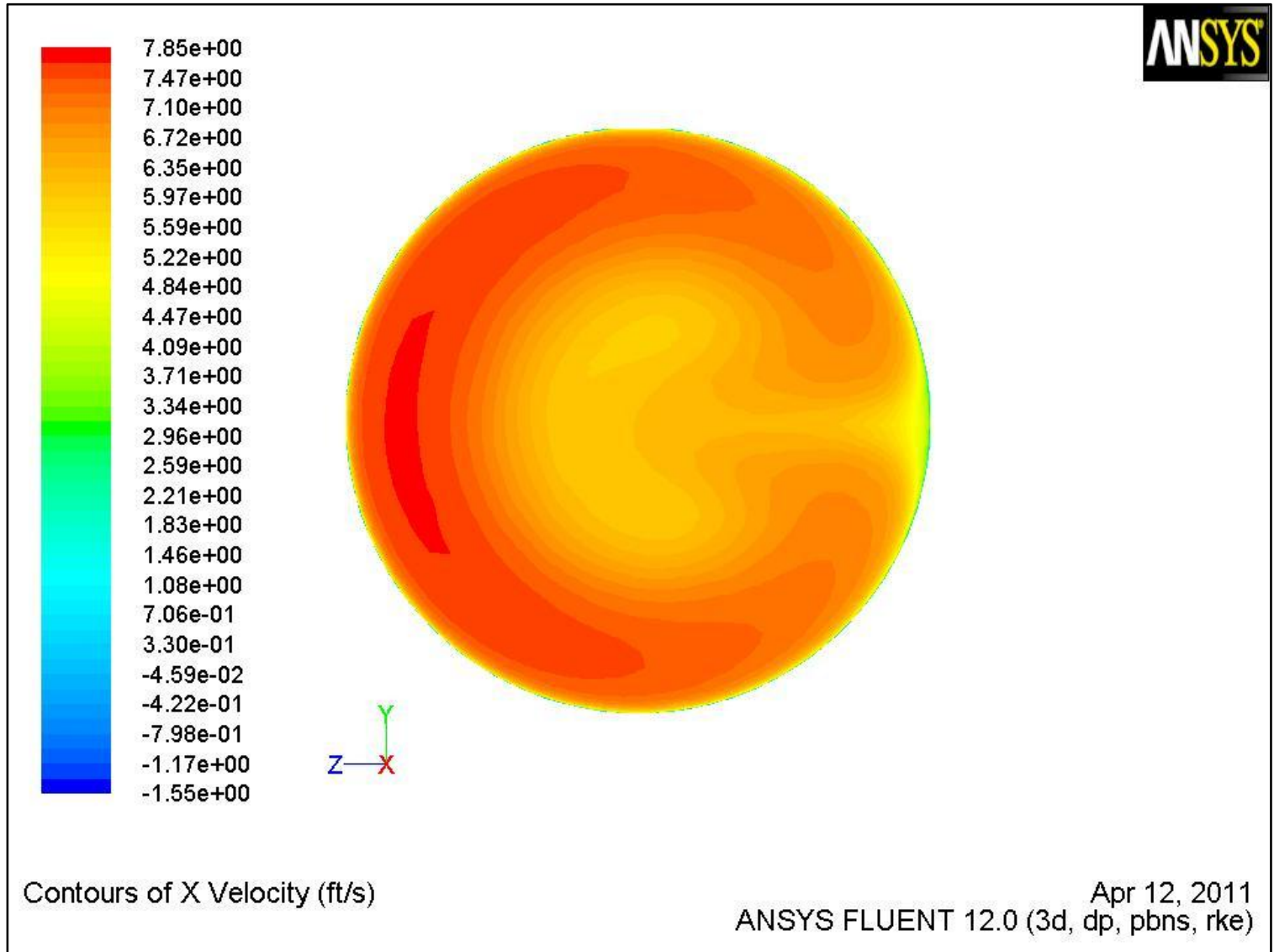

Figure 41. Contours of X-Velocity at 3D Downstream $(\operatorname{Re}=500,000)$ 


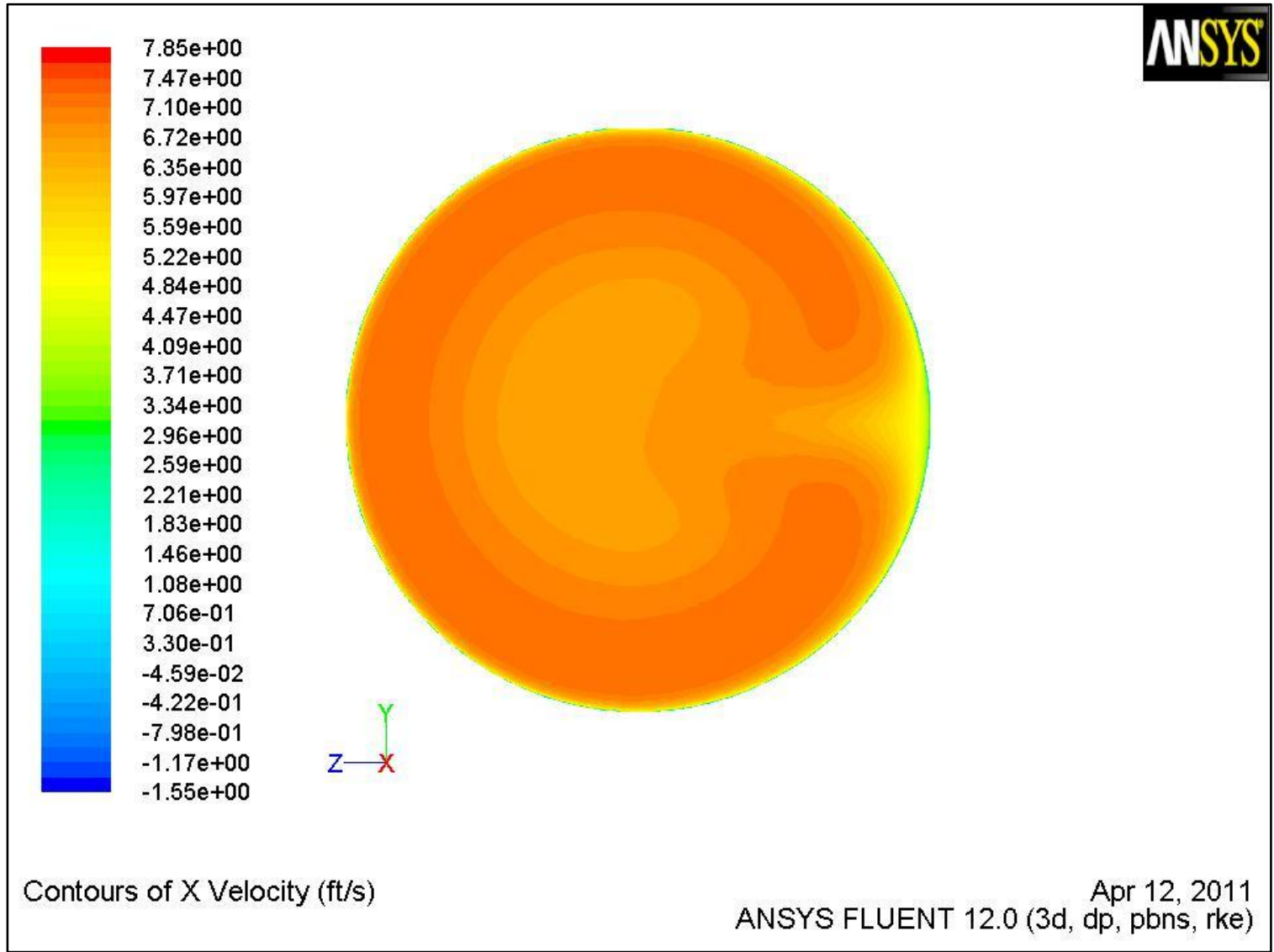

Figure 42. Contours of X-Velocity at 5D Downstream $(\operatorname{Re}=500,000)$ 


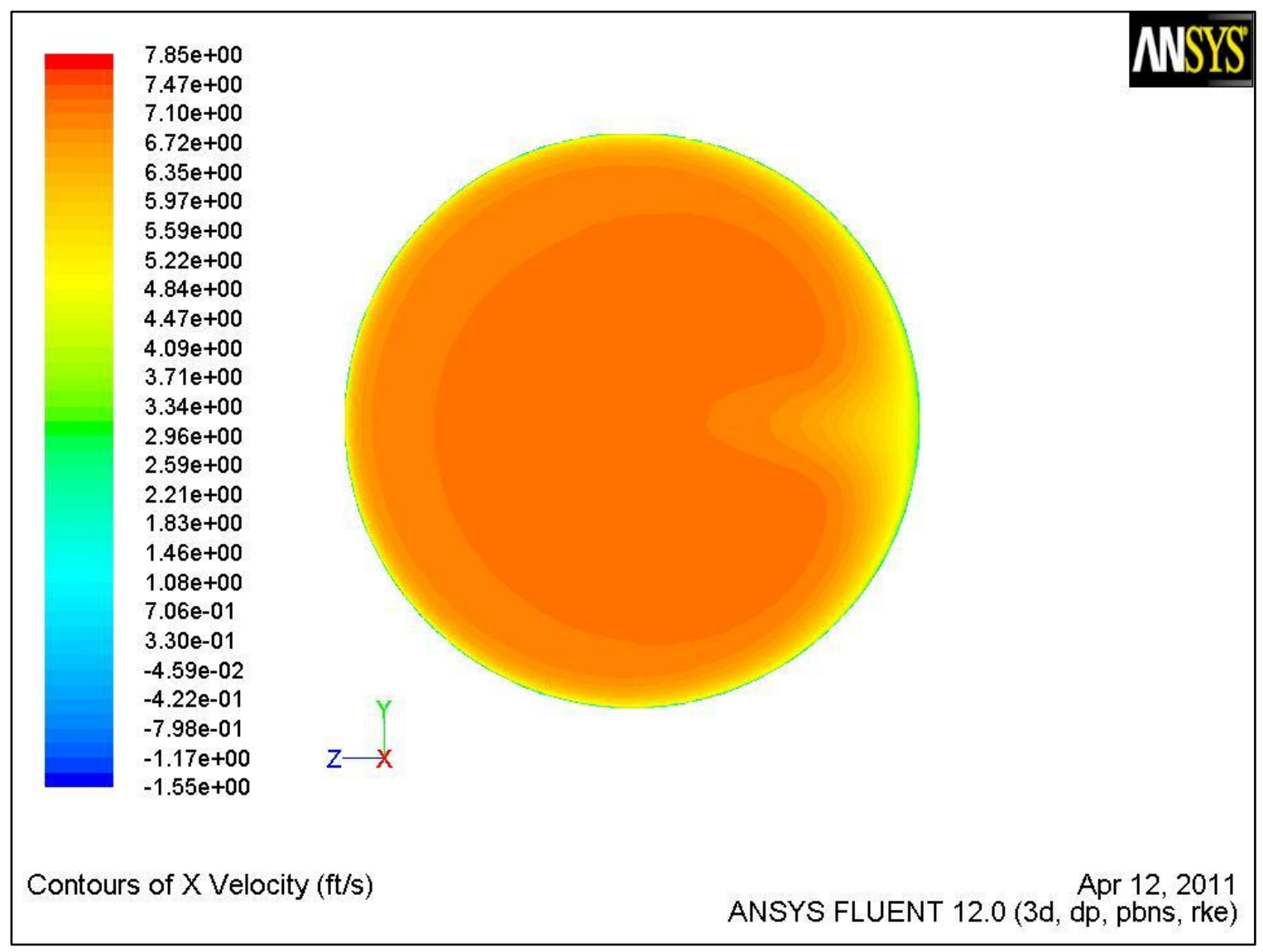

Figure 43. Contours of X-Velocity at 10D Downstream $(R e=500,000)$ 


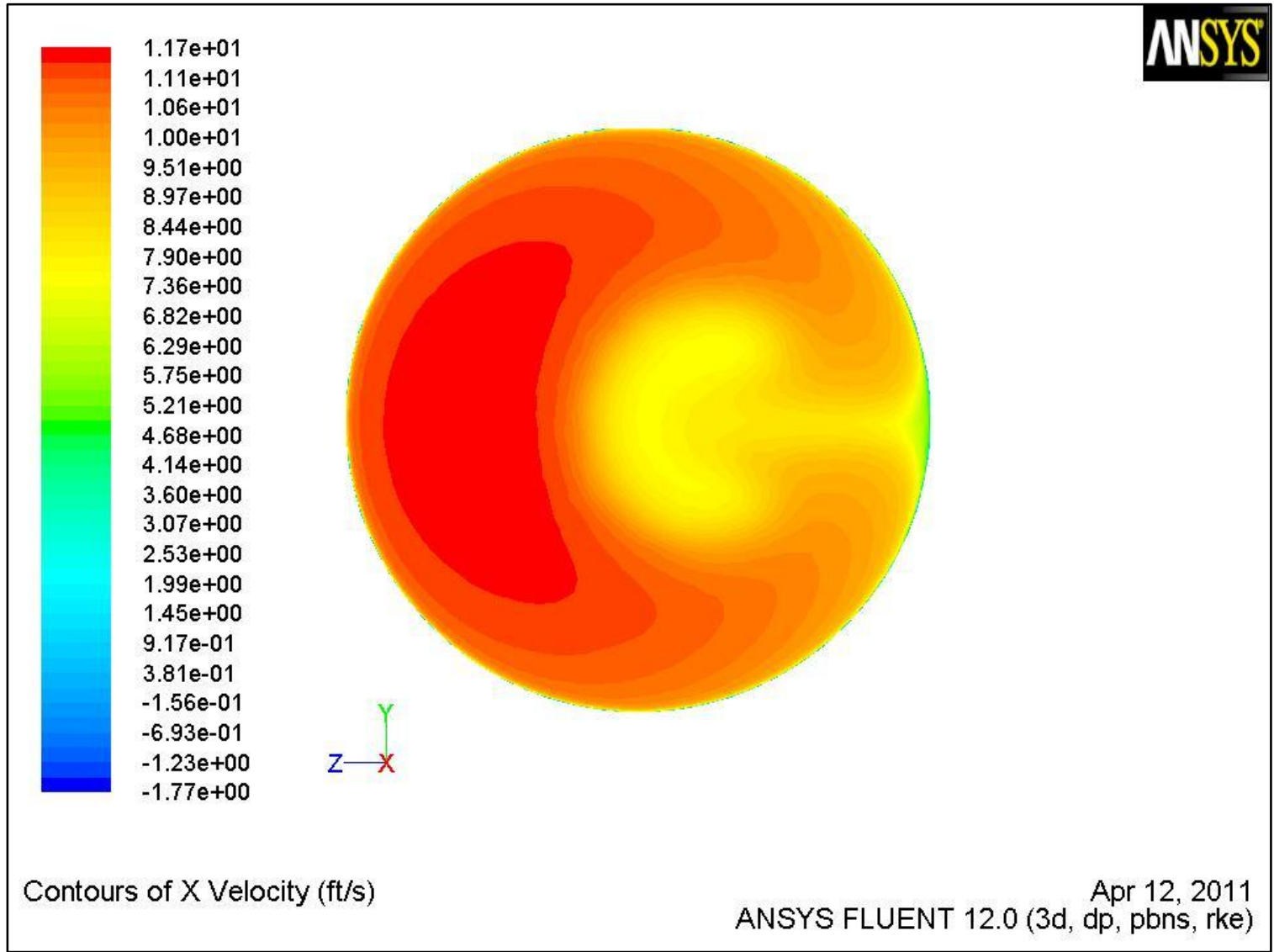

Figure 44. Contours of X-Velocity at 1.5D Downstream $(\operatorname{Re}=750,000)$ 


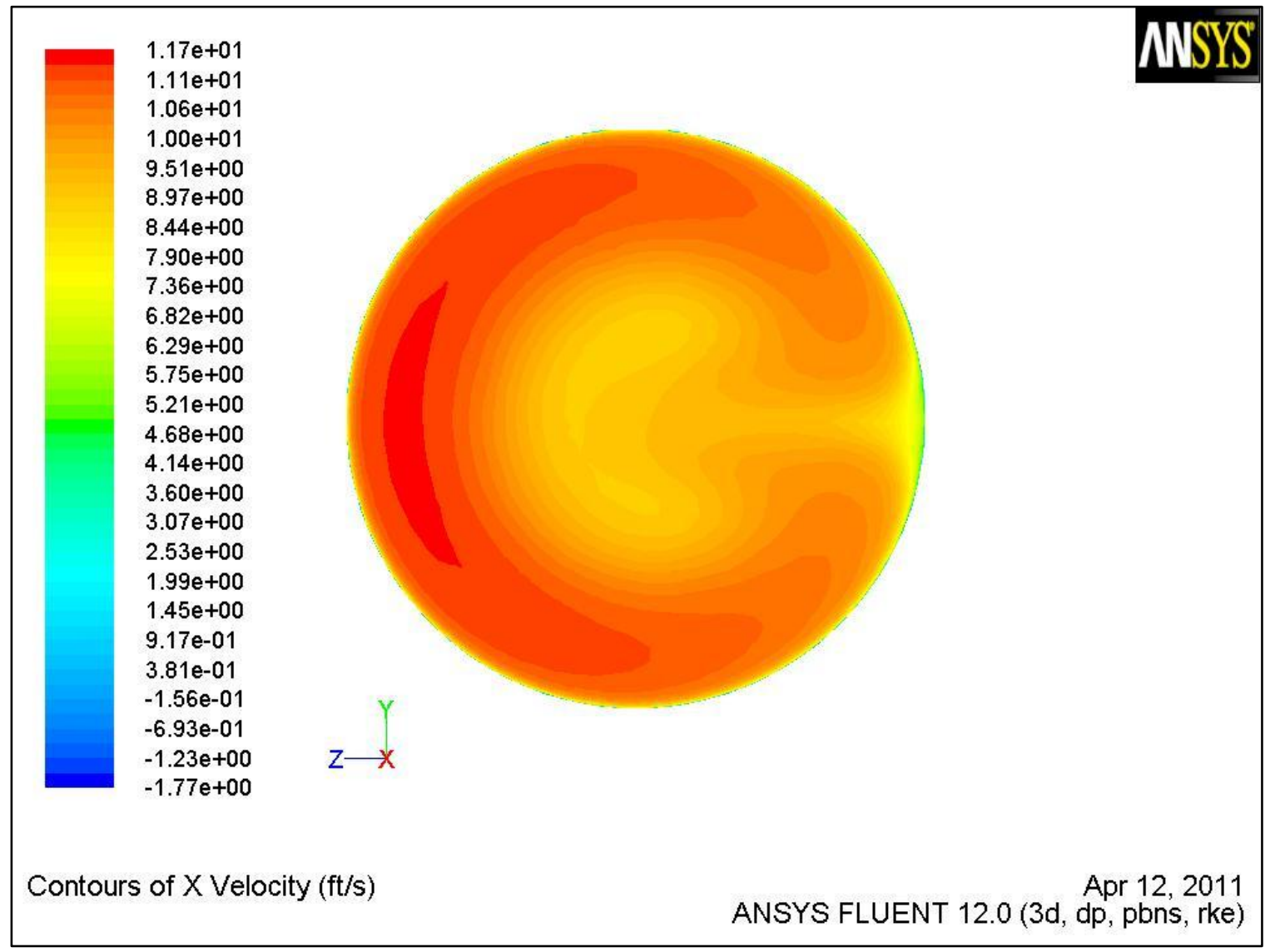

Figure 45. Contours of X-Velocity at 3D Downstream $(R e=750,000)$ 


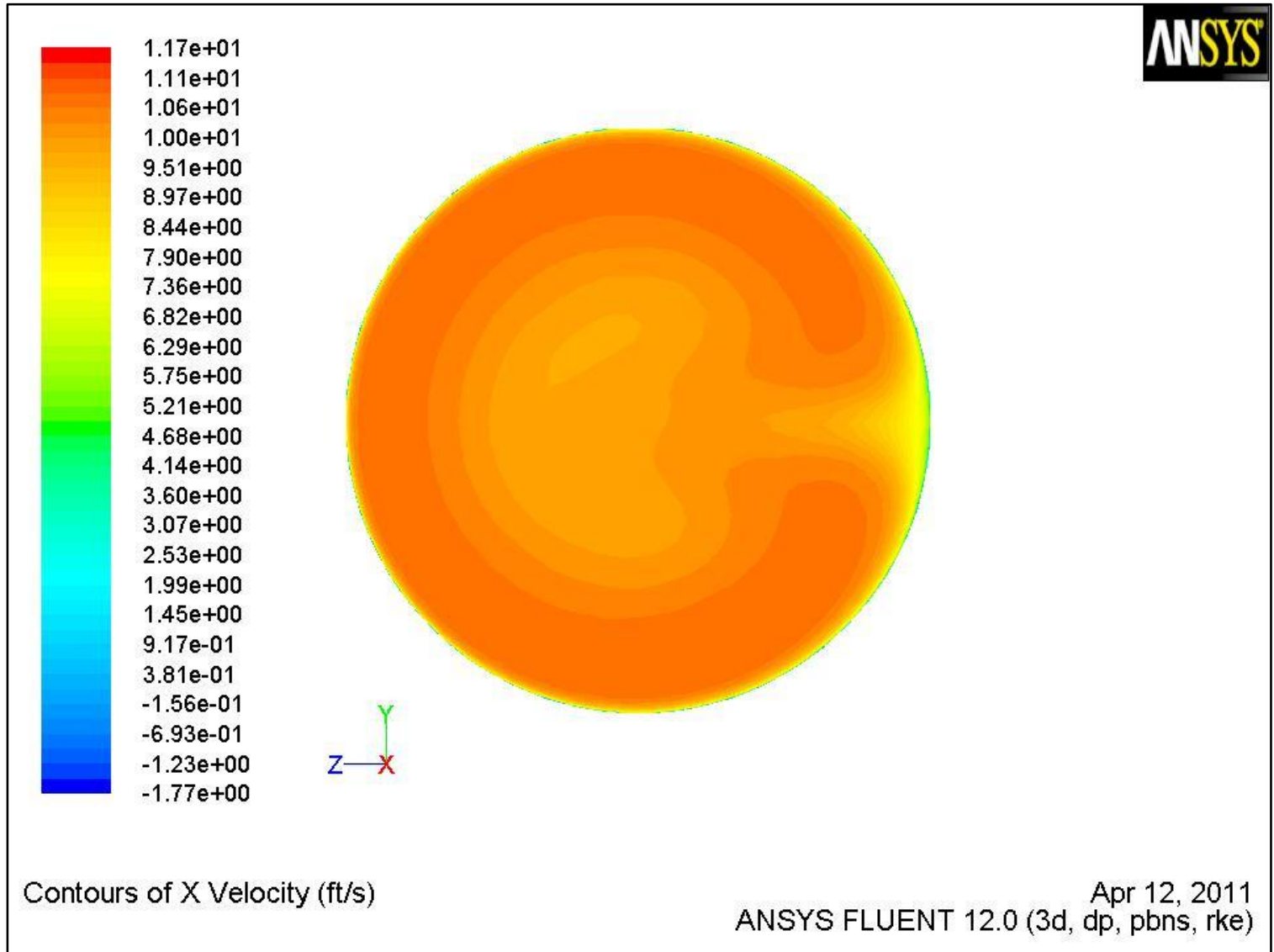

Figure 46. Contours of X-Velocity at 5D Downstream $(\operatorname{Re}=750,000)$ 


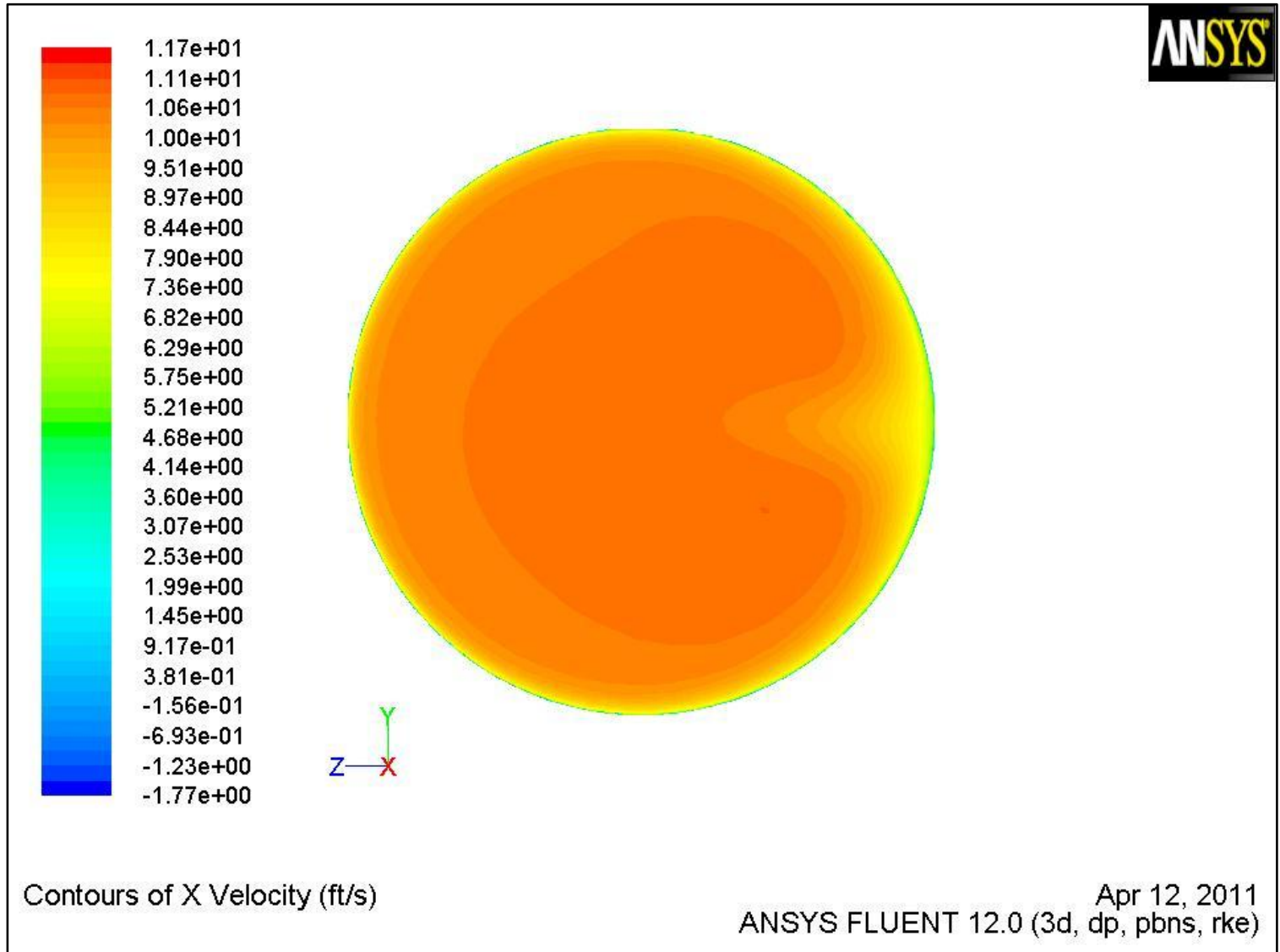

Figure 47. Contours of X-Velocity at 10D Downstream $(\operatorname{Re}=750,000)$ 